\title{
2019 HRS/EHRA/APHRS/LAHRS expert consensus statement on catheter ablation of ventricular arrhythmias: Executive \\ summary
}

\author{
Edmond M. Cronin ${ }^{1}$ • Frank M. Bogun ${ }^{2} \cdot$ Philippe Maury $^{3} \cdot$ Petr Peichl $^{4} \cdot$ Minglong Chen $^{5}$ - Narayanan Namboodiri ${ }^{6}$ \\ Luis Aguinaga $^{7} \cdot$ Luiz Roberto Leite $^{8}$ - Sana M. Al-Khatib ${ }^{9}$ • Elad Anter ${ }^{10}$ • Antonio Berruezo ${ }^{11}$ • David J. Callans ${ }^{12}$. \\ Mina K. Chung ${ }^{13}$. Phillip Cuculich ${ }^{14}$. Andre d'Avila ${ }^{15} \cdot$ Barbara J. Deal $^{16}$. Paolo Della Bella ${ }^{17} \cdot$ Thomas Deneke $^{18}$. \\ Timm-Michael Dickfeld ${ }^{19}$. Claudio Hadid ${ }^{20}$ • Haris M. Haqqani ${ }^{21}$ • G. Neal Kay ${ }^{22}$ - Rakesh Latchamsetty ${ }^{2}$. \\ Francis Marchlinski ${ }^{12}$. John M. Miller ${ }^{23}$. Akihiko Nogami ${ }^{24}$. Akash R. Patel ${ }^{25}$. Rajeev Kumar Pathak ${ }^{26}$. \\ Luis C. Saenz Morales ${ }^{27}$ • Pasquale Santangeli ${ }^{12}$ • John L. Sapp Jr ${ }^{28}$ • Andrea Sarkozy ${ }^{29} \cdot$ Kyoko Soejima $^{30}$. \\ William G. Stevenson ${ }^{31}$ • Usha B. Tedrow ${ }^{32}$ • Wendy S. Tzou ${ }^{33}$ • Niraj Varma ${ }^{13}$ - Katja Zeppenfeld ${ }^{34}$
}

Published online: 20 January 2020

(C) The Heart Rhythm Society; the European Heart Rhythm Association, a registered branch of the European Society of Cardiology; the Asia Pacific Heart Rhythm Society; and the Latin American Heart Rhythm Society 2020

Published by Elsevier Inc./Oxford University Press/Wiley. This article is published under the Creative Commons CC-BY license.

Document Reviewers: Samuel J. Asirvatham, MD, FHRS; Eduardo Back Sternick, MD, PhD; Janice Chyou, MD; Sabine Ernst, MD, PhD; Guilherme Fenelon, MD, PhD; Edward P. Gerstenfeld, MD, MS, FACC; Gerhard Hindricks, MD; Koichi Inoue, MD, PhD; Jeffrey J. Kim, MD; Kousik Krishnan, MD, FHRS, FACC; Karl-Heinz Kuck, MD, FHRS; Martin Ortiz Avalos, MD; Thomas Paul, MD, FACC, FHRS; Mauricio I. Scanavacca, MD, PhD; Roderick Tung, MD, FHRS; Jamie Voss, MBChB; Takumi Yamada, MD; Teiichi Yamane, MD, PhD, FHRS

Developed in partnership with and endorsed by the European Heart Rhythm Association (EHRA), the Asia Pacific Heart Rhythm Society (APHRS), and the Latin American Heart Rhythm Society (LAHRS). Developed in collaboration with and endorsed by the American College of Cardiology (ACC), the American Heart Association (AHA), the Japanese Heart Rhythm Society (JHRS), the Pediatric and Congenital Electrophysiology Society (PACES), and the Sociedade Brasileira de Arritmias Cardíacas (SOBRAC). Endorsed by the Canadian Heart Rhythm Society. For copies of this document, please contact the Elsevier Inc. Reprint Department (reprints@elsevier.com). Permissions: Multiple copies, modification, alteration, enhancement, and/or distribution of this document are not permitted without the express permission of the Heart Rhythm Society. Instructions for obtaining permission are located at https://www.elsevier.com/about/our-business/policies/copyright/ permissions. This article has been copublished in Heart Rhythm, Europace, and the Journal of Arrhythmia. Correspondence: Heart Rhythm Society, 1325 G Street NW, Suite 400, Washington, DC 20005. E-mail address: clinicaldocs@hrsonline.org

Edmond M. Cronin is the Chair.

Frank M. Bogun is the Vice-Chair.

Philippe Maury is the Chair representing the European Heart Rhythm Association (EHRA)

Petr Peichl is the Vice-Chair representing the European Heart Rhythm Association (EHRA).

Minglong Chen is the Chair representing the Asia Pacific Heart Rhythm Society (APHRS).
Narayanan Namboodiri is the Vice-Chair representing the Asia Pacific Heart Rhythm Society (APHRS).

Luis Aguinaga is the Chair representing the Latin American Heart Rhythm Society (LAHRS).

Luiz Roberto Leite is the Vice-Chair representing the Latin American Heart Rhythm Society (LAHRS).

Antonio Berruezo, Paolo Della Bella, Thomas Deneke, Andrea Sarkozy and Katja Zeppenfeld are the Representatives of the European Heart Rhythm Association (EHRA).

Mina K. Chung and John M. Miller are the Representatives of the American College of Cardiology (ACC).

Andre d'Avila is the Representative of the Sociedade Brasileira de Arritmias Cardiacas (SOBRAC).

Barbara J. Deal is the Representative of the American Heart Association (AHA).

Claudio Hadid and Luis C. Saenz Morales are the Representatives of the Latin American Heart Rhythm Society (LAHRS).

Haris M. Haqqani, Rajeev Kumar Pathak and Kyoko Soejima are the Representatives of the Asia Pacific Heart Rhythm Society (APHRS).

Akihiko Nogami is the Representative of the Japanese Heart Rhythm Society (JHRS).

Akash R. Patel is the Representative of the Pediatric and Congenital Electrophysiology Society (PACES).

Sana M. Al-Khatib, Elad Anter, David J. Callans, Phillip Cuculich, Timm-Michael Dickfeld, G. Neal Kay, Rakesh Latchamsetty, Francis Marchlinski, Pasquale Santangeli, John L. Sapp Jr, William G. Stevenson, Usha B. Tedrow, Wendy S. Tzou and Niraj Varma are the Representatives of the Heart Rhythm Society (HRS).

Electronic supplementary material The online version of this article (https://doi.org/10.1007/s10840-019-00664-2) contains supplementary material, which is available to authorized users.

Heart Rhythm Society clinicaldocs@hrsonline.org

Extended author information available on the last page of the article 


\section{Abstract}

Ventricular arrhythmias are an important cause of morbidity and mortality and come in a variety of forms, from single premature ventricular complexes to sustained ventricular tachycardia and fibrillation. Rapid developments have taken place over the past decade in our understanding of these arrhythmias and in our ability to diagnose and treat them. The field of catheter ablation has progressed with the development of new methods and tools, and with the publication of large clinical trials. Therefore, global cardiac electrophysiology professional societies undertook to outline recommendations and best practices for these procedures in a document that will update and replace the 2009 EHRA/HRS Expert Consensus on Catheter Ablation of Ventricular Arrhythmias. An expert writing group, after reviewing and discussing the literature, including a systematic review and metaanalysis published in conjunction with this document, and drawing on their own experience, drafted and voted on recommendations and summarized current knowledge and practice in the field. Each recommendation is presented in knowledge byte format and is accompanied by supportive text and references. Further sections provide a practical synopsis of the various techniques and of the specific ventricular arrhythmia sites and substrates encountered in the electrophysiology lab. The purpose of this document is to help electrophysiologists around the world to appropriately select patients for catheter ablation, to perform procedures in a safe and efficacious manner, and to provide follow-up and adjunctive care in order to obtain the best possible outcomes for patients with ventricular arrhythmias.

Keywords Catheter ablation · Clinical document · Electrical storm · Electroanatomical mapping · Electrocardiogram · Expert consensus statement $\cdot$ Imaging $\cdot$ Premature ventricular complex $\cdot$ Radiofrequency ablation $\cdot$ Ventricular arrhythmia $\cdot$ Ventricular tachycardia

$\begin{array}{ll}\text { Abbreviations } \\ \text { AAD } & \text { Antiarrhythmic drug } \\ \text { AIV } & \text { Anterior interventricular vein } \\ \text { AMC } & \text { Aortomitral continuity } \\ \text { ARVC } & \text { Arrhythmogenic right ventricular cardiomyopathy } \\ \text { ATP } & \text { Antitachycardia pacing } \\ \text { AV } & \text { Atrioventricular } \\ \text { BBRVT } & \text { Bundle branch reentrant ventricular tachycardia } \\ \text { CHD } & \text { Congenital heart disease } \\ \text { CMR } & \text { Cardiac magnetic resonance imaging } \\ \text { COR } & \text { Class of recommendation } \\ \text { CS } & \text { Coronary sinus } \\ \text { DCM } & \text { Dilated cardiomyopathy } \\ \text { EAM } & \text { Electroanatomical mapping } \\ \text { ECG } & \text { Electrocardiogram } \\ \text { GCV } & \text { Great cardiac vein } \\ \text { HCM } & \text { Hypertrophic cardiomyopathy } \\ \text { HS } & \text { Hemodynamic support } \\ \text { ICD } & \text { Implantable cardioverter defibrillator } \\ \text { ICE } & \text { Intracardiac echocardiography } \\ \text { ICM } & \text { Ischemic cardiomyopathy } \\ \text { IHD } & \text { Ischemic heart disease } \\ \text { LBB } & \text { Left bundle branch } \\ \text { LBBB } & \text { Left bundle branch block } \\ \text { LMNA } & \text { Lamin A/C } \\ \text { LOE } & \text { Level of evidence } \\ \text { LSV } & \text { Left sinus of Valsalva } \\ \text { LV } & \text { Left ventricle } \\ \text { LVOT } & \text { Left ventricular outflow tract } \\ \text { NCSV } & \text { Noncoronary sinus of Valsalva } \\ \text { NICM } & \text { Nonischemic cardiomyopathy } \\ \text { PES } & \text { Programmed electrical stimulation } \\ & \end{array}$

PVC Premature ventricular complex

RBB Right bundle branch

RBBB Right bundle branch block

RSV Right sinus of Valsalva

RV Right ventricle

RVOT Right ventricular outflow tract

RWI Relationship with industry and other entities

SHD Structural heart disease

SV Sinus of Valsalva

VA Ventricular arrhythmia

VF Ventricular fibrillation

VT Ventricular tachycardia 


\section{TABLE OF CONTENTS}

Section 1 Introduction in this issue

1.1. Document Scope and Rationale ............in this issue

1.2. Methods ..in this issue

Section 2 Background in this issue

Section 3 Clinical Evaluation in this issue

3.1. Clinical Presentation in this issue

3.2. Diagnostic Evaluation in this issue

3.2.1. Resting 12-Lead Electrocardiogram ...in this issue

3.2.2. Assessment of Structural Heart Disease and Myocardial Ischemia in this issue

3.2.3. Risk Stratification in the Setting of Frequent Premature Ventricular Complexes ...in this issue

3.2.4. Longitudinal Follow-up in the Setting of Frequent Premature Ventricular Complexes ...in this issue

Section 4 Indications for Catheter Ablation ........in this issue

4.1. Idiopathic Outflow Tract Ventricular Arrhythmia ...

4.2. Idiopathic Nonoutflow Tract Ventricular Arrhythmia in this issue

4.3. Premature Ventricular Complexes With or Without Left Ventricular Dysfunction in this issue

4.4. Ventricular Arrhythmia in Ischemic Heart Disease ...in this issue

4.5. Nonischemic Cardiomyopathy ..............in this issue

4.6. Ventricular Arrhythmia Involving the His-Purkinje System, Bundle Branch Reentrant Ventricular Tachycardia, and Fascicular Ventricular Tachycardia in this issue

4.7. Congenital Heart Disease in this issue

4.8. Inherited Arrhythmia Syndromes ...........in this issue

4.9. Ventricular Arrhythmia in Hypertrophic Cardiomyopathy in this issue

Section 5 Procedural Planning. in this issue

Section 6 Intraprocedural Patient Care in this issue

6.1. Anesthesia in this issue

6.2. Vascular Access ...in this issue

6.3. Epicardial Access in this issue

6.4. Intraprocedural Hemodynamic Support ...in this issue

6.5. Intraprocedural Anticoagulation in this issue

Section 7 Electrophysiological Testing in this issue

Section 8 Mapping and Imaging Techniques ....in this issue

8.1. Overview in this issue

8.2. Substrate Mapping in Sinus Rhythm ...in this issue

8.3. Intraprocedural Imaging During Catheter Ablation of Ventricular Arrhythmias ..in this issue

8.4. Electroanatomical Mapping Systems and Robotic Navigation ...in this issue

Section 9 Mapping and Ablation in this issue
9.1. Ablation Power Sources and Techniques ..in this issue.

9.2. Idiopathic Outflow Tract Ventricular Arrhythmia ...in this issue

9.3. Idiopathic Nonoutflow Tract Ventricular Arrhythmia in this issue

9.4. Bundle Branch Reentrant Ventricular Tachycardia and Fascicular Ventricular Tachycardia ...in this issue

9.5. Postinfarction Ventricular Tachycardia ...in this issue

9.6. Dilated Cardiomyopathy .......................in this issue

9.7. Ventricular Tachycardia Ablation in Hypertrophic Cardiomyopathy ..... in this issue

9.8. Brugada Syndrome ...............................in this issue

9.9. Polymorphic Ventricular Tachycardia/Ventricular Fibrillation Triggers in this issue

9.10. Arrhythmogenic Right Ventricular Cardiomyopathy in this issue

9.11. Mapping and Ablation in Congenital Heart Disease in this issue

9.12. Sarcoidosis in this issue

9.13. Chagas Disease ...................................in this issue

9.14. Miscellaneous Diseases and Clinical ScenariosWith Ventricular Tachycardia ...in this issue

9.15. Surgical Therapy ...in this issue

9.16. Sympathetic Modulation .....................in this issue

9.17. Endpoints of Catheter Ablation of Ventricular Tachycardia in this issue

Section 10 Postprocedural Care in this issue

10.1. Postprocedural Care: Access, Anticoagulation, Disposition in this issue

10.1.1. Postprocedural Care: Access ...in this issue

10.1.2. Postprocedural Care:Anticoagulation ...in this issue

10.2. Incidence and Management of Complications ...in this issue

10.3. Hemodynamic Deterioration and Proarrhythmia in this issue

10.4. Follow-up of Patients Post Catheter Ablation of Ventricular Tachycardia in this issue

Section 11 Training and Institutional Requirements and Competencies in this issue

11.1. Training Requirements and Competencies for Catheter Ablation of Ventricular Arrhythmias ....in this issue

11.2. Institutional Requirements for Catheter Ablation of Ventricular Tachycardia ...in this issue

Section 12 Future Directions .............................. in this issue

Appendix 1 Author Disclosure Table ..................in this issue Appendix 2 Reviewer Disclosure Table ..............in this issue 


\section{Introduction}

\subsection{Document Scope and Rationale}

The field of electrophysiology has undergone rapid progress in the last decade, with advances both in our understanding of the genesis of ventricular arrhythmias (VAs) and in the technology used to treat them. In 2009, a joint task force of the European Heart Rhythm Association (EHRA) and the Heart Rhythm Society (HRS), in collaboration with the American College of Cardiology (ACC) and the American Heart Association (AHA), produced an expert consensus document that outlined the state of the field and defined the indications, techniques, and outcome measures of VA ablation [1]. In light of advances in the treatment of VAs in the interim, and the growth in the number of VA ablations performed in many countries and regions $[2,3]$, an updated document is needed. This effort represents a worldwide partnership between transnational cardiac electrophysiology societies, namely, HRS, EHRA, the Asia Pacific Heart Rhythm Society (APHRS), and the Latin American Heart Rhythm Society (LAHRS), and collaboration with ACC, AHA, the Japanese Heart Rhythm Society (JHRS), the Brazilian Society of Cardiac Arrhythmias (Sociedade Brasileira de Arritmias Cardíacas [SOBRAC]), and the Pediatric and Congenital Electrophysiology Society (PACES). The consensus statement was also endorsed by the Canadian Heart Rhythm Society (CHRS).

This clinical document is intended to supplement, not replace, the 2017 AHA/ACC/HRS Guideline for Management of Patients with Ventricular Arrhythmias and the Prevention of Sudden Cardiac Death [4] and the 2015 ESC Guidelines for the Management of Patients with Ventricular Arrhythmias and the Prevention of Sudden Cardiac Death [5]. The scope of the current document relates to ablation therapy for VAs, from premature ventricular complexes (PVCs) to monomorphic and polymorphic ventricular tachycardia (VT) and triggers of ventricular fibrillation (VF). Due to its narrower scope, the consensus statement delves into greater detail with regard to indications and technical aspects of VA ablation than the above-mentioned guidelines.

Where possible, the recommendations in this document are evidence based. It is intended to set reasonable standards that can be applicable worldwide, while recognizing the different resources, technological availability, disease prevalence, and health care delivery logistics in various parts of the world. In addition, parts of this document, particularly Section 9, present a practical guide on how to accomplish the procedures described in a manner that reflects the current standard of care, while recognizing that some procedures are better performed, and some disease states better managed, in settings in which there is specific expertise.

\subsection{Methods}

The writing group was selected according to each society's procedures, including content and methodology experts representing the following organizations: HRS, EHRA, APHRS, LAHRS, ACC, AHA, JHRS, PACES, and SOBRAC. Each partner society nominated a chair and co-chair, who did not have relevant relationships with industry and other entities (RWIs). In accordance with HRS policies, disclosure of any RWIs was required from the writing committee members (Appendix 1) and from all peer reviewers (Appendix 2). Of the 38 committee members, 17 (45\%) had no relevant RWIs. Recommendations were drafted by the members who did not have relevant RWIs. Members of the writing group conducted comprehensive literature searches of electronic databases, including Medline (via PubMed), Embase, and the Cochrane Library. Evidence tables were constructed to summarize the retrieved studies, with nonrandomized observational designs representing the predominant form of evidence (Supplementary Appendix 3). Case reports were not used to support recommendations. Supportive text was drafted in the "knowledge byte" format for each recommendation. The writing committee discussed all recommendations and the evidence that informed them before voting. Initial failure to reach consensus was resolved by subsequent discussions, revisions as needed, and re-voting. Although the consensus threshold was set at $67 \%$, all recommendations were approved by at least $80 \%$ of the writing committee members. The mean consensus over all recommendations was $95 \%$. A quorum of two-thirds of the writing committee was met for all votes [6].

Each recommendation in this document was assigned a Class of Recommendation (COR) and a Level of Evidence (LOE) according to the system developed by ACC and AHA (Table 1) [7]. The COR denotes the strength of the recommendation based on a careful assessment of the estimated benefits and risks; COR I indicates that the benefit of an intervention far exceeds its risk; COR IIa indicates that the benefit of the intervention moderately exceeds the risk; COR $\mathrm{IIb}$ indicates that the benefit may not exceed the risk; and COR III indicates that the benefit is equivalent to or is exceeded by the risk. The LOE reflects the quality of the evidence that supports the recommendation. LOE A is derived from highquality randomized controlled trials; LOE B-R is derived from moderate-quality randomized controlled trials; LOE B-NR is derived from well-designed nonrandomized studies; LOE C$\mathrm{LD}$ is derived from randomized or nonrandomized studies with limitations of design or execution; and LOE C-EO indicates that a recommendation was based on expert opinion [7].

Unique to this consensus statement is the systematic review commissioned specifically for this document as part of HRS's efforts to adopt the rigorous methodology required for guideline development. The systematic review was performed by an experienced evidence-based practice committee based at the 
Table 1 ACC/AHA Recommendation System: Applying Class of Recommendation and Level of Evidence to Clinical Strategies, Interventions, Treatments, and Diagnostic Testing in Patient Care*

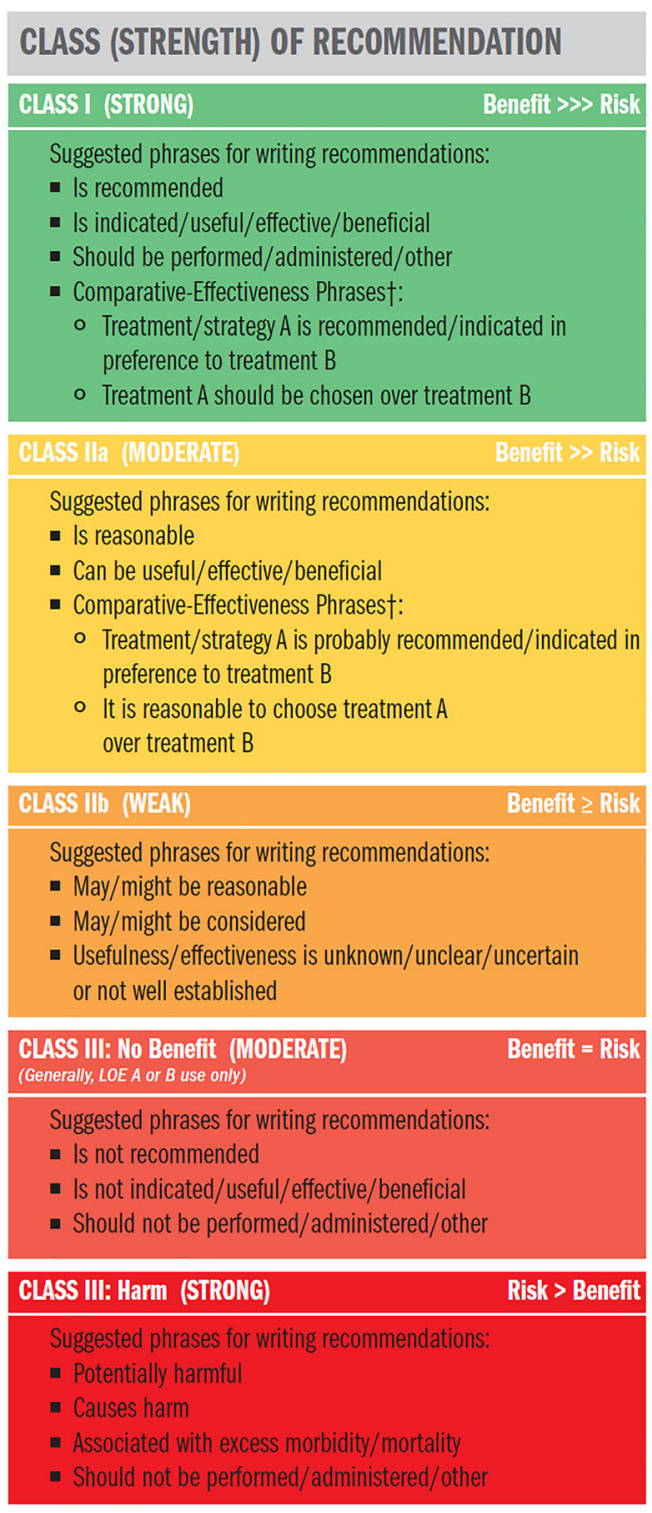

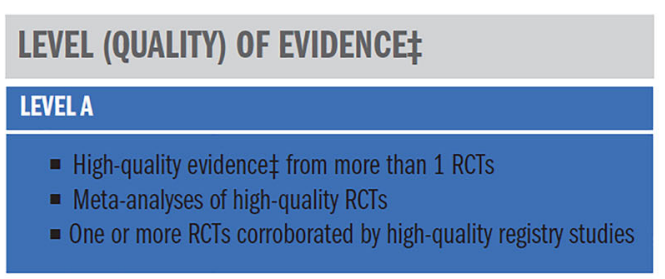

LEVEL B-R (Randomized)

- Moderate-quality evidenceł from 1 or more RCTs

- Meta-analyses of moderate-quality RCTs

LEVEL B-NR
- Moderate-quality evidenceł from 1 or more well-designed,
well-executed nonrandomized studies, observational
studies, or registry studies
- Meta-analyses of such studies

\begin{tabular}{l}
\hline LEVIEL C-LD \\
\hline - Randomized or nonrandomized observational or registry \\
studies with limitations of design or execution \\
- Meta-analyses of such studies \\
- Physiological or mechanistic studies in human subjects \\
\hline LEVEL. C-EO \\
\hline Consensus of expert opinion based on clinical experience \\
\hline
\end{tabular}

COR and LOE are determined independently (any COR may be paired with any LOE). A recommendation with $L O E C$ does not imply that the recommendation is weak. Many important clinical questions addressed in guidelines do not lend themselves to clinical trials. Although RCTs are unavailable, there may be a very clear clinical consensus that a particular test or therapy is useful or effective.

* The outcome or result of the intervention should be specified (an improved clinical outcome or increased diagnostic accuracy or incremental prognostic information).

† For comparative-effectiveness recommendations (COR I and Ila; LOE A and B only), studies that support the use of comparator verbs should involve direct comparisons of the treatments or strategies being evaluated.

$\ddagger$ The method of assessing quality is evolving, including the application of standardized, widely used, and preferably validated evidence grading tools; and for systematic reviews, the incorporation of an Evidence Review Committee.

COR indicates Class of Recommendation; EO, expert opinion; LD, limited data; LOE, Level of Evidence; NR, nonrandomized; R, randomized; and RCT, randomized controlled trial.

Reproduced with permission of the American College of Cardiology (ACC) and the American Heart Association (AHA) [7]

University of Connecticut, which examined the question of VT ablation vs control in patients with VT and ischemic heart disease (IHD) [8]. The question, in PICOT format, was as follows: In adults with history of sustained VT and IHD, what is the effectiveness and what are the detriments of catheter ablation compared with other interventions? Components of the PICOT were as follows: $\mathrm{P}=$ adults with history of sustained VT and IHD; I = catheter ablation; $\mathrm{C}=$ control (no therapy or antiarrhythmic drug [AAD]); $\mathrm{O}=$ outcomes of interest, which included 1) appropriate implantable cardioverter defibrillator (ICD) therapies (ICD shock or antitachycardia pacing [ATP]), 2) appropriate ICD shocks, 3) VT storm (defined as three shocks within 24 hours), 4) recurrent VT/VF, 5) cardiac hospitalizations, and 6) all-cause mortality; and $\mathrm{T}=$ no time restrictions.
An industry forum was conducted to achieve a structured dialogue to address technical questions and to gain a better understanding of future directions and challenges. Because of the potential for actual or perceived bias, HRS imposes strict parameters on information sharing to ensure that industry participates only in an advisory capacity and has no role in either the writing of the document or its review.

The draft document underwent review by the HRS Scientific and Clinical Documents Committee and was approved by the writing committee. Recommendations were subject to a period of public comment, and the entire document underwent rigorous peer review by each of the participating societies and revision by the Chairs, before endorsement. 


\section{Background}

This section reviews the history of VT ablation, details the mechanisms of VT, and provides definitions of frequently used terms (Table 2), including anatomic definitions (Table 3), as well as illustrating some types of sustained VA (Fig. 1).

Table 2 Definitions

\section{Clinical Characteristics}

Clinical ventricular tachycardia (VT): VT that has occurred spontaneously based on analysis of 12-lead electrocardiogram (ECG) QRS morphology.

Hemodynamically unstable VT: causes hemodynamic compromise requiring prompt termination.

Idiopathic VT: used to indicate VT that is known to occur in the absence of clinically apparent structural heart disease (SHD).

Idioventricular rhythm: three or more consecutive beats at a rate of up to 100 per minute that originate from the ventricles independent of atrial or atrioventricular $(\mathrm{AV})$ nodal conduction. Although various arbitrary rates have been used to distinguish it from VT, the mechanism of ventricular rhythm is more important than the rate. Idioventricular rhythm can be qualified as "accelerated" when the rate exceeds $40 \mathrm{bpm}$.

Incessant VT: continuous sustained VT that recurs promptly despite repeated intervention for termination over several hours.

Nonclinical VT: VT induced by programmed electrical stimulation (PES) that has not been documented previously.

Nonsustained VT: terminates spontaneously within 30 seconds.

PVC: premature ventricular complex; it is an early ventricular depolarization with or without mechanical contraction. We recommend avoiding the use of the terms "ventricular premature depolarization" and "premature ventricular contraction" to standardize the literature and acknowledge that early electrical activity does not necessarily lead to mechanical contraction.

Presumptive clinical VT: similar to a spontaneous VT based on rate, limited ECG, or electrogram data available from ICD interrogation, but without the 12-lead ECG documentation of spontaneous VT.

PVC burden: the amount of ventricular extrasystoles, preferably reported as the $\%$ of beats of ventricular origin of the total amount of beats over a 24-hour recording period.

Repetitive monomorphic VT: continuously repeating episodes of self-terminating nonsustained VT.

Sustained VT: continuous VT for 30 seconds, or which requires an intervention for termination (such as cardioversion).

$V T$ : a tachycardia (rate $>100 \mathrm{bpm}$ ) with 3 or more consecutive beats that originates from the ventricles independent of atrial or AV nodal conduction.

VT storm: three or more separate episodes of sustained VT within 24 hours, each requiring termination by an intervention.

\section{VT Morphologies}

Monomorphic VT: a similar QRS configuration from beat to beat (Fig. 1a). Some variability in QRS morphology at initiation is not uncommon, followed by stabilization of the QRS morphology.

Monomorphic VT with indeterminate QRS morphology: preferred over ventricular flutter; it is a term that has been applied to rapid VT that has a sinusoidal QRS configuration that prevents identification of the QRS morphology.

Multiple monomorphic VTs: more than one morphologically distinct monomorphic VT, occurring as different episodes or induced at different times.

Pleomorphic VT: has more than one morphologically distinct QRS complex occurring during the same episode of VT, but the QRS is not continuously changing (Fig. 1b).

Polymorphic VT: has a continuously changing QRS configuration from beat to beat, indicating a changing ventricular activation sequence (Fig. 1c).

Right bundle branch block (RBBB)- and left bundle branch block (LBBB)-like VT configurations: terms used to describe the dominant deflection in V1, with a dominant $\mathrm{R}$ wave described as "RBBB-like" and a dominant S wave with a negative final component in V1 described as "LBBB-like" configurations.

Torsades de pointes: a form of polymorphic VT with continually varying QRS complexes that appear to spiral around the baseline of the ECG lead in a sinusoidal pattern. It is associated with QT prolongation.

Unmappable VT: does not allow interrogation of multiple sites to define the activation sequence or perform entrainment mapping; this could be due to hemodynamic intolerance that necessitates immediate VT termination, spontaneous or pacing-induced transition to other morphologies of VT, or repeated termination during mapping.

Ventricular fibrillation (VF): a chaotic rhythm defined on the surface ECG by undulations that are irregular in both timing and morphology, without discrete QRS complexes.

\section{PVC Morphologies}

Monomorphic PVC: PVCs felt reasonably to arise from the same focus. Slight changes in QRS morphology due to different exit sites from the same focus can be present.

Multiple morphologies of PVC: PVCs originating from several different focal locations.

Predominant PVC morphology: the one or more monomorphic PVC morphologies occurring most frequently and serving as the target for ablation. 
Table 2 (continued)

\section{Mechanisms}

Focal VT: a point source of earliest ventricular activation with a spread of activation away in all directions from that site. The mechanism can be automaticity, triggered activity, or microreentry.

Scar-related reentry: arrhythmias that have characteristics of reentry that originate from an area of myocardial scar identified from electrogram characteristics or myocardial imaging. Large reentry circuits that can be defined over several centimeters are commonly referred to as "macroreentry."

$A V$ atrioventricular, $E C G$ electrocardiogram, ICD implantable cardioverter defibrillator, $L B B B$ left bundle branch block, $P E S$ programmed electrical stimulation, $P V C$ premature ventricular complex, $R B B B$ right bundle branch block, $S H D$ structural heart disease, $V T$ ventricular tachycardia

Fig. 1 Monomorphic (a), pleomorphic (b), and polymorphic (c) VT. Reproduced with permission of the Heart Rhythm Society from Aliot et al. EHRA/HRS expert consensus on catheter ablation of ventricular arrhythmias. Heart Rhythm 2009;6:886-933. VT = ventricular tachycardia

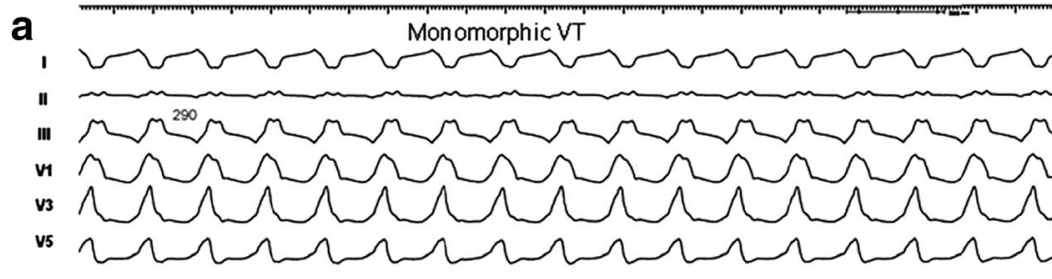

(n)

C Polymorphic VT

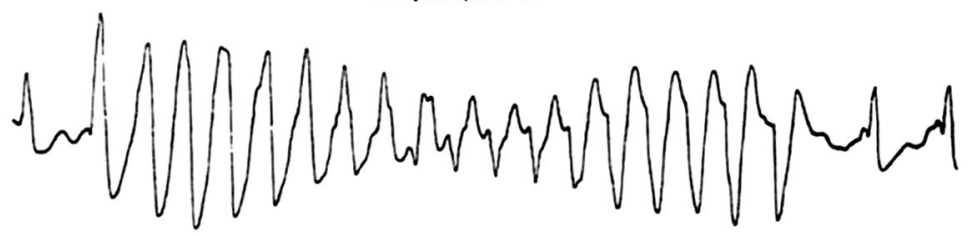


Table 3 Anatomical terminology

Term Definition

RV inflow

RV outflow tract (RVOT)

Tricuspid annulus

Moderator band

RV papillary muscles

Supraventricular crest

Pulmonary valves

Sinuses of Valsalva (SV), aortic cusps, aortic commissures

\section{LV outflow tract (LVOT)}

\section{LV ostium}

Aortomitral continuity (AMC); aortomitral curtain, or mitral-aortic intervalvular fibrosa

Mitral valve annulus

LV papillary muscles

LV false tendon (or LV moderator band)

Posterior-superior process

Endocardium

Purkinje network

Interventricular septum

Membranous ventricular septum

LV summit

Crux of the heart (crux cordis)

Epicardium

Epicardial fat

Pericardial space or cavity
The part of the right ventricle (RV) containing the tricuspid valve, chordae, and proximal RV.

The conus or infundibulum of the RV, derived from the bulbus cordis. It is bounded by the supraventricular crest and the pulmonic valve.

Area immediately adjacent to the tricuspid valve, including septal, free wall, and para-Hisian regions.

A muscular band in the RV, typically located in the mid to apical RV, connecting the interventricular septum to the RV free wall, supporting the anterior papillary muscle. It typically contains a subdivision of the right bundle branch (RBB).

Three muscles connecting the RV myocardium to the tricuspid valve via the tricuspid chordae tendineae, usually designated as septal, posterior, and anterior papillary muscles. The septal papillary muscle is closely associated with parts of the RBB.

Muscular ridge in the RV between the tricuspid and pulmonic valves, representing the boundary between the conus arteriosus and the rest of the RV. The exact components and terminology are controversial; however, some characterize it as being composed of a parietal band that extends from the anterior RV free wall to meet the septal band, which extends from the septal papillary muscle to meet it.

The pulmonic valve includes three cusps and associated sinus, variously named right, left, and anterior; or anterolateral right, anterolateral left, and posterior sinuses. The posterior-right anterolateral commissure adjoins the aorta (junction of the right and left aortic sinuses). Muscle is present in each of the sinuses, and VA can originate from muscle fibers located within or extending beyond the pulmonary valve apparatus.

The right $(\mathrm{R})$, left $(\mathrm{L})$, and noncoronary aortic valve cusps are attached to the respective SV. The left sinus of Valsalva (LSV) is posterior and leftward on the aortic root. The noncoronary sinus of Valsalva (NCSV) is typically the most inferior and posterior SV, located posterior and rightward, superior to the His bundle, and anterior and superior to the paraseptal region of the atria near the superior AV junctions, typically adjacent to atrial myocardium. The right sinus of Valsalva (RSV) is the most anterior cusp and may be posterior to the RVOT infundibulum. VAs can also arise from muscle fibers at the commissures (connections) of the cusps, or from myocardium accessible to mapping and ablation from this location, especially from the RSV/LSV junction.

The aortic vestibule, composed of an infra-valvular part, bounded by the anterior mitral valve leaflet, but otherwise not clearly distinguishable from the rest of the LV; the aortic valve; and a supra-valvular part.

The opening at the base of the LV to which the mitral and aortic valves attach.

Continuation of the anteromedial aspect of the mitral annulus to the aortic valve; a curtain of fibrous tissue extending from the anterior mitral valve leaflet to the left and noncoronary

aortic cusps. The AMC is connected by the left and right fibrous trigones to ventricular myocardium, the right fibrous trigone to the membranous ventricular septum.

Area immediately adjacent to the mitral valve. This can be approached endocardially, or epicardially, either through the coronary venous system or percutaneously.

Muscles connecting the mitral valve chordae tendineae to the LV, typically with posteromedial and anterolateral papillary muscles. Papillary muscle anatomy is variable and can have single or multiple heads.

A fibrous or fibromuscular chord-like band that crosses the LV cavity, attaching to the septum, papillary muscles, trabeculations, or free wall of the LV. They may contain conduction tissue and may impede catheter manipulation in the LV.

The posterior-superior process of the left ventricle (LV) is the most inferior and posterior aspect of the basal LV, posterior to the plane of the tricuspid valve. VAs originating from the posterior-superior process of the LV can be accessed from the right atrium, the LV endocardium, and the coronary venous system.

Inner lining of the heart.

The specialized conduction system of the ventricles, which includes the His bundle, RBB and left bundle branches (LBB), and the ramifications of these, found in the subendocardium. The Purkinje system can generate focal or reentrant VTs, typically manifesting Purkinje potentials preceding QRS onset.

Muscular wall between the LV and RV.

The ventricular septum beneath the RSV and NCSV, through which the penetrating His bundle reaches the ventricular myocardium.

Triangular region of the most superior part of the LV epicardial surface bounded by the left circumflex coronary artery, the left anterior descending artery, and an approximate line from the first septal coronary artery laterally to the left AV groove. The great cardiac vein (GCV) bisects the triangle. An area superior to the GCV is considered to be inaccessible to catheter ablation due to proximity of the coronary arteries and overlying epicardial fat.

Epicardial area formed by the junction of the AV groove and posterior interventricular groove, at the base of the heart, approximately at the junction of the middle cardiac vein and coronary sinus (CS) and near the origin of the posterior descending coronary artery.

The outer layer of the heart - the visceral layer of the serous pericardium.

Adipose tissue variably present over the epicardial surface around coronary arteries, LV apex, RV free wall, left atrial appendage, right atrial appendage, and AV and interventricular grooves.

The potential space between the parietal and visceral layers of serous pericardium, which normally contains a small amount of serous fluid. This space can be accessed for epicardial procedures. 
Table 3 (continued)

\begin{tabular}{|c|c|}
\hline Term & Definition \\
\hline Parietal pericardium & $\begin{array}{l}\text { The layer of the serous pericardium that is attached to the inner surface of the fibrous pericardium and is } \\
\text { normally apposed to the visceral pericardium, separated by a thin layer of pericardial fluid. }\end{array}$ \\
\hline Fibrous pericardium & Thick membrane that forms the outer layer of the pericardium. \\
\hline Subxiphoid area & Area inferior to the xiphoid process; typical site for percutaneous epicardial access. \\
\hline Phrenic nerve & $\begin{array}{l}\text { The right phrenic nerve lays along the right atrium and does not usually pass over ventricular tissue. The } \\
\text { course of the left phrenic nerve on the fibrous pericardium can be quite variable and may run along the } \\
\text { lateral margin of the LV near the left obtuse marginal artery and vein; inferior, at the base of the heart; } \\
\text { or anterior over the sternocostal surface over the L main stem coronary artery or left anterior } \\
\text { descending artery. }\end{array}$ \\
\hline Coronary sinus (CS) and branches & $\begin{array}{l}\text { The CS and its branches comprise the coronary venous system with the ostium of the CS opening into the } \\
\text { right atrium. Tributaries of the CS, which runs along the left } \\
\text { AV groove, may be used for mapping. These include the anterior interventricular vein (AIV), which } \\
\text { arises at the apex and runs along the anterior interventricular septum, connecting to the GCV that } \\
\text { continues in the AV groove to the CS; the communicating vein located between aortic and pulmonary } \\
\text { annulus; various posterior and lateral marginal branches or perforator veins; and the middle cardiac } \\
\text { vein that typically runs along the posterior interventricular septum from the apex to join the CS or } \\
\text { empty separately into the right atrium. The junction of the GCV and the CS is at the vein or ligament of } \\
\text { Marshall (or persistent left superior vena cava, when present), and the valve of Vieussens (where } \\
\text { present). }\end{array}$ \\
\hline
\end{tabular}

Anatomical terminology [9-17]. See also Figs. 3, 4, 7, and 8

$A I V$ anterior interventricular vein, $A M C$ aortomitral continuity, $A V$ atrioventricular, $C S$ coronary sinus, $G C V$ great cardiac vein, $L B B$ left bundle branch, $L S V$ left sinus of Valsalva, $L V$ left ventricle, $L V O T$ left ventricular outflow tract, $N C S V$ noncoronary sinus of Valsalva, $R B B$ right bundle branch, $R S V$ right sinus of Valsalva, $R V$ right ventricle, $R V O T$ right ventricular outflow tract, $S V$ sinus of Valsalva, $V A$ ventricular arrhythmia, $V T$ ventricular tachycardia

\section{Clinical Evaluation}

This section discusses clinical presentations of patients with VAs and their workup as it pertains to documentation of arrhythmias and appropriate testing to assess for the presence of SHD.

\subsection{Clinical Presentation}

\section{Recommendation for clinical evaluation of patients with VAs}

\begin{tabular}{cll} 
COR & LOE & Recommendation \\
\hline I & C-EO & $\begin{array}{l}\text { 1. A careful clinical evaluation including history, physical examination, review of available } \\
\text { cardiac rhythm data, prior imaging, and relevant laboratory workup should be performed } \\
\text { in patients presenting with VAs. }\end{array}$ \\
\hline
\end{tabular}

\subsection{Diagnostic Evaluation}

\subsubsection{Resting 12-Lead Electrocardiogram}

\section{Recommendations for resting 12-lead ECG}

\begin{tabular}{c|lll} 
COR & LOE & Recommendations & References \\
\hline I & B-NR & $\begin{array}{l}\text { 1. In patients with wide complex tachycardia, a 12-lead ECG during tachycardia should be } \\
\text { obtained whenever possible. }\end{array}$ [18-32] \\
I & B-NR & $\begin{array}{l}\text { 2. In patients with suspected or documented VA, a 12-lead ECG should be obtained in } \\
\text { sinus rhythm to look for evidence of underlying heart disease. }\end{array}$ \\
\hline
\end{tabular}




\subsubsection{Assessment of Structural Heart Disease and Myocardial}

\section{Ischemia}

Recommendations for assessment of SHD and myocardial ischemia

\begin{tabular}{cccccc}
\hline COR & LOE & Recommendations & References \\
\hline I & B-NR & $\begin{array}{l}\text { 1. In patients with known or suspected VA, echocardiography is recommended for } \\
\text { evaluation of cardiac structure and function. }\end{array}$ & {$[36-40]$} \\
IIa & B-NR & $\begin{array}{l}\text { 2. In patients presenting with VA who are suspected of having SHD, even after normal } \\
\text { echocardiographic evaluation, advanced cardiac imaging can be useful to detect and } \\
\text { characterize underlying SHD. }\end{array}$ & {$[34,35]$} \\
IIa & C-EO & $\begin{array}{l}\text { 3. In patients with VA in whom myocardial ischemia is suspected, stress testing and/or } \\
\text { coronary angiography and subsequent revascularization can be beneficial before } \\
\text { catheter ablation to avoid significant ischemia during induced VT. }\end{array}$ \\
$\begin{array}{c}\text { III: No } \\
\text { Benefit }\end{array}$ & B-NR & $\begin{array}{l}\text { 4. In patients presenting with monomorphic VT, revascularization alone is not effective } \\
\text { to prevent VT recurrence. }\end{array}$ & {$[41-43]$} \\
\hline
\end{tabular}

\subsubsection{Risk Stratification in the Setting of Frequent Premature}

Ventricular Complexes

Recommendations for cardiac magnetic resonance imaging (CMR) in patients with frequent PVCs and for PES in patients with SHD and frequent PVCs

\begin{tabular}{cclll}
\hline COR & LOE & Recommendations & References \\
\hline IIa & B-NR & $\begin{array}{l}\text { 1. CMR can be useful for risk stratification for sudden cardiac death in patients with } \\
\text { frequent PVCs. }\end{array}$ & {$[44,45]$} \\
IIa & C-LD & $\begin{array}{l}\text { 2. PES can be useful for risk stratification for sudden cardiac death in patients with SHD } \\
\text { undergoing ablation of frequent PVCs. }\end{array}$ \\
\hline
\end{tabular}

\subsubsection{Longitudinal Follow-up in the Setting of Frequent \\ Premature Ventricular Complexes}

Recommendation for longitudinal follow-up of patients with frequent PVCs

\begin{tabular}{cllll} 
COR & LOE & Recommendation & Reference \\
\hline IIa & B-NR & $\begin{array}{l}\text { 1. Periodic monitoring of PVC burden and LV function and dimensions can be useful in } \\
\text { patients with frequent, asymptomatic PVCs and normal LV function and dimensions. }\end{array}$ & {$[46]$} \\
\hline
\end{tabular}

\section{Indications for Catheter Ablation}

Following are the consensus recommendations for catheter ablation of VAs organized by underlying diagnosis and substrate. These recommendations are each assigned a COR and an LOE according to the current recommendation classification system [47]. In drafting each of these recommendations, the writing committee took into account the published literature in the specific area, including the methodological quality and size of each study, as well as the collective clinical experience of the writing group when published data were not available. Implicit in each recommendation are several points: 1) the procedure is being performed by an electrophysiologist with appropriate training and experience in the procedure and in a facility with appropriate resources; 2) patient and procedural complexity vary widely, and some patients or situations merit a more experienced operator or a center with more capabilities than others, even within the same recommendation (eg, when an epicardial procedure is indicated and the operator or institution has limited experience with this procedure, it might be preferable to refer the patient to an operator or institution with adequate experience in performing epicardial procedures); 3 ) the patient is an appropriate candidate for the procedure, as outlined in Section 5, recognizing that the level of patient suitability for a procedure will vary widely with the clinical scenario; and 4) the patient's (or designee's) informed consent, values, and overall clinical trajectory are fundamental to a decision to proceed (or not) with any procedure. Therefore, in some clinical scenarios, initiation or continuation of medical therapy instead of an ablation procedure may be the most appropriate option, even when a class 1 recommendation for ablation is present. There may also 
be scenarios not explicitly covered in this document, and on which little or no published literature is available, in which the physician and patient must rely solely on their own judgment.
Figure 2 provides an overview of care for the patient with congenital heart disease (CHD) and VA.

\subsection{Idiopathic Outflow Tract Ventricular Arrhythmia}

\section{Recommendations for catheter ablation of idiopathic outflow tract VA}

\begin{tabular}{c|c|c|c|}
\hline COR & LOE & $\begin{array}{l}\text { Recommendations } \\
\text { I }\end{array}$ B-R & $\begin{array}{l}\text { 1. In patients with frequent and symptomatic PVCs originating from the RVOT } \\
\text { in an otherwise normal heart, catheter ablation is recommended in preference to } \\
\text { metoprolol or propafenone. }\end{array}$ \\
\hline I & B-NR & $\begin{array}{l}\text { 2. In patients with symptomatic VAs from the RVOT in an otherwise normal heart for whom } \\
\text { antiarrhythmic medications are ineffective, not tolerated, or not the patient's preference, } \\
\text { catheter ablation is useful. }\end{array}$ \\
\hline I & B-NR & $\begin{array}{l}\text { 3. In patients with symptomatic idiopathic sustained monomorphic VT, catheter ablation is } \\
\text { useful. }\end{array}$ \\
\hline IIa & B-NR & $\begin{array}{l}\text { 4. In patients with symptomatic VAs from the endocardial LVOT, including the SV, } \\
\text { in an otherwise normal heart for whom anti arrhythmic medications are ineffective, } \\
\text { not tolerated, or not the patient's preference, catheter ablation can be useful. }\end{array}$ \\
IIa & B-NR & $\begin{array}{l}\text { 5. In patients with symptomatic VAs from the epicardial outflow tract or LV summit in an } \\
\text { otherwise normal heart for whom antiarrhythmic medications are ineffective, not tolerated, } \\
\text { or not the patient's preference, catheter ablation can be useful. }\end{array}$ & {$[50]$} \\
\hline
\end{tabular}

\subsection{Idiopathic Nonoutflow Tract Ventricular Arrhythmia}

\section{Recommendations for catheter ablation of nonoutflow tract VAs in the absence of SHD}

\begin{tabular}{|c|c|c|c|}
\hline COR & LOE & Recommendations & References \\
\hline I & B-NR & $\begin{array}{l}\text { 1. In patients with symptomatic VAs from the RV at sites other than the outflow tracts (tricuspid } \\
\text { annulus, moderator band, parietal band, or papillary muscles) in an otherwise normal heart } \\
\text { for whom antiarrhythmic medications are ineffective, not tolerated, or not the patient's } \\
\text { preference, catheter ablation is useful. }\end{array}$ & {$[25,81-93]$} \\
\hline I & B-NR & $\begin{array}{l}\text { 2. In patients with symptomatic VAs from the LV at sites other than the outflow tracts (mitral } \\
\text { annulus, papillary muscles, or AMC) in an otherwise normal heart for whom antiarrhythmic } \\
\text { medications are ineffective, not tolerated, or not the patient's preference, catheter ablation } \\
\text { is useful. }\end{array}$ & [16, 26, \\
\hline IIa & B-NR & $\begin{array}{l}\text { 3. In patients with symptomatic VAs from the epicardial coronary venous system in an otherwise } \\
\text { normal heart for whom antiarrhythmic medications are ineffective, not tolerated, or not the } \\
\text { patient's preference, catheter ablation can be useful. }\end{array}$ & $\begin{array}{l}{[77,109-} \\
119]\end{array}$ \\
\hline IIa & B-NR & $\begin{array}{l}\text { 4. In patients with symptomatic VAs from para-Hisian sites in an otherwise normal heart for } \\
\text { whom antiarrhythmic medications are ineffective, not tolerated, or not the patient's } \\
\text { preference, catheter ablation can be useful. }\end{array}$ & $\begin{array}{l}{[86,92,93,} \\
120-125]\end{array}$ \\
\hline IIa & C-LD & $\begin{array}{l}\text { 5. In patients with symptomatic VAs from the posterior-superior process of the } L V \text { in an } \\
\text { otherwise normal heart for whom antiarrhythmic medications are ineffective, not tolerated, } \\
\text { or not the patient's preference, catheter ablation from the } L V \text { endocardium, right atrium, or } \\
\text { CS, can be useful. }\end{array}$ & [126-128] \\
\hline
\end{tabular}




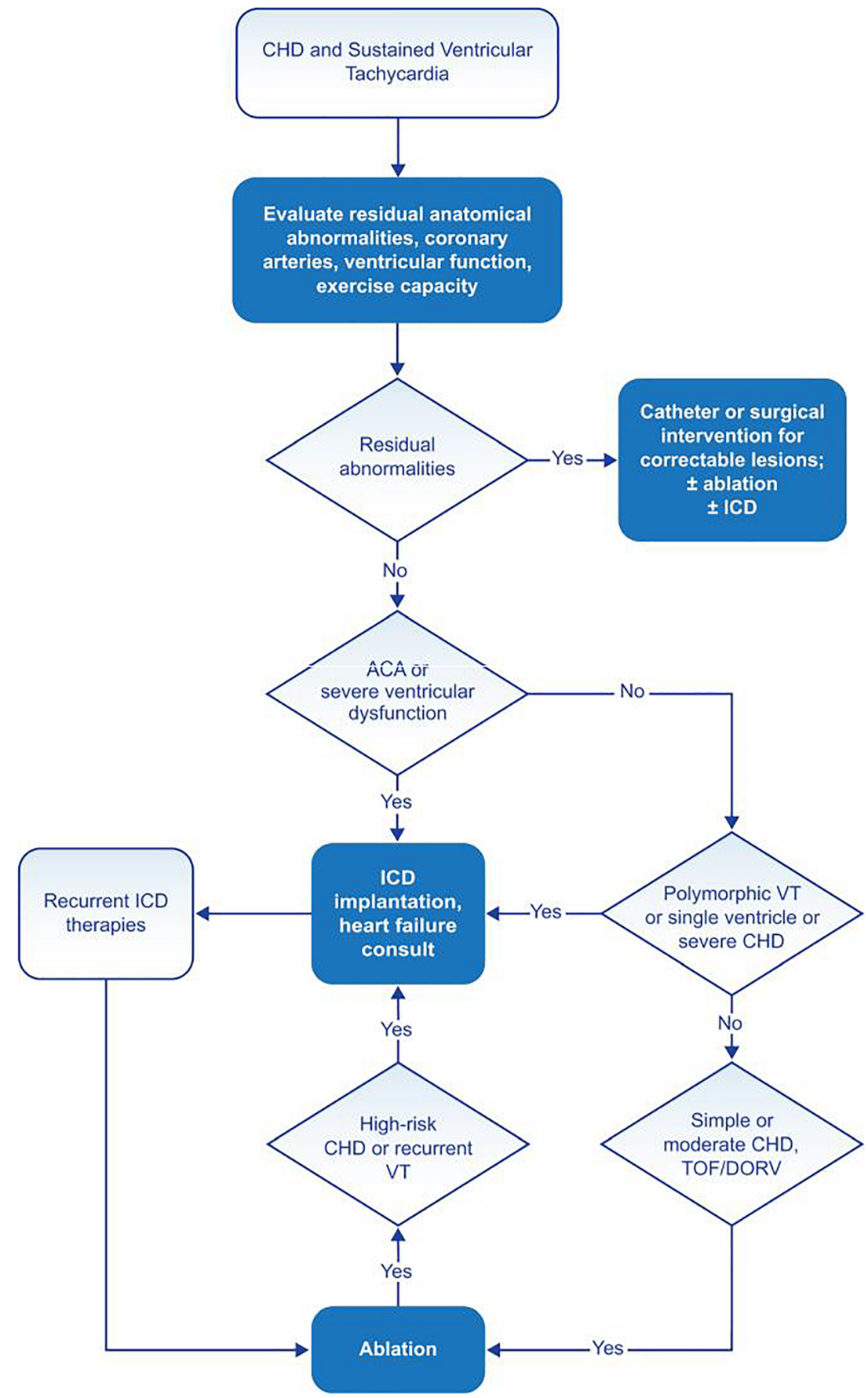

Fig. 2 Congenital heart disease and sustained VT. For further discussion of ICD candidacy, please see PACES/HRS Expert Consensus Statement on the Recognition and Management of Arrhythmias in Adult Congenital Heart Disease [48] and 2012 ACCF/AHA/HRS Focused Update of the 2008 Guidelines for Device-Based Therapy of Cardiac Rhythm
Abnormalities [49]. ACA $=$ aborted cardiac arrest $\mathrm{CHD}=$ congenital heart disease; DORV = double outlet right ventricle; $\mathrm{ICD}=$ implantable cardioverter defibrillator; TOF $=$ tetralogy of Fallot; VT $=$ ventricular tachycardia 


\subsection{Premature Ventricular Complexes With or Without Left Ventricular Dysfunction}

Recommendations for catheter ablation of PVCs in patients with or without LV dysfunction

$\left.\begin{array}{cccccc}\hline \text { COR } & \text { LOE } & \text { Recommendations } & \text { References } \\ \hline \text { I } & \text { B-NR } & \begin{array}{l}\text { 1. In patients with cardiomyopathy suspected to be caused by frequent and } \\ \text { predominately monomorphic PVCs and for whom AADs are ineffective, not } \\ \text { tolerated, or not preferred for long-term therapy, catheter ablation is } \\ \text { recommended. }\end{array} & {[58,129-} \\ \text { IIa } & \text { B-NR } & \begin{array}{l}\text { 2. In patients with SHD in whom frequent PVCs are suspected to be contributing to a } \\ \text { cardiomyopathy and for whom AADs are ineffective, not tolerated, or not preferred } \\ \text { for long-term therapy, catheter ablation can be useful. }\end{array} \quad[131,138, & 139] \\ \text { IIa } & \text { B-NR } & \begin{array}{l}\text { 3. In patients with focally triggered VF refractory to AADs and triggered by a similar } \\ \text { PVC, catheter ablation can be useful. }\end{array} & {[82,140-} \\ \text { IIa } & \text { C-LD } & \begin{array}{l}\text { 4. In nonresponders to cardiac resynchronization therapy with very frequent unifocal } \\ \text { PVCs limiting optimal biventricular pacing despite pharmacological therapy, } \\ \text { catheter ablation can be useful. }\end{array} & {[144]}\end{array}\right]$

\subsection{Ventricular Arrhythmia in Ischemic Heart Disease}

\section{Recommendations for catheter ablation of VAs in patients with IHD}

\begin{tabular}{|c|c|c|c|}
\hline COR & LOE & Recommendations & References \\
\hline I & B-R & $\begin{array}{l}\text { 1. In patients with IHD who experience recurrent monomorphic VT despite chronic } \\
\text { amiodarone therapy, catheter ablation is recommended in preference to escalating } \\
\text { AAD therapy. }\end{array}$ & [145] \\
\hline $\mathbf{I}$ & B-NR & $\begin{array}{l}\text { 2. In patients with IHD and recurrent symptomatic monomorphic VT despite AAD therapy } \\
\text { or when AAD therapy is contraindicated or not tolerated, catheter ablation is } \\
\text { recommended to reduce recurrent VT. }\end{array}$ & [146-148] \\
\hline $\mathbf{I}$ & B-NR & $\begin{array}{l}\text { 3. In patients with IHD and VT storm refractory to AAD therapy, catheter ablation is } \\
\text { recommended. }\end{array}$ & [149-153] \\
\hline IIa & C-EO & $\begin{array}{l}\text { 4. In patients with IHD and recurrent monomorphic VT, in whom AADs are not desired, } \\
\text { catheter ablation can be useful. }\end{array}$ & \\
\hline IIb & $\mathbf{A}$ & $\begin{array}{l}\text { 5. In patients with IHD and an ICD who experience a first episode of monomorphic VT, } \\
\text { catheter ablation may be considered to reduce the risk of recurrent VT or ICD therapies. }\end{array}$ & $\begin{array}{l}{[8,154-} \\
157]\end{array}$ \\
\hline IIb & C-LD & $\begin{array}{l}\text { 6. In patients with prior myocardial infarction and recurrent episodes of symptomatic } \\
\text { sustained VT for whom prior endocardial catheter ablation has not been successful and } \\
\text { who have ECG, endocardial mapping, or imaging evidence of a subepicardial VT } \\
\text { substrate, epicardial ablation may be considered. }\end{array}$ & [158-162] \\
\hline
\end{tabular}




\subsection{Nonischemic Cardiomyopathy}

Recommendations for catheter ablation of VT in nonischemic cardiomyopathy (NICM)

\begin{tabular}{c|c|c|c|}
\hline COR & LOE & Recommendations & References \\
\hline I & B-NR & $\begin{array}{l}\text { 1. In patients with NICM and recurrent sustained monomorphic VT for whom } \\
\text { antiarrhythmic medications are ineffective, contraindicated, or not tolerated, } \\
\text { catheter ablation is useful for reducing recurrent VT and ICD shocks. }\end{array}$ \\
\hline I & B-NR & $\begin{array}{l}\text { 2. In patients with NICM and electrical storm refractory to AAD therapy, catheter } \\
\text { ablation is useful for reducing recurrent VT and ICD shocks. }\end{array}$ & {$[163-168]$} \\
IIa & B-NR & $\begin{array}{l}\text { 3. In patients with NICM, epicardial catheter ablation of VT can be useful after failure } \\
\text { of endocardial ablation or as the initial ablation approach when there is a suspicion } \\
\text { of an epicardial substrate or circuit. }\end{array}$ & {$[169,170-$} \\
IIa & B-NR & $\begin{array}{l}\text { 4. In patients with cardiac sarcoidosis and recurrent VT despite medical therapy, } \\
\text { catheter ablation can be useful to reduce the risk of VT recurrence and ICD shocks. }\end{array}$ \\
\hline IIb & B-EO & $\begin{array}{l}\text { 5. In patients with NICM and recurrent sustained monomorphic VT for whom } \\
\text { antiarrhythmic medications are not desired, catheter ablation can be useful for } \\
\text { reducing recurrent VT and ICD shocks. }\end{array}$ \\
\hline $\begin{array}{l}\text { 6. In patients with NICM related to lamin A/C (LMNA) mutations and recurrent VT, } \\
\text { catheter ablation may be considered as a palliative strategy for short-term } \\
\text { arrhythmia control. }\end{array}$
\end{tabular}

\subsection{Ventricular Arrhythmia Involving the His-Purkinje System, Bundle Branch Reentrant Ventricular Tachycardia, and Fascicular Ventricular Tachycardia}

Recommendations for catheter ablation of bundle branch reentrant VT and for catheter ablation of fascicular VT

\begin{tabular}{|c|c|c|c|}
\hline COR & LOE & Recommendations & References \\
\hline I & B-NR & $\begin{array}{l}\text { 1. In patients with bundle branch reentrant VT, catheter ablation is useful for reducing } \\
\text { the risk of recurrent VT. }\end{array}$ & [180-188] \\
\hline I & B-NR & $\begin{array}{l}\text { 2. In patients with idiopathic left fascicular reentrant VT for whom medications are } \\
\text { ineffective, not tolerated, or not the patient's preference, catheter ablation is useful. }\end{array}$ & [189-201] \\
\hline I & B-NR & $\begin{array}{l}\text { 3. In larger pediatric patients ( } \geq 15 \mathrm{~kg} \text { ) with idiopathic left fascicular reentrant VT in } \\
\text { whom medical treatment is ineffective or not tolerated, catheter ablation is useful. }\end{array}$ & [202-205] \\
\hline I & B-NR & 4. In patients with focal fascicular VT with or without SHD, catheter ablation is useful. & {$[190,206-208]$} \\
\hline $\mathbf{I}$ & B-NR & $\begin{array}{l}\text { 5. In patients with postinfarction reentrant Purkinje fiber-mediated VT, catheter ablation } \\
\text { is useful. }\end{array}$ & [209-211] \\
\hline
\end{tabular}

\subsection{Congenital Heart Disease}

\section{Recommendations for catheter ablation of VA in patients with CHD}

\begin{tabular}{cccccc}
\hline COR & LOE & Recommendations & References \\
\hline I & B-NR & $\begin{array}{l}\text { 1. In patients with CHD presenting with sustained VAs, evaluation for potential residual } \\
\text { anatomical or coronary abnormalities should be performed. }\end{array}$ & {$[212-217]$} \\
I & B-NR & $\begin{array}{l}\text { 2. In patients with CHD presenting with sustained VT in the presence of important } \\
\text { hemodynamic lesions, treatment of hemodynamic abnormalities as feasible should be } \\
\text { performed in conjunction with consideration for ablation. }\end{array}$ & {$[48,213$,} \\
I & B-NR & $\begin{array}{l}\text { 3. In patients with repaired tetralogy of Fallot and sustained monomorphic VT or } \\
\text { recurrent appropriate ICD therapy for VAs, catheter ablation is effective. }\end{array}$ & {$[227-234]$} \\
IIa & B-NR & $\begin{array}{l}\text { 4. In select patients with CHD and clinical episodes of sustained VT who are undergoing } \\
\text { surgical repair of residual hemodynamic abnormalities, surgical ablation of VT guided } \\
\text { by preoperative or intraoperative electroanatomical mapping (EAM) can be beneficial. }\end{array}$ & {$[213,219$,} \\
& & &
\end{tabular}




\subsection{Inherited Arrhythmia Syndromes}

Recommendations for catheter ablation of VA in inherited primary arrhythmia disorders

\begin{tabular}{|c|c|c|c|}
\hline COR & LOE & Recommendations & References \\
\hline I & B-NR & $\begin{array}{l}\text { 1. In patients with arrhythmogenic right ventricular cardiomyopathy (ARVC) who } \\
\text { experience recurrent sustained VT or frequent appropriate ICD interventions for } \\
\text { VT in whom AAD therapy is ineffective or not tolerated, catheter ablation, at a } \\
\text { center with specific expertise, is recommended. }\end{array}$ & [236-246] \\
\hline $\mathbf{I}$ & B-NR & $\begin{array}{l}\text { 2. In patients with ARVC who have failed one or more attempts of endocardial } \\
\text { VT catheter ablation, an epicardial approach for VT ablation is recommended. }\end{array}$ & $\begin{array}{l}{[238-242,247,} \\
248]\end{array}$ \\
\hline IIa & B-NR & $\begin{array}{l}\text { 3. In patients with ARVC who experience recurrent sustained VT or frequent } \\
\text { appropriate ICD interventions for VT in whom AAD therapy is not desired or } \\
\text { preferred, catheter ablation, at a center with specific expertise, is reasonable. }\end{array}$ & [236, 238-241, \\
\hline IIa & B-NR & $\begin{array}{l}\text { 4. In patients with Brugada syndrome who experience recurrent sustained VAs or } \\
\text { frequent appropriate ICD interventions, catheter ablation can be useful. }\end{array}$ & [249-252] \\
\hline IIa & C-LD & $\begin{array}{l}\text { 5. In patients with ARVC, a first-line combined endocardial/epicardial approach } \\
\text { for VT ablation is reasonable. }\end{array}$ & {$[236,241,247$,} \\
\hline
\end{tabular}

\subsection{Ventricular Arrhythmia in Hypertrophic Cardiomyopathy}

Recommendation for VA ablation in hypertrophic cardiomyopathy (HCM)

\begin{tabular}{cllll} 
COR & LOE & Recommendation & References \\
\hline IIa & B-NR & $\begin{array}{l}\text { 1. In patients with HCM and recurrent monomorphic VT in whom AAD therapy is } \\
\text { ineffective or not tolerated, catheter ablation can be useful. }\end{array}$ & {$[254-258]$} \\
\hline
\end{tabular}

\section{Procedural Planning}

This section includes preprocedural risk assessment (Table 4), preprocedural patient preparation, and preprocedural arrhythmia documentation with a focus on the regionalizing information of the ECG regarding the origin of VAs (Figs. 3 and 4). Furthermore, the capabilities of multimodality imaging in localizing the arrhythmogenic substrate are discussed in detail. Topics including the required equipment, personnel, and facility are detailed in this section.
Table 4 The PAAINESD Score, developed to predict the risk of periprocedural hemodynamic decompensation

\begin{tabular}{ll}
\hline Variable & Points \\
\hline Pulmonary disease (COPD) & 5 \\
Age $>60$ & 3 \\
General anesthesia & 4 \\
Ischemic cardiomyopathy & 6 \\
NYHA class III/IV & 6 \\
EF <25\% & 3 \\
VT storm & 5 \\
Diabetes mellitus & 3 \\
\hline
\end{tabular}

The PAAINESD Score, developed to predict the risk of periprocedural hemodynamic decompensation, has values that range from 0 to 35 points (or 0 to 31 [PAINESD] when the modifiable intraprocedural variable "general anesthesia" is excluded) (Santangeli et al. Circ Arrhythm Electrophysiol 2015;8:68-75)

$C O P D$ chronic obstructive pulmonary disease, $E F$ ejection fraction, NYHA New York Heart Association, $V T$ ventricular tachycardia 
a

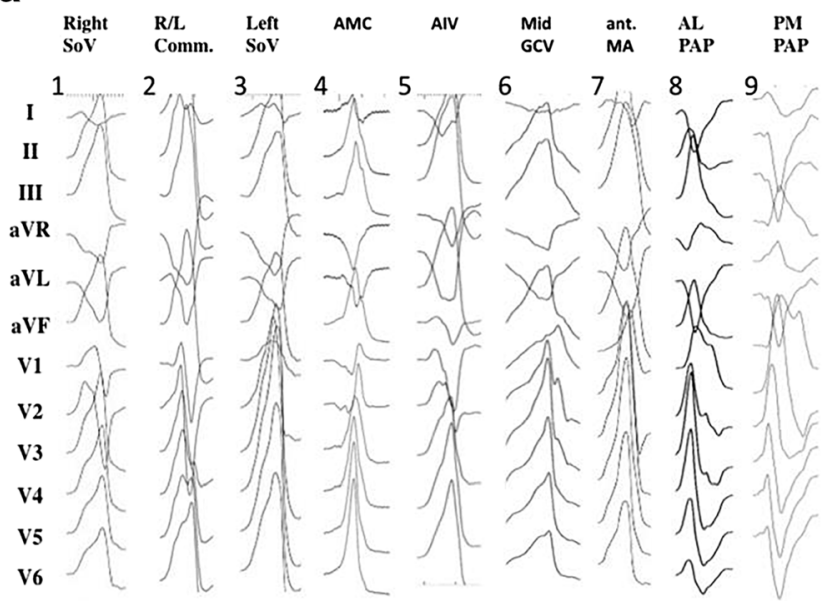

b

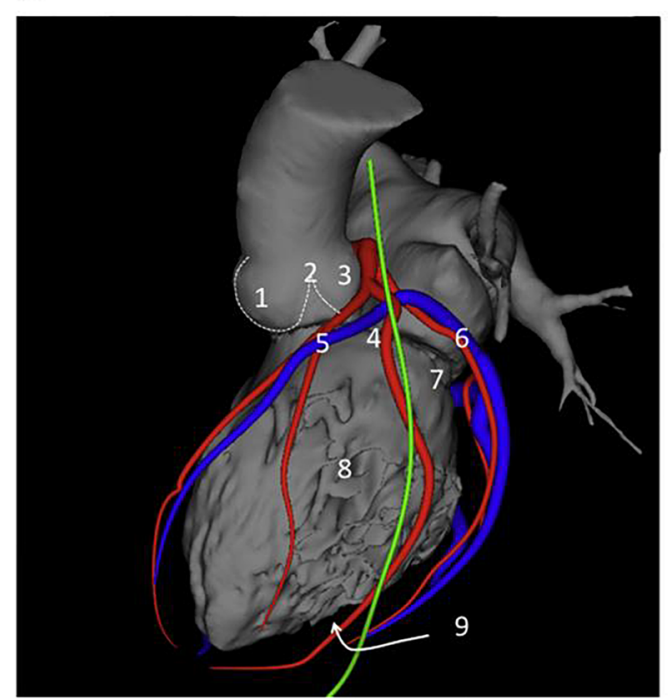

Fig. 3 Examples of 12-lead ECGs of premature ventricular complexes from different LV sites, as corroborated by successful focal ablation. a shows 12-lead ECG patterns of common ventricular arrhythmia origins in patients without SHD [1-9] from the left ventricle. All leads are displayed at the same amplification and sweep speed. These locations are illustrated in $\mathbf{b}$ based on $3 \mathrm{D}$ reconstruction of a cardiac computed tomography using the MUSIC software that was developed at the University of Bordeaux. The reconstruction shows an anterolateral view of the left ventricle, aorta, and left atrium. Also shown are the coronary arteries (red), the coronary venous system (blue), and the phrenic nerve (green). AIV = anterior interventricular vein; $\mathrm{AL}$ PAP $=$ anterolateral papillary muscle; $\mathrm{AMC}=$ aortomitral continuity; $\mathrm{ECG}=$ electrocardiogram; $\mathrm{GCV}=$ great cardiac vein; ant. $\mathrm{MA}=$ anterior mitral valve annulus; $\mathrm{PM} \mathrm{PAP}=$ posteromedial papillary muscle; $\mathrm{R} / \mathrm{L}=$ right-left; $\mathrm{SHD}=$ structural heart disease; $\mathrm{SoV}=$ sinus of Valsalva

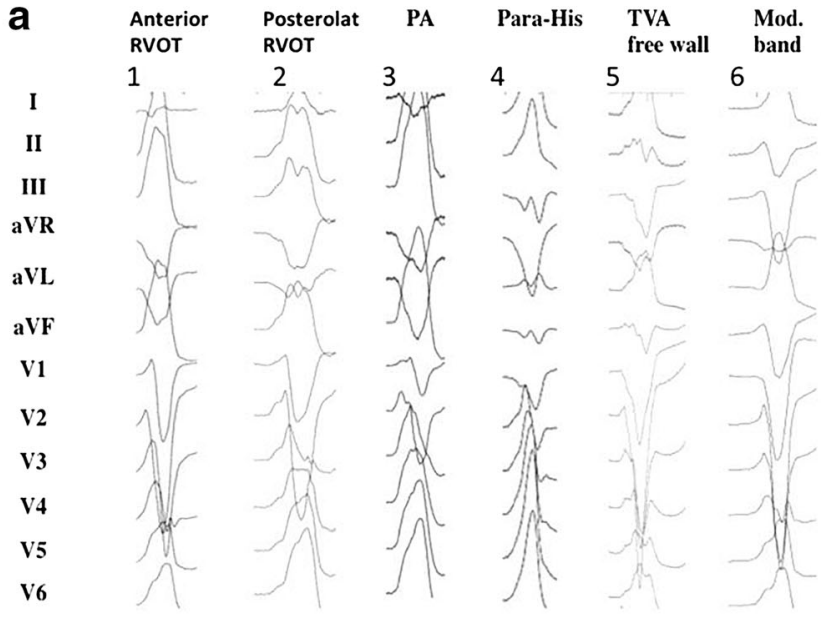

b

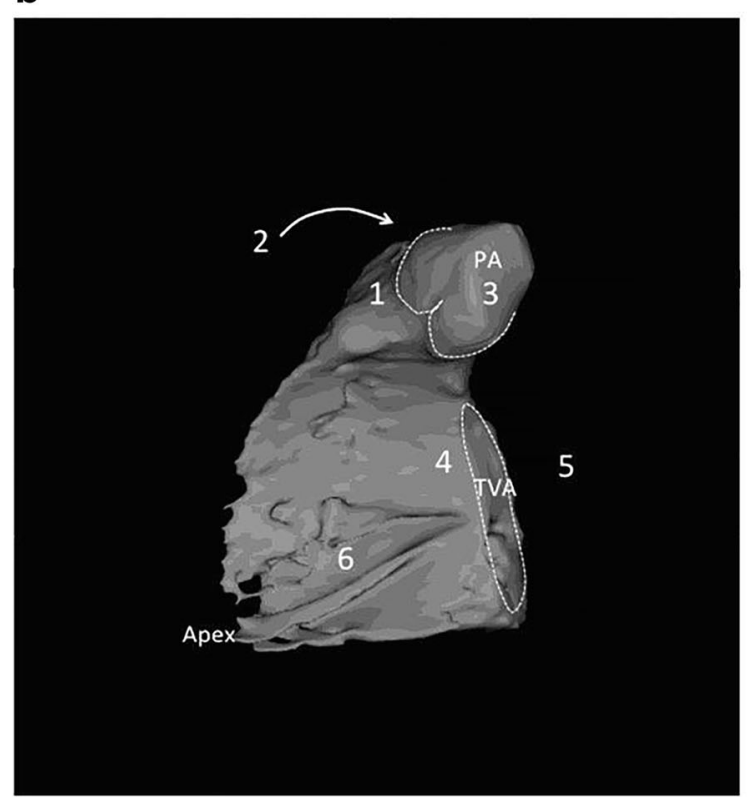

Fig. 4 Examples of 12-lead ECGs of premature ventricular complexes from different right ventricular sites, as corroborated by successful focal ablation. All leads are displayed at the same amplification and sweep speed. a shows the 12-lead ECG pattern of common origins of right ventricular arrhythmias in patients without SHD [1-6]. The locations are detailed in a $3 \mathrm{D}$ reconstruction of the computed tomography using the MUSIC software that was developed at the University of Bordeaux. The reconstruction shown in $\mathbf{b}$ illustrates the septal view of the right ventricle. Indicated are the pulmonary artery, the tricuspid valve annulus, and the right ventricular apex. $E C G=$ electrocardiogram; $\mathrm{PA}=$ pulmonary artery; RVOT= right ventricular outflow tract; SHD = structural heart disease; TVA = tricuspid valve annulus 
Recommendations for preprocedural imaging for VA catheter ablation

\begin{tabular}{cc|c|c|}
\hline COR & LOE & Recommendations & References \\
\hline I & B-NR & $\begin{array}{l}\text { 1. In patients with LV dysfunction undergoing catheter ablation of VA, preprocedural or } \\
\text { intraprocedural imaging is recommended to rule out cardiac thrombi. }\end{array}$ \\
\hline IIa & B-NR & $\begin{array}{l}\text { 2. In patients with NICM or ischemic cardiomyopathy (ICM) undergoing catheter ablation } \\
\text { of VT, preprocedural CMR can be useful to reduce VT recurrence. }\end{array}$ \\
IIa & B-NR & $\begin{array}{l}\text { 3. In patients with NICM or ICM undergoing catheter ablation of VA, preprocedural } \\
\text { imaging can be useful for procedural planning. }\end{array}$ \\
IIa & C-EO & $\begin{array}{l}\text { 4. In patients with NICM, CMR can be useful prior to ICD implantation to allow imaging } \\
\text { without device-related artifact for diagnostic purposes and identification of potential } \\
\text { arrhythmogenic substrate. }\end{array}$ \\
\hline IIb & C-EO & $\begin{array}{l}\text { 5. In patients with ICM, CMR may be considered prior to ICD implantation to allow } \\
\text { imaging without device-related artifact for identfication of the potential } \\
\text { arrhythmogenic substrate. }\end{array}$ \\
\hline
\end{tabular}

\section{Intraprocedural Patient Care}

Important aspects regarding intraprocedural sedation and its potential problems are highlighted in this section. Furthermore, vascular access, epicardial access with its many potential complications are discussed in detail, as well as anticoagulation and the indications for the use of hemodynamic support (HS) during VT ablation procedures.

\subsection{Anesthesia}

Recommendations for anesthesia during catheter ablation of VA

\begin{tabular}{|c|c|c|c|}
\hline COR & LOE & Recommendations & References \\
\hline I & C-EO & $\begin{array}{l}\text { 1. Provision of variable depth of sedation, analgesia, and anesthesia during mapping and } \\
\text { ablation of VA is recommended. }\end{array}$ & \\
\hline I & C-EO & $\begin{array}{l}\text { 2. In patients undergoing VA ablation, careful preprocedural assessment is indicated to } \\
\text { define the ideal strategy for sedation and analgesia. }\end{array}$ & \\
\hline IIa & C-LD & $\begin{array}{l}\text { 3. It is reasonable to avoid general anesthesia and deeper levels of sedation in patients } \\
\text { with idiopathic VA, particularly if the arrhythmia is suspected to be catecholamine- } \\
\text { sensitive or was not inducible at a prior procedure. }\end{array}$ & [285] \\
\hline IIb & B-NR & $\begin{array}{l}\text { 4. Moderate to deep sedation under close hemodynamic and respiratory monitoring might } \\
\text { be considered for VA ablation in stable patients with idiopathic or scar-related VAs } \\
\text { expected to have a longer procedure or undergo a painful technique, such as epicardial } \\
\text { access. }\end{array}$ & [285-287] \\
\hline
\end{tabular}

\subsection{Vascular Access}

Recommendation for vascular access during catheter ablation of VA

\begin{tabular}{cclll}
\hline COR & LOE & Recommendation & References \\
\hline I & B-NR & $\begin{array}{l}\text { 1. Ultrasound-guided femoral arterial and venous access is recommended to reduce the } \\
\text { incidence of vascular access complications during VA ablation. }\end{array}$ & {$[288-292]$} \\
\hline
\end{tabular}




\subsection{Epicardial Access}

Recommendations for epicardial access for catheter ablation

\begin{tabular}{ccc} 
COR & LOE & Recommendations \\
\hline I & C-EO & $\begin{array}{l}\text { 1. In patients undergoing epicardial VT ablation, imaging of the epicardial coronary arteries by coronary } \\
\text { arteriography or coronary computed tomography angiogram prior to ablation is recommended to reduce } \\
\text { the risk of arterial injury. }\end{array}$ \\
I & C-EO & $\begin{array}{l}\text { 2. In patients undergoing epicardial VT ablation via a percutaneous approach, provision for immediate } \\
\text { echocardiography, blood transfusion, and onsite cardiothoracic surgical backup is recommended. }\end{array}$ \\
I & C-EO & $\begin{array}{l}\text { 3. In patients with prior cardiac surgery or pericardial adhesions for whom epicardial VT ablation via a } \\
\text { percutaneous approach is considered, careful assessment of the risk/benefit ratio and alternative } \\
\text { therapies such as surgical dissection are recommended. }\end{array}$ \\
I & C-EO & $\begin{array}{l}\text { 4. In patients undergoing epicardial VT ablation, pacing with high stimulus intensity from the ablation } \\
\text { electrode to rule out diaphragmatic stimulation is recommended to avoid phrenic nerve injury. }\end{array}$ \\
\hline
\end{tabular}

\subsection{Intraprocedural Hemodynamic Support}

Recommendations for catheter ablation of VA with mechanical HS

\begin{tabular}{|c|c|c|c|}
\hline COR & LOE & Recommendations & References \\
\hline I & C-EO & $\begin{array}{l}\text { 1. In select patients at risk of requiring HS, a decision to proceed with catheter ablation } \\
\text { of VA should be made in collaboration with specialists in advanced heart failure } \\
\text { management. }\end{array}$ & \\
\hline IIa & B-NR & $\begin{array}{l}\text { 2. In select patients, HS with a percutaneous ventricular assist device and extracorporeal } \\
\text { membrane oxygenation during VT ablation can be useful to avoid acute hemodynamic } \\
\text { deterioration. }\end{array}$ & [293-299] \\
\hline IIb & B-NR & $\begin{array}{l}\text { 3. Mechanical HS may be considered in select cases to allow mapping and ablation of } \\
\text { unstable VTs. }\end{array}$ & [293-298] \\
\hline
\end{tabular}

\subsection{Intraprocedural Anticoagulation}

Recommendations for intraprocedural anticoagulation

\begin{tabular}{clllll}
\hline COR & LOE & Recommendations & References \\
\hline I & B-NR & $\begin{array}{l}\text { 1. In patients undergoing endocardial LV catheter mapping and/or ablation, } \\
\text { intraprocedural systemic anticoagulation with intravenous heparin is recommended. }\end{array}$ & {$[145,154-157,300]$} \\
I & C-EO & $\begin{array}{l}\text { 2. In patients undergoing RV endocardial mapping and/or ablation who are considered } \\
\text { high risk for thromboembolism, intraprocedural systemic anticoagulation with } \\
\text { intravenous heparin is recommended. }\end{array}$ & $\begin{array}{c}\text { 3. In patients undergoing epicardial access after systemic heparinization, reversal of } \\
\text { heparin with protamine is reasonable. }\end{array}$ \\
IIa & C-LD & {$[147,301]$}
\end{tabular}

\section{Electrophysiological Testing}

The benefits and limitations of PES are detailed in this section.

\section{Mapping and Imaging Techniques}

\subsection{Overview}

Activation mapping with multipolar catheters, entrainment mapping (Figs. 5 and 6), and pace mapping are the main techniques used to map VAs. This section reviews these techniques including the technique of substrate mapping aiming to identify the arrhythmogenic substrate in sinus rhythm. Furthermore, intraprocedural imaging as it pertains to procedural safety and to identification of the arrhythmogenic substrate is reviewed in this section. 


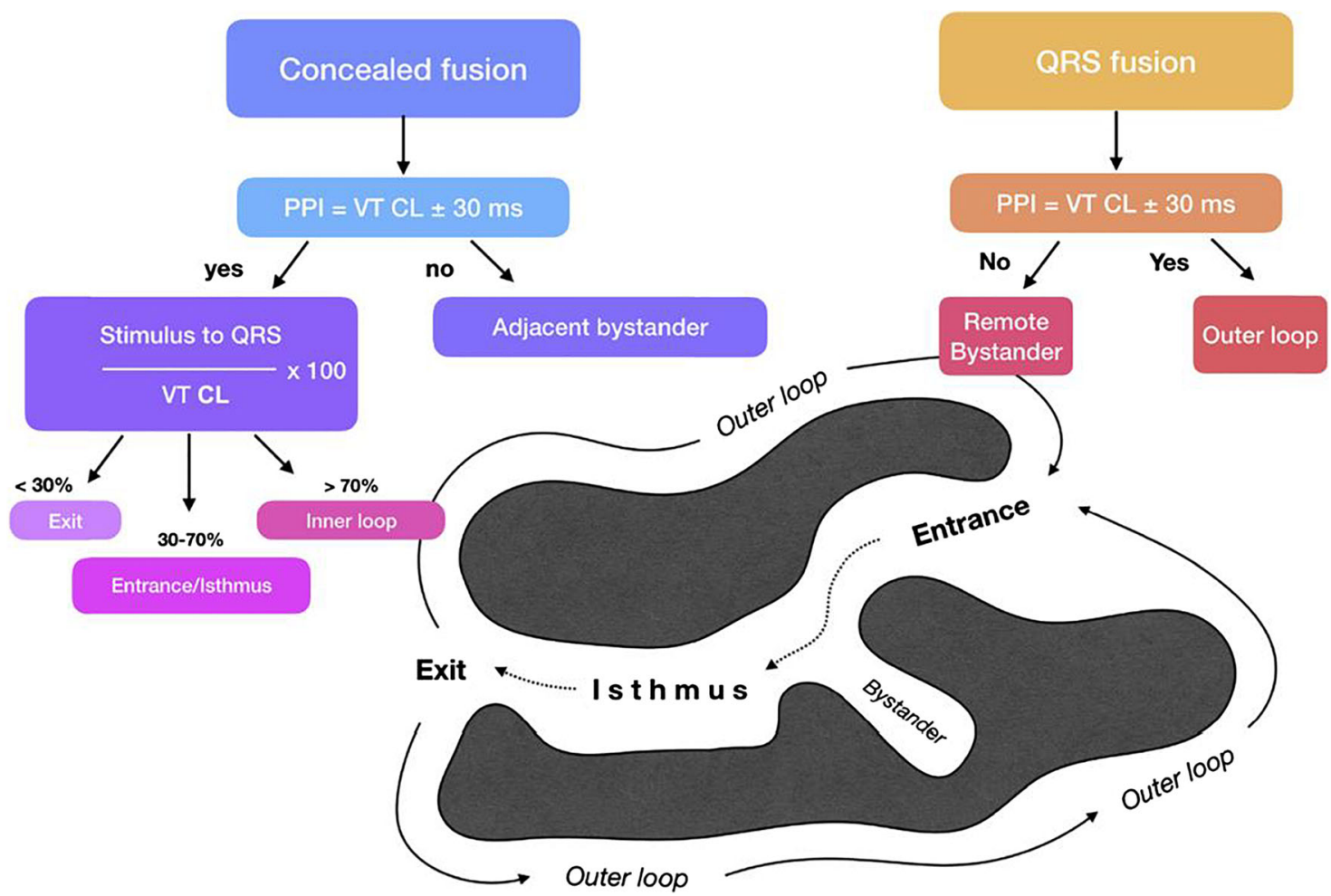

Fig. 5 Entrainment responses from components of reentrant VT circuit. CL = cycle length; PPI = postpacing interval; VT = ventricular tachycardia. Adapted with permission from Elsevier (Stevenson et al. J Am Coll Cardiol 1997;29:1180-1189)

Fig. 6 Pacing from the protected isthmus of a VT circuit.

Entrainment mapping during VT.

The VT CL is $620 \mathrm{~ms}$, and pacing is performed at a CL of $580 \mathrm{~ms}$. A low-voltage electrogram is located in diastole on the recordings of the ablation catheter (Map). The stimulus-QRS interval is $230 \mathrm{~ms}$ and matches with the electrogram-QRS interval. The postpacing interval is equal to the VT CL. The stimulus-QRS/VT CL ratio is 0.37 , indicating that the catheter is located in the common pathway. $\mathrm{CL}=$ cycle length; $\mathrm{PPI}=$ postpacing interval; $\mathrm{VT}=$ ventricular tachycardia

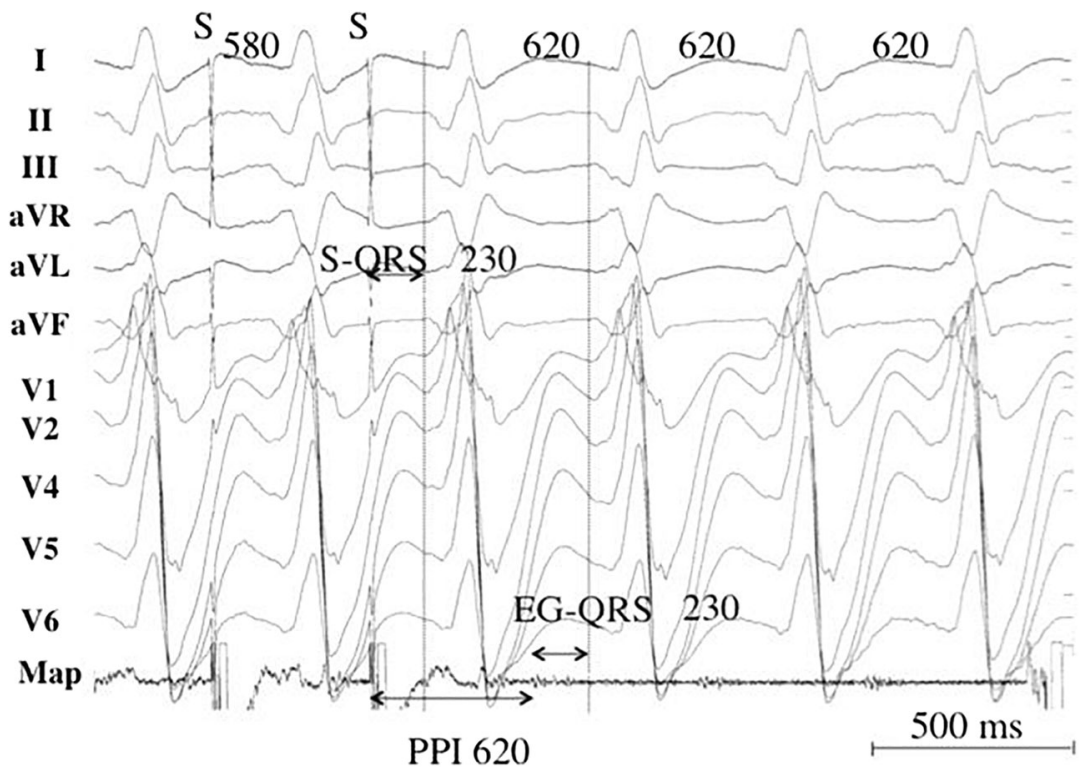




\subsection{Substrate Mapping in Sinus Rhythm}

Recommendations for substrate mapping in sinus rhythm

\begin{tabular}{cclll}
\hline COR & LOE & Recommendations & References \\
\hline I & B-NR & $\begin{array}{l}\text { 1. In patients with scar-related VT, substrate-guided ablation is useful for prevention of } \\
\text { arrhythmia recurrences. }\end{array}$ & {$[145,146,154$,} \\
IIa & B-NR & $\begin{array}{l}\text { 2. High-density multielectrode mapping to obtain a more comprehensive } \\
\text { characterization of the arrhythmogenic tissue during catheter ablation of scar-related } \\
\text { VT can be useful. }\end{array}$ & {$[308-310]$} \\
IIa & B-NR & $\begin{array}{l}\text { 3. In patients with no or minimal endocardial bipolar electrogram abnormalities, reduced } \\
\text { unipolar voltage can be useful for detection of epicardial or intramural scar. }\end{array}$ & {$[38,311-314]$} \\
\hline
\end{tabular}

\subsection{Intraprocedural Imaging During Catheter Ablation of Ventricular Arrhythmias}

Recommendations for intraprocedural imaging during catheter ablation of VAs

\begin{tabular}{|c|c|c|c|}
\hline COR & LOE & Recommendations & References \\
\hline I & B-NR & $\begin{array}{l}\text { 1. Coronary angiography or intracardiac echocardiography (ICE) is recommended to localize the } \\
\text { ostia of the coronary arteries prior to ablation within the SV. }\end{array}$ & {$[74,315-317]$} \\
\hline $\mathbf{I}$ & B-NR & $\begin{array}{l}\text { 2. Coronary angiography is recommended to identify the course of the coronary arteries when } \\
\text { ablation is performed in the coronary venous system or in the epicardium. }\end{array}$ & {$[77,113,172,318]$} \\
\hline $\mathbf{I}$ & B-NR & $\begin{array}{l}\text { 3. ICE is beneficial to identify and target the papillary muscles with ablation and to assess for } \\
\text { catheter stability. }\end{array}$ & $\begin{array}{l}{[25,26,95-100,} \\
319-322]\end{array}$ \\
\hline $\mathbf{I}$ & B-NR & $\begin{array}{l}\text { 4. ICE or transthoracic echocardiography is useful to assess for pericardial effusion in case of } \\
\text { hemodynamic deterioration of the patient. }\end{array}$ & [323-325] \\
\hline I & C-LD & 5. ICE is useful for early recognition of complications, including pericardial effusion. & [323-325] \\
\hline IIb & B-NR & $\begin{array}{l}\text { 6. ICE may be useful as an adjuvant technique to identify wall segments with wall thinning, wall } \\
\text { motion abnormalities, and segments with increased echogenicity, and also to identify } \\
\text { intracardiac thrombi. }\end{array}$ & {$[326,327]$} \\
\hline
\end{tabular}

\subsection{Electroanatomical Mapping Systems and Robotic Navigation}

Recommendations for the use of EAM systems and remote navigation in ablation procedures for VAs

\begin{tabular}{|c|c|c|c|}
\hline COR & LOE & Recommendations & References \\
\hline I & B-NR & $\begin{array}{l}\text { 1. In patients with VA due to SHD undergoing an ablation procedure, EAM is } \\
\text { useful. }\end{array}$ & {$[146,268,238-334]$} \\
\hline II & B-NR & 2. In patients with idiopathic VA undergoing an ablation procedure, EAM can be useful. & {$[146,331]$} \\
\hline IIa & B-NR & $\begin{array}{l}\text { 3. In patients undergoing an ablation procedure for } \mathrm{VA} \text {, magnetic catheter navigation can be } \\
\text { useful to reduce fluoroscopy use. }\end{array}$ & {$[51,335-338]$} \\
\hline
\end{tabular}




\section{Mapping and Ablation}

This section is designed as a "how-to" section that details the procedural steps of VT ablation in different patient populations ranging from ablation of PVCs in patients without heart disease to ablation of VT/VF in patients with different types of SHD (Figs. 7, 8, 9, 10, 11 and 12 and Tables 5, 6, 7 and 8). Bullet points summarize the key points in this section.

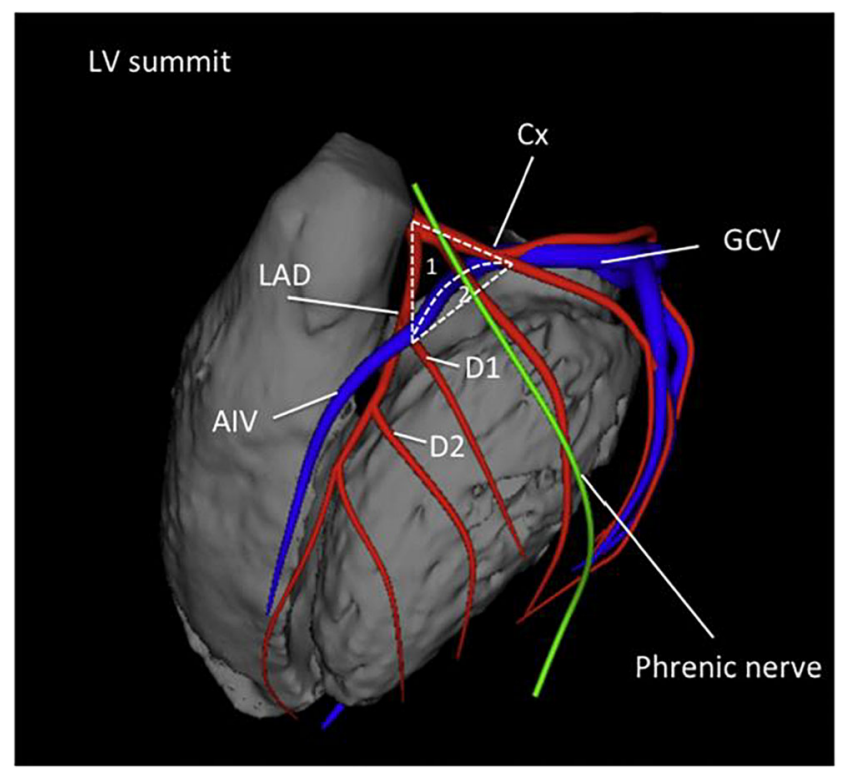

Fig. 7 Anatomical boundaries of the LV summit, with the inaccessible [1] and accessible [2] parts. Shown are the left anterior descending artery (LAD), the circumflex artery $(\mathrm{Cx})$, the great cardiac vein (GCV), the anterior interventricular vein (AIV), and the first and second diagonal branch of the LAD (D1, D2)

\subsection{Ablation Power Sources and Techniques}

\section{Key Points}

- An impedance drop $\geq 10$ ohms or a contact force $\geq 10 \mathrm{~g}$ is commonly used as a target for radiofrequency energy delivery.

- The use of half normal saline generates larger ablation lesions but can result in steam pops.

- Simultaneous bipolar or unipolar ablation can result in larger ablation lesions.

- Cryoablation can be beneficial for achieving more stable contact on the papillary muscles.

- Ethanol ablation can generate lesions in areas where the arrhythmogenic substrate cannot be otherwise reached, provided that suitable target vessels are present.

- Stereotactic radiotherapy is an emerging alternative to ablation, requiring identification of a region of interest that can be targeted prior to the radiation treatment.

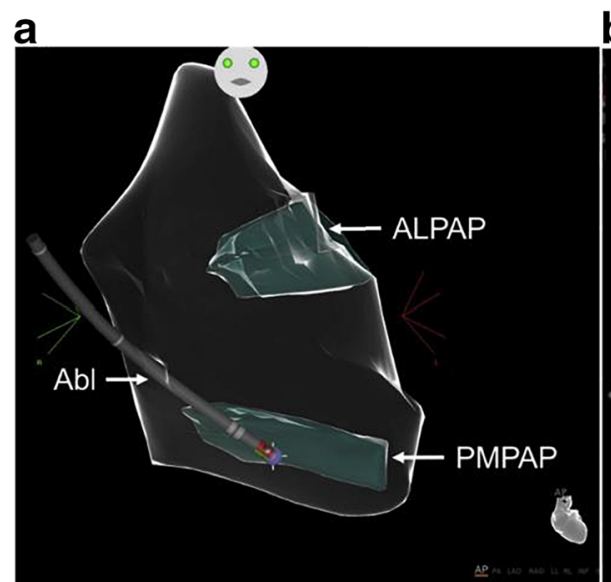

Fig. 8 Intraprocedural imaging during ablation of papillary muscle arrhythmias. a Anatomical map of the left ventricle (CARTO, Biosense Webster) showing contact of the ablation catheter (Abl) with the

b

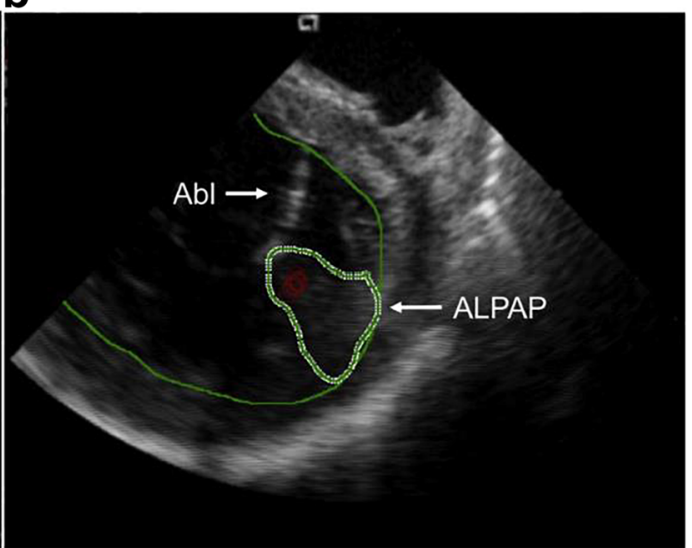

posteromedial papillary muscle (PMPAP). b Intracardiac echocardiogram showing real-time visualization of the ablation catheter during ablation on the anterolateral papillary muscle (ALPAP) 


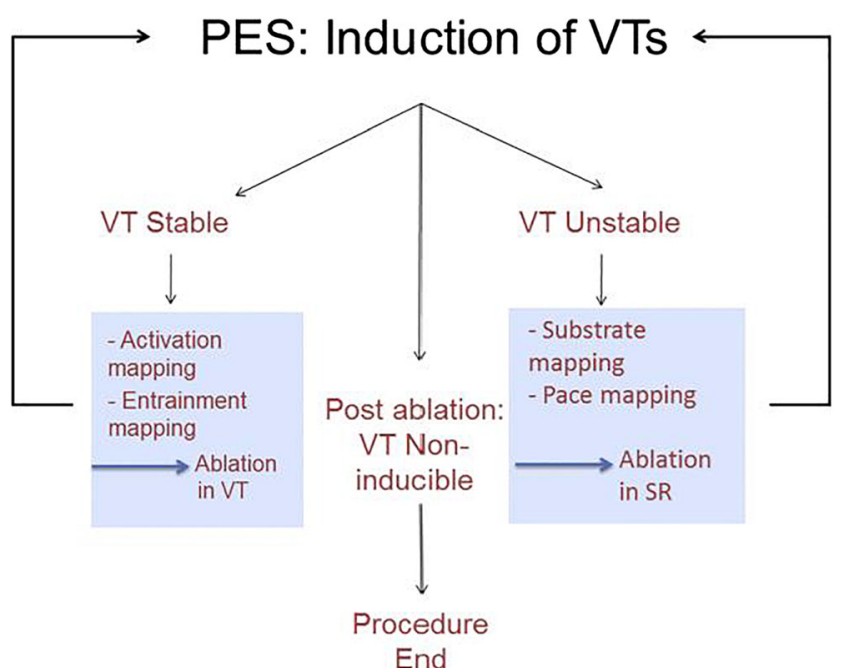

Fig. 9 Overview of the workflow for catheter ablation of VT in patients with IHD. Not all of these steps might be required, and steps can be performed in a different sequence. For instance, repeat VT induction can be deferred in patients with hemodynamic instability. In addition, the operator might have to adapt to events that arise during the case, for instance, to take advantage of spontaneous initiation of stable VT during substrate mapping and switch to activation mapping. IHD = ischemic heart disease; $\mathrm{PES}=$ programmed electrical stimulation; $\mathrm{SR}=$ sinus rhythm; VT = ventricular tachycardia

\subsection{Idiopathic Outflow Tract Ventricular Arrhythmia}

\section{Key Points}

- The RVOT, pulmonary arteries, SVs, LV epicardium and endocardium contain most of the outflow tract arrhythmias.

- Activation mapping and pace mapping can be used to guide ablation in the RVOT.

- Imaging of coronary artery ostia is essential before ablation in the aortic SVs.

- The LV summit is a challenging site of origin, often requiring mapping and/or ablation from the RVOT, LVOT, SVs, coronary venous system, and sometimes the epicardial space.

- Deep intraseptal VA origins can be challenging to reach.

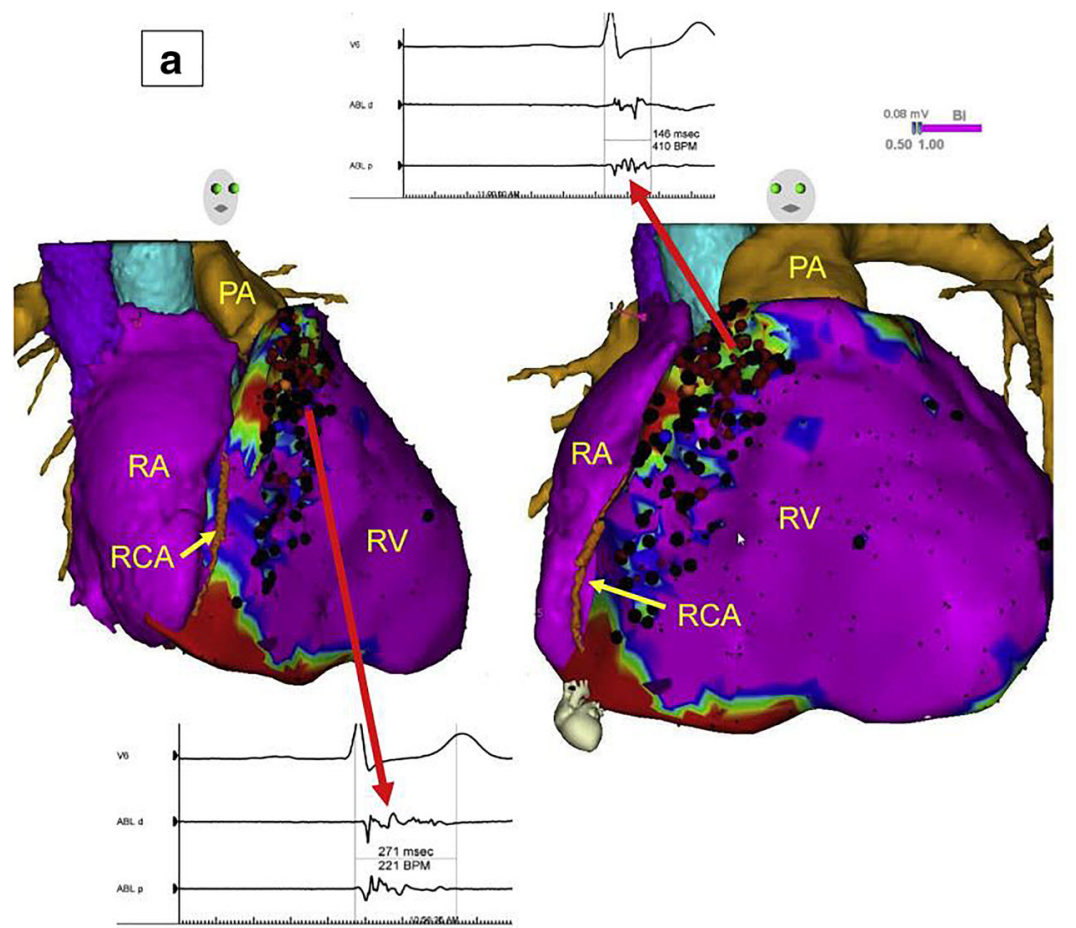

b

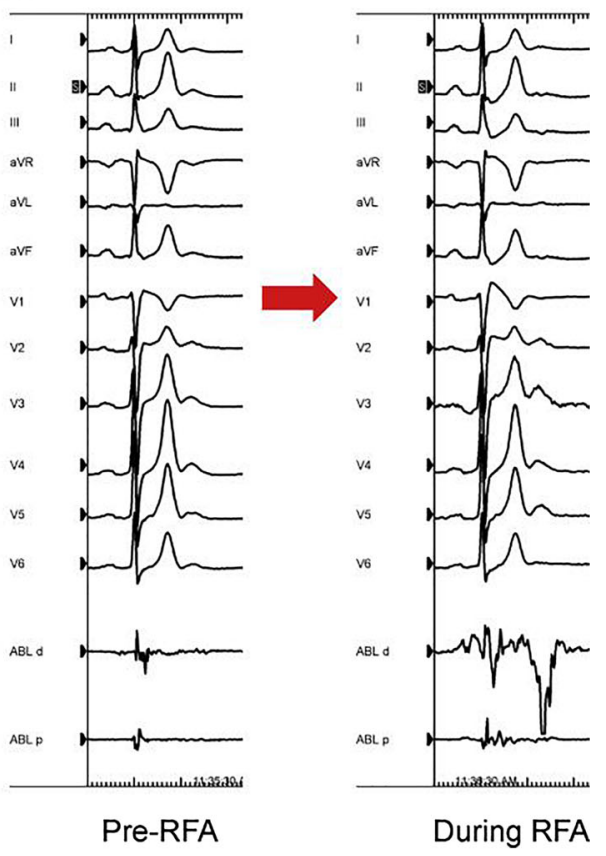

Fig. 10 Epicardial substrate ablation in a patient with Brugada syndrome and appropriate ICD shocks for VF. Image integration of a preacquired $\mathrm{CT}$ with the electroanatomical epicardial substrate map is shown in (A). Purple represents bipolar voltage $>1.5 \mathrm{mV}$. Fractionated potentials (arrows) are tagged with black dots, and a representative example is displayed. Widespread fractionated potentials were recorded from the epicardial aspect of the RVOT extending down into the basal RV body. Ablation lesions are tagged with red dots. Some fractionated potentials could not be ablated due to the proximity of the acute marginal branches of the right coronary artery. Panel (B) shows the significant transient accentuation of the Brugada ECG pattern during the application of radiofrequency energy at one of these sites. $\mathrm{CT}=$ computed tomography; $\mathrm{ECG}=$ electrocardiogram; ICD = implantable cardioverter defibrillator; $\mathrm{PA}=$ pulmonary artery; $\mathrm{RA}=$ right atrium; $\mathrm{RCA}=$ right coronary artery; $\mathrm{RFA}=$ radiofrequency ablation; $\mathrm{RV}=$ right ventricle; $\mathrm{RVOT}=$ right ventricular outflow tract; $\mathrm{VF}=$ ventricular fibrillation 


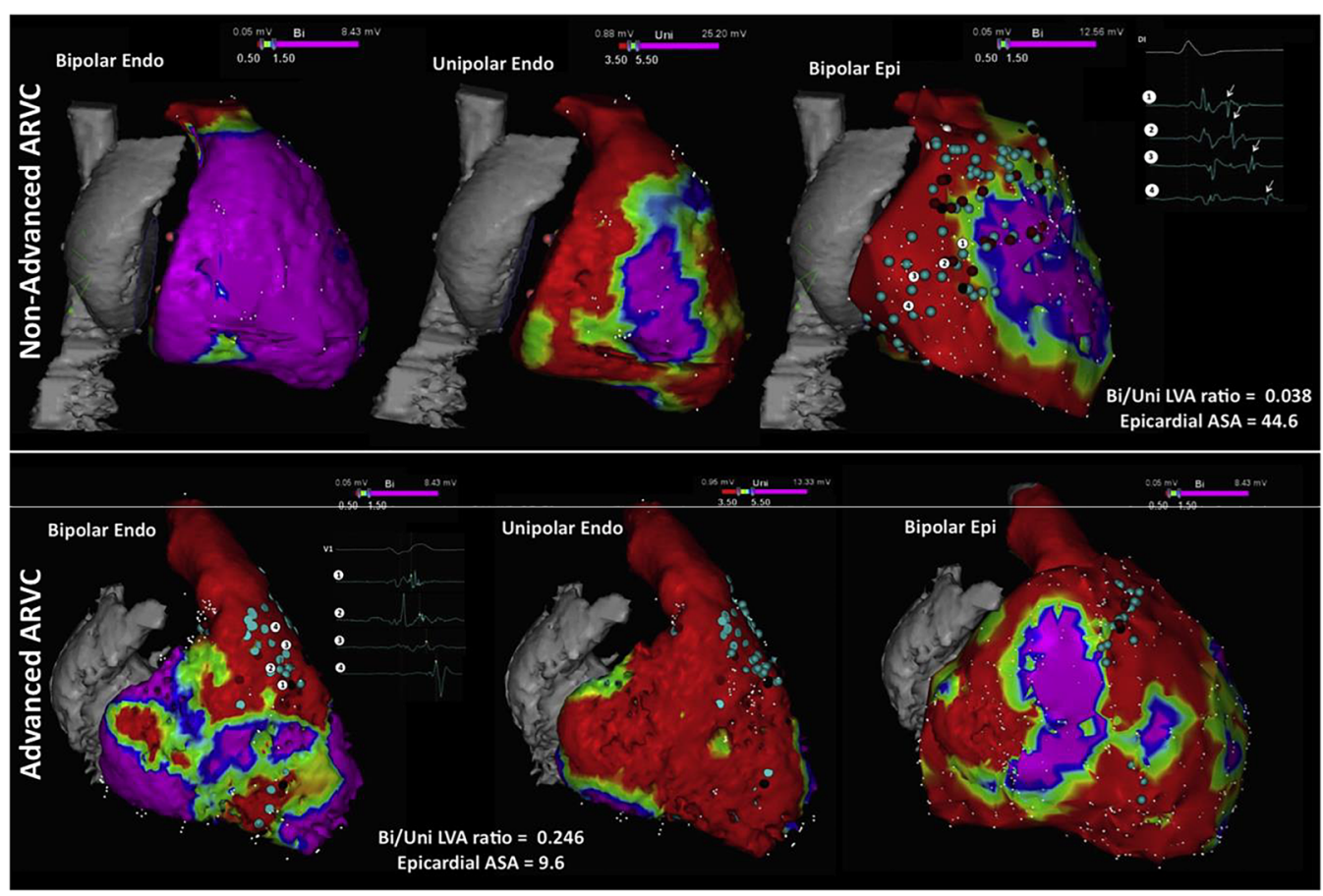

Fig. 11 Right ventricular voltage maps from cases of moderate (upper row) and advanced (lower row) arrhythmogenic right ventricular cardiomyopathy (ARVC) are shown. Purple represents a voltage $>1.5 \mathrm{mV}$ in the bipolar maps (left and right) and $>5.5 \mathrm{mV}$ in the unipolar maps (center); red represents a voltage $<0.5 \mathrm{mV}$ in the bipolar maps and $<3.5 \mathrm{mV}$ in the unipolar maps. Moderate ARVC is defined as having a bipolar/unipolar low-voltage area ratio of $<0.23$ and is associated with epicardial arrhythmogenic substrate area (ASA) (defined by the presence of electrograms with delayed components of $>10 \mathrm{~cm}^{2}$. Advanced ARVC displays a bipolar/unipolar endocardial lowvoltage area of $\geq 0.23$, which is associated with an epicardial arrhythmogenic substrate area of $\leq 10 \mathrm{~cm}^{2}$. Adapted with permission from Oxford University Press (Berruezo et al. Europace 2017;19:607616)
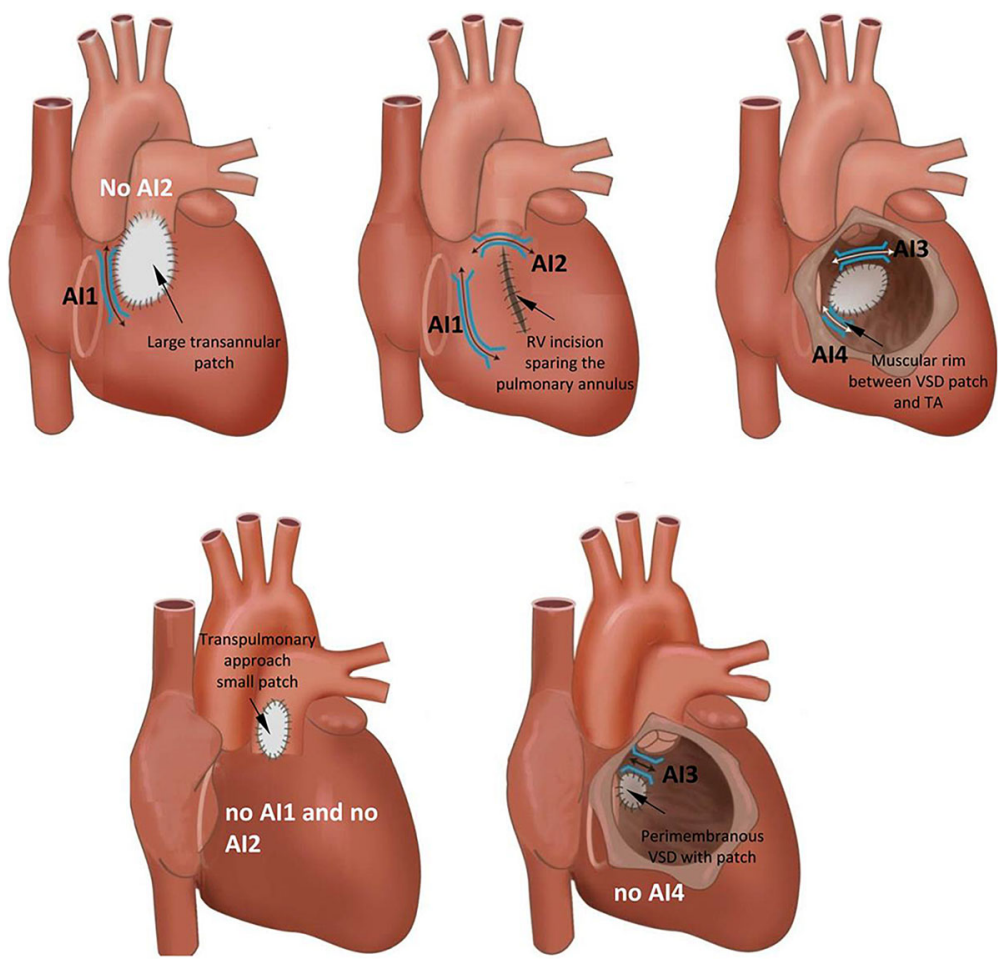

Fig. 12 Anatomical isthmuses (AI) in repaired tetralogy of Fallot according to the surgical approach and variation of the malformation. RV = right ventricular; $\mathrm{TA}=$ tricuspid annulus; $\mathrm{VSD}=$ ventricular septal defect 
Table 5 Types of bundle branch reentrant tachycardia

\begin{tabular}{llll}
\hline & Type A & Type B (Interfascicular tachycardia) & Type C \\
\hline ECG morphology & LBBB pattern & RBBB pattern & RBBB pattern \\
Anterograde limb & RBB & LAF or LPF & LBB \\
Retrograde limb & LBB & LPF or LAF & RBB \\
\hline
\end{tabular}

$L A F$ left anterior fascicle, $L B B$ left bundle branch, $\angle B B B$ left bundle branch block, $L P F$ left posterior fascicle, $R B B$ right bundle branch, $R B B B$ right bundle branch block

\subsection{Idiopathic Nonoutflow Tract Ventricular Arrhythmia}

\section{Key Points}

- VAs originating from the papillary muscles can be challenging due to multiple morphologies of the VA and the difficulty in achieving and maintaining sufficient contact during ablation.

- VAs originate in LV papillary muscles more often than in RV papillary muscles; they more often originate from the posteromedial than the anterolateral papillary muscle and occur more often at the tip than at the base.

- Pace mapping is less accurate than in other focal VAs.

- ICE is particularly useful for assessing contact and stability.

- Cryoablation can also aid in catheter stability during lesion delivery.

\subsection{Bundle Branch Reentrant Ventricular Tachycardia and Fascicular Ventricular Tachycardia}

\section{Key Points}

- Bundle branch reentry can occur in a variety of patients in whom the conduction system can be affected, including patients with dilated cardiomyopathy (DCM), valvular heart disease, myocardial infarction,

Table 6 Fascicular ventricular tachycardias

\section{Verapamil-sensitive fascicular reentrant VT \\ 1. Left posterior type \\ i. Left posterior septal fascicular reentrant VT \\ ii. Left posterior papillary muscle fascicular reentrant VT \\ 2. Left anterior type \\ i. Left anterior septal fascicular reentrant VT \\ ii. Left anterior papillary muscle fascicular reentrant VT}

3. Upper septal type

II. Nonreentrant fascicular VT

$V T$ ventricular tachycardia. myotonic dystrophy, Brugada syndrome, and ARVC, among others.

- Ablation of either the right or left bundle branch eliminates bundle branch reentrant ventricular tachycardia (BBRVT) but does not eliminate other arrhythmic substrates.

- A correct diagnosis of BBRVT is crucial and should employ established criteria prior to ablation of either of the bundle branches.

- Ablation of the AV node does not cure BBRVT.

- Ablation of either bundle branch does not cure interfascicular VT.

- For posterior fascicular VTs, the P1 potential is targeted during VT; if P1 cannot be identified or VT is not tolerated, an anatomical approach can be used.

- Purkinje fibers can extend to the papillary muscles, and these can be part of the VT circuit.

- For anterior fascicular VTs, the P1 potential is targeted with ablation.

- Focal nonreentrant fascicular VT is infrequent and can occur in patients with IHD; however, it cannot be induced with programmed stimulation, and the target is the earliest Purkinje potential during VT.

\subsection{Postinfarction Ventricular Tachycardia}

\section{Key Points}

- In cases of multiple inducible VTs, the clinical VT should be preferentially targeted.

- Elimination of all inducible VTs reduces VT recurrence and is associated with prolonged arrhythmia-free survival.

- For tolerated VTs, entrainment mapping allows for focal ablation of the critical isthmus.

- For nontolerated VTs, various ablation strategies have been described, including targeting abnormal potentials, matching pace mapping sites, areas of slow conduction, linear lesions, and scar homogenization.

- Imaging can be beneficial in identifying the arrhythmogenic substrate.

- Epicardial ablation is infrequently required, but epicardial substrate is an important reason for VT recurrence after VT ablation in patients with prior infarcts. 


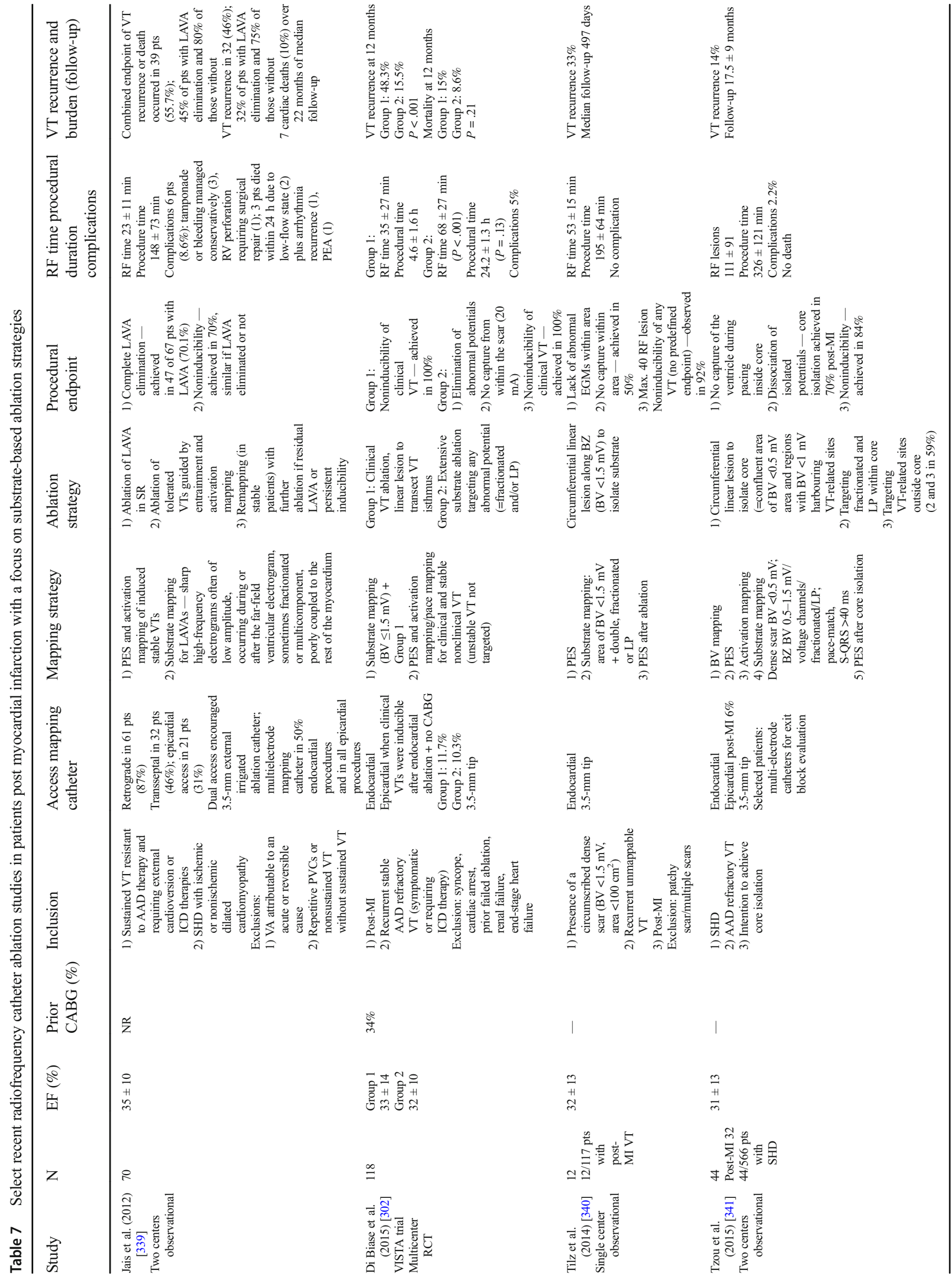




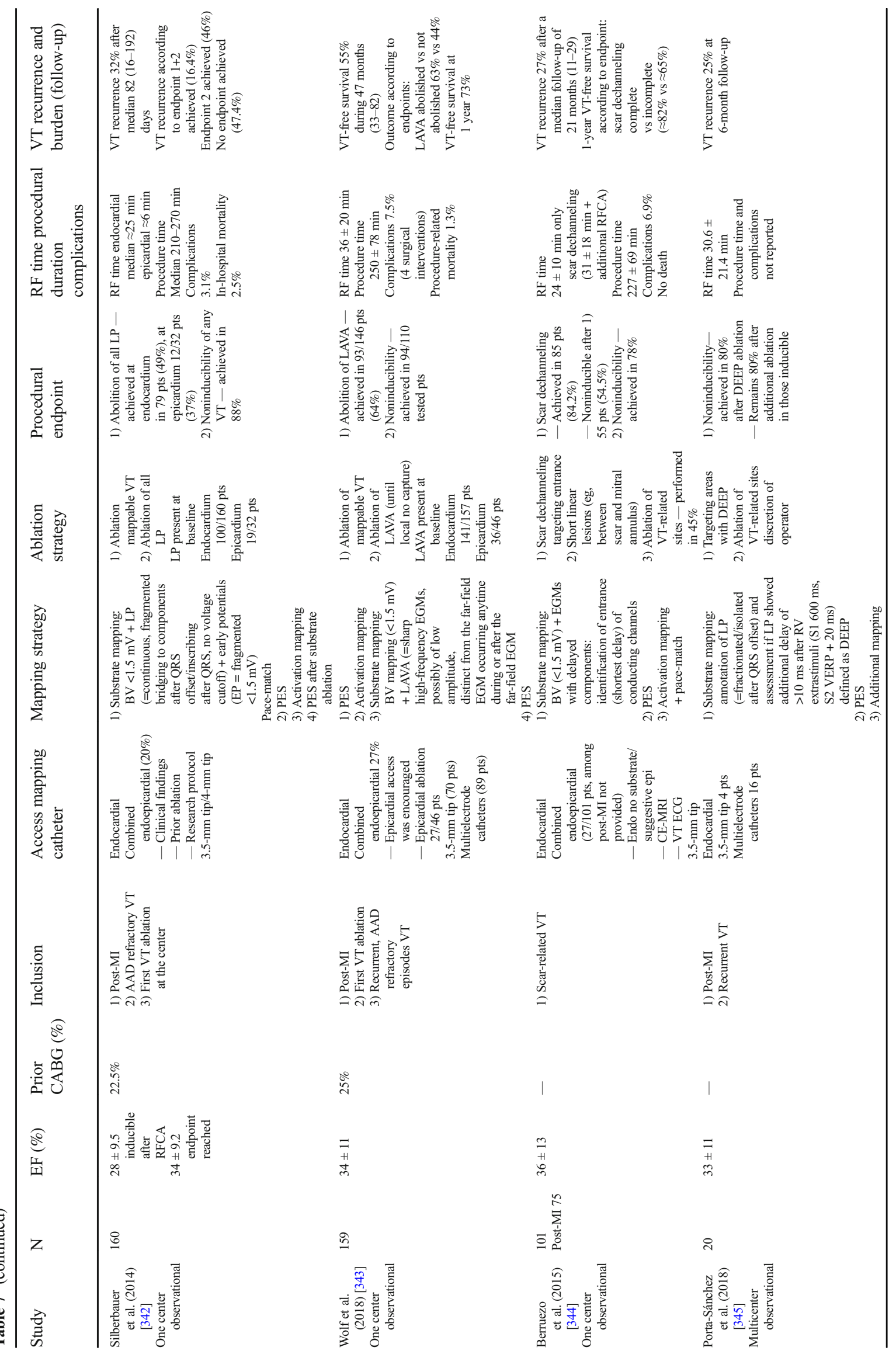




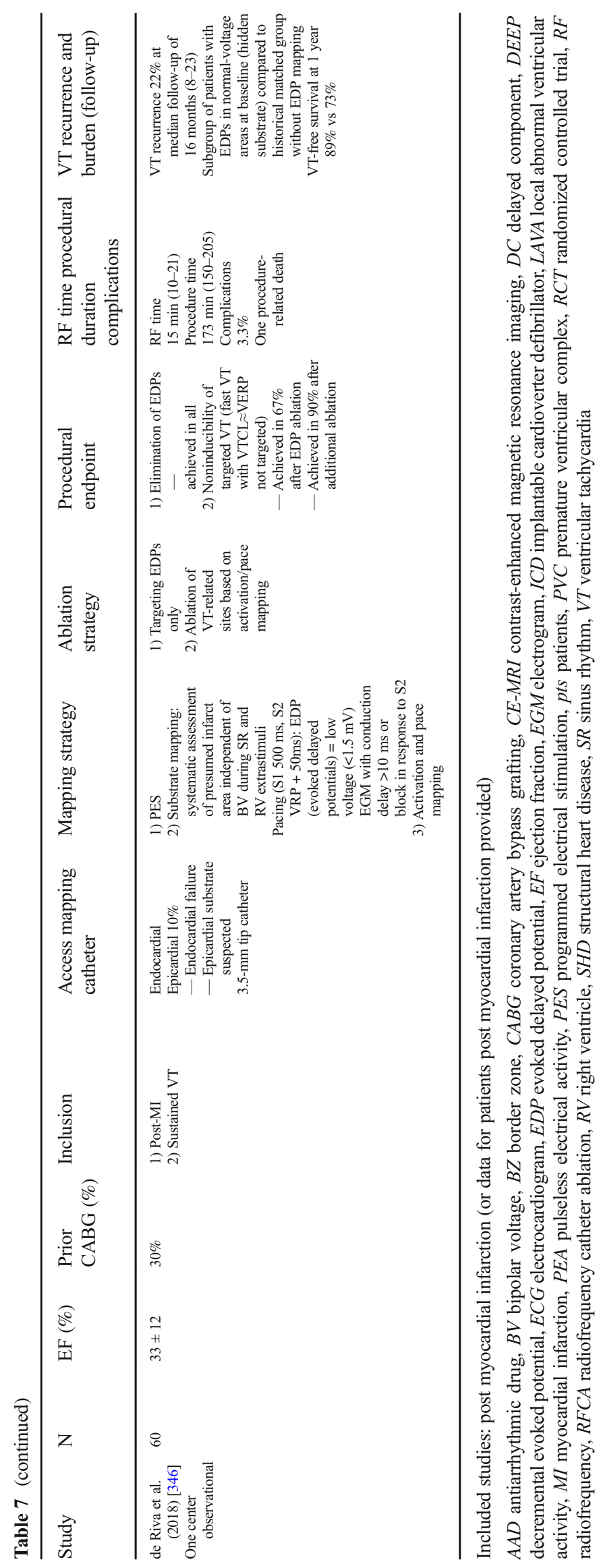




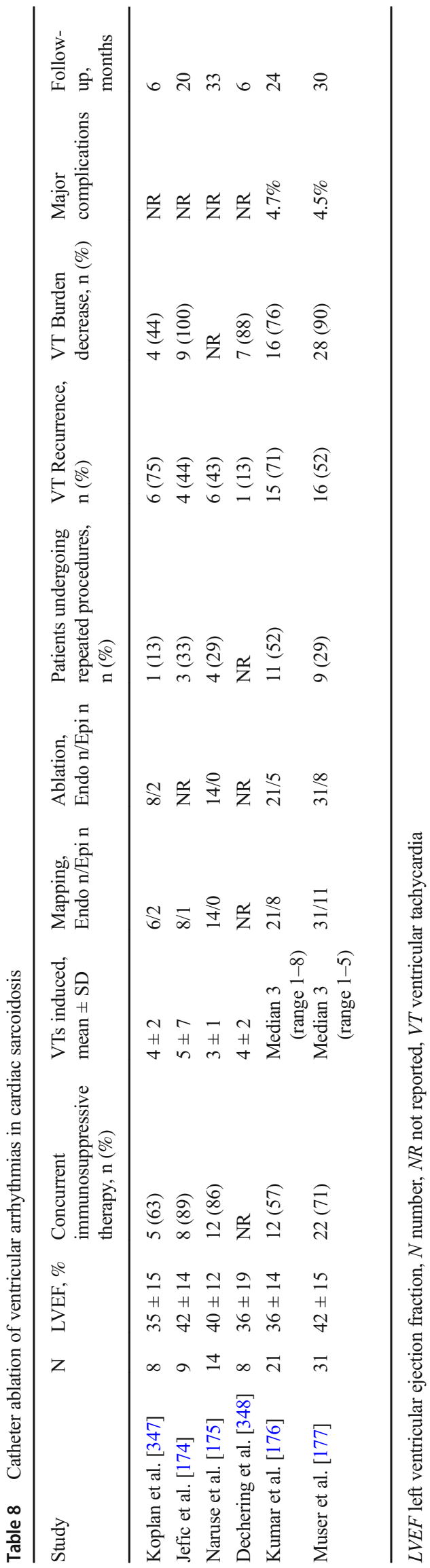

\subsection{Dilated Cardiomyopathy}

\section{Key Points}

- Identifying the location and extent of scarring on CMR is beneficial in procedural planning and has improved the outcomes of ablation in patients with DCM.

- The ablation strategy is similar to postinfarction VT.

- An intramural substrate is more frequently encountered in DCM than in postinfarction patients and requires a different ablation strategy than for patients with either epicardial or endocardial scarring.

- Epicardial ablation is beneficial if the scar is located in the epicardium of the LV free wall.

- For intramural circuits involving the septum, epicardial ablation is not beneficial.

- In the absence of CMR, unipolar voltage mapping has been described as a method to indicate a deeper-seated scar.

\subsection{Ventricular Tachycardia Ablation in Hypertrophic Cardiomyopathy}

\section{Key Points}

- Polymorphic VT and VF are the most common VAs in HCM; monomorphic VT is less common.

- The arrhythmogenic substrate in HCM often involves the septum but can extend to the epicardium, often necessitating combined endocardial and epicardial ablation procedures to eliminate the VT.

- VT associated with apical aneurysms is often ablated endocardially.

\subsection{Brugada Syndrome}

\section{Key Points}

- PVC-triggered VF or polymorphic VT are the most prevalent VAs that motivate device therapy in patients with Brugada syndrome.

- Monomorphic VT is less frequent but can be caused by BBRVT in patients with Brugada syndrome.

- The arrhythmogenic substrate is located in the RV epicardium and can be demonstrated by sodium channel blockers.

- Ablation targets include fractionated prolonged electrograms on the epicardial aspect of the RV. 


\subsection{Polymorphic Ventricular Tachycardia/Ventricular Fibrillation Triggers}

\section{Key Points}

- Recurrent PVC-induced VF is most often triggered by PVCs originating from Purkinje fibers, located in the RVOT, the moderator band, or the LV.

- Patients with a single triggering PVC are better ablation candidates; however, there are often multiple triggers.

- Patients with healed myocardial infarction often require extensive ablation of the Purkinje fiber system within or at the scar border.

- Ischemia should be ruled out as a trigger for VF prior to ablation.

\subsection{Arrhythmogenic Right Ventricular Cardiomyopathy}

\section{Key Points}

- The arrhythmogenic substrate in ARVC is located in the epicardium and can involve the endocardium in advanced stages.

- The most commonly affected areas are the subtricuspid and RV outflow regions.

- LV involvement is not uncommon.

- Endocardial-epicardial ablation is often required and results in higher acute success and lower recurrence rates compared with endocardial ablation alone.

- Conventional mapping and ablation techniques, including entrainment mapping of tolerated VT, pace mapping, and substrate ablation, are used.

\subsection{Mapping and Ablation in Congenital Heart Disease}

\section{Key Points}

- Patients with a VT substrate after congenital heart defect surgery include those with repaired tetralogy of Fallot, repaired ventricular septal defect, and repaired d-transposition of the great arteries (D-TGA), as well as Ebstein's anomaly among other disease processes.

- VT isthmuses are often located between anatomical barriers and surgical incisions or patch material.

- An anatomical isthmus can be identified and targeted during sinus rhythm.

- For tolerated VTs, entrainment mapping is the method of choice for identifying critical components of the reentry circuit.

\subsection{Sarcoidosis}

\section{Key Points}

- The arrhythmogenic substrate in cardiac sarcoidosis is often intramurally located but can include the endocardium and epicardium.

- A CMR is beneficial in planning an ablation procedure in cardiac sarcoidosis.

- The arrhythmogenic substrate can be complex and can include areas of active inflammation and chronic scarring.

- The VT recurrence rate after ablation is high.

\subsection{Chagas Disease}

\section{Key Points}

- The pathogenesis of Chagas disease is poorly understood but often results in an inferolateral LV aneurysm.

- The arrhythmogenic substrate is located intramurally and on the epicardial surface, often necessitating an epicardial ablation procedure.

\subsection{Miscellaneous Diseases and Clinical Scenarios With Ventricular Tachycardia}

\section{Key Points}

- Lamin cardiomyopathy often has a poor prognosis, progressing to end-stage heart failure.

- VT ablation is challenging due to intramural substrates

- VT recurrence rate is high after ablations.

- VT in patients with noncompaction tends to originate from regions of noncompacted myocardium where scar can be identified in the midapical LV.

- VT ablation in patients with LV assist device can be challenging due to the limitation of preprocedural imaging, and the electromagnetic noise generated by the LV assist device.

\subsection{Surgical Therapy}

\section{Key Points}

- Surgery-facilitated access to the epicardium via a limited subxiphoid incision can be helpful in the case of adhesions.

- Cryoablation via thoracotomy is possible for posterolateral substrates and via sternotomy for anterior substrates. 


\subsection{Sympathetic Modulation}

\section{Key Points}

- Sympathetic modulation targeting the stellate ganglia by video-assisted thoracoscopy may be considered for failed VT ablation procedures or VF storms.

- A temporary effect can be obtained with the percutaneous injection or infusion of local anesthetics.

\subsection{Endpoints of Catheter Ablation of Ventricular Tachycardia}

\section{Key Points}

- Noninducibility of VT by PES after ablation is a reasonable endpoint and predictor for VT recurrence after VT ablation in patients with SHD.
- Due to the limitations of programmed stimulation, endpoints other than noninducibility have been described, including elimination of excitability, elimination of late potentials or local abnormal ventricular activity, dechanneling, substrate homogenization, core isolation, image-guided ablation, and anatomically fixed substrate ablation.

\section{Postprocedural Care}

Access-related issues, anticoagulation (Table 9), and complications (Table 10), as well as the management thereof, are reviewed in this section. Furthermore, assessment of outcomes and determinants of outcomes are detailed (Fig. 13).

\subsection{Postprocedural Care: Access, Anticoagulation, Disposition}

\subsubsection{Postprocedural Care: Access}

\section{Recommendations for management of venous access sites after catheter ablation of VA}

$\left.\begin{array}{cclll}\hline \text { COR } & \text { LOE } & \text { Recommendations } & \text { References } \\ \hline \text { I } & \text { A } & \begin{array}{l}\text { 1. Manual compression is effective in achieving hemostasis after venous access for VT } \\ \text { ablation. }\end{array} & \begin{array}{c}\text { 2. Venous access closure using temporary purse-string or figure-of-8 suture techniques can be } \\ \text { useful in achieving faster hemostasis and earlier ambulation and reducing pain or discomfort } \\ \text { associated with hemostasis compared to manual compression. }\end{array} \\ \hline \text { IIa } & \text { B-R } & \text { [354, 355] }\end{array}\right]$

Recommendation for management of arterial access sites after catheter ablation of VA

\begin{tabular}{ccl}
\hline COR & LOE & Recommendation \\
\hline I & A & $\begin{array}{l}\text { 1. Achieving arterial access site hemostasis using either manual compression or a } \\
\text { vascular closure device is recommended. }\end{array}$ \\
\hline
\end{tabular}

Recommendations for management of epicardial access sites after catheter ablation of VA

\begin{tabular}{|c|c|c|c|}
\hline COR & LOE & Recommendations & References \\
\hline I & C-EO & $\begin{array}{l}\text { 1. If pericardial bleeding or cardiac tamponade has occurred during epicardial VT ablation, a } \\
\text { pericardial drain should be left in place until bleeding has resolved. }\end{array}$ & \\
\hline IIa & B-NR & $\begin{array}{l}\text { 2. The instillation of intrapericardial corticosteroids can be effective in reducing pericarditic } \\
\text { chest pain after epicardial VT mapping or ablation. }\end{array}$ & {$[171,359]$} \\
\hline IIa & B-NR & $\begin{array}{l}\text { 3. To reduce pericardial pain after epicardial VT ablation, unless pericardial bleeding or cardiac } \\
\text { tamponade has occurred, it is reasonable to remove all pericardial access sheaths at the end } \\
\text { of the procedure. }\end{array}$ & {$[171,359]$} \\
\hline IIb & C-EO & $\begin{array}{l}\text { 4. Leaving a pericardial drain in place might be reasonable in patients at high risk for late } \\
\text { bleeding or cardiac tamponade after epicardial VT ablation. }\end{array}$ & \\
\hline
\end{tabular}


Fig. 13 Factors influencing outcomes post VA ablation. ICD

= implantable cardioverter defibrillator; LVAD = left ventricular assist device; $\mathrm{VA}=$ ventricular arrhythmia; $\mathrm{VT}=$ ventricular tachycardia

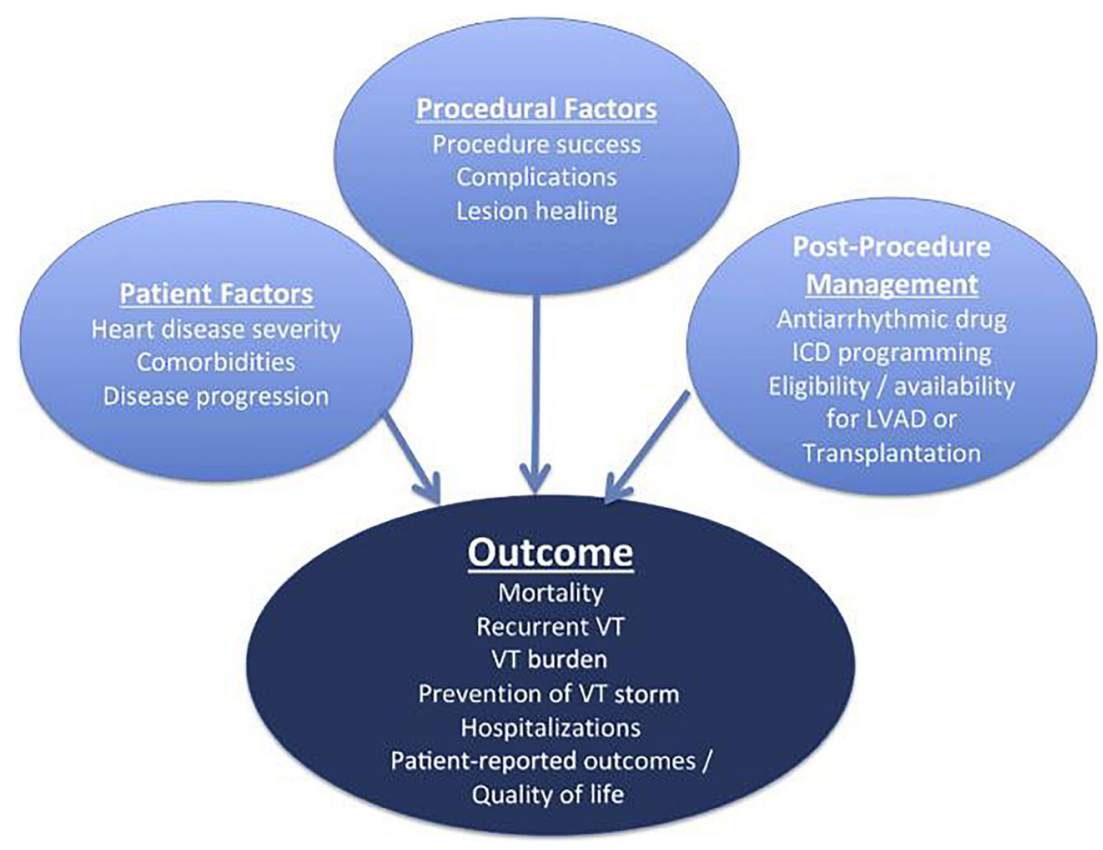

\subsubsection{Postprocedural Care: Anticoagulation}

Recommendations for anticoagulation after VA ablation procedures

\begin{tabular}{cclll}
\hline COR & LOE & Recommendations & References \\
\hline IIa & C-LD & $\begin{array}{l}\text { 1. After less extensive endocardial VT ablation, treatment with an antiplatelet agent for a } \\
\text { limited period of time is reasonable. }\end{array}$ \\
IIa & C-LD & $\begin{array}{l}\text { 2. Heparin reversal with protamine for sheath removal after ablation is reasonable. } \\
\text { IIb }\end{array}$ C-LD & $\begin{array}{l}\text { 3. After extensive endocardial VT ablation, treatment with an oral anticoagulant for a limited } \\
\text { period of time might be reasonable. }\end{array}$ & {$[146,301]$} \\
IIb & C-EO & $\begin{array}{l}\text { 4. The use of heparin bridging after endocardial VT ablation may be considered but can be } \\
\text { associated with an increased risk of periprocedural bleeding. }\end{array}$ \\
\hline
\end{tabular}




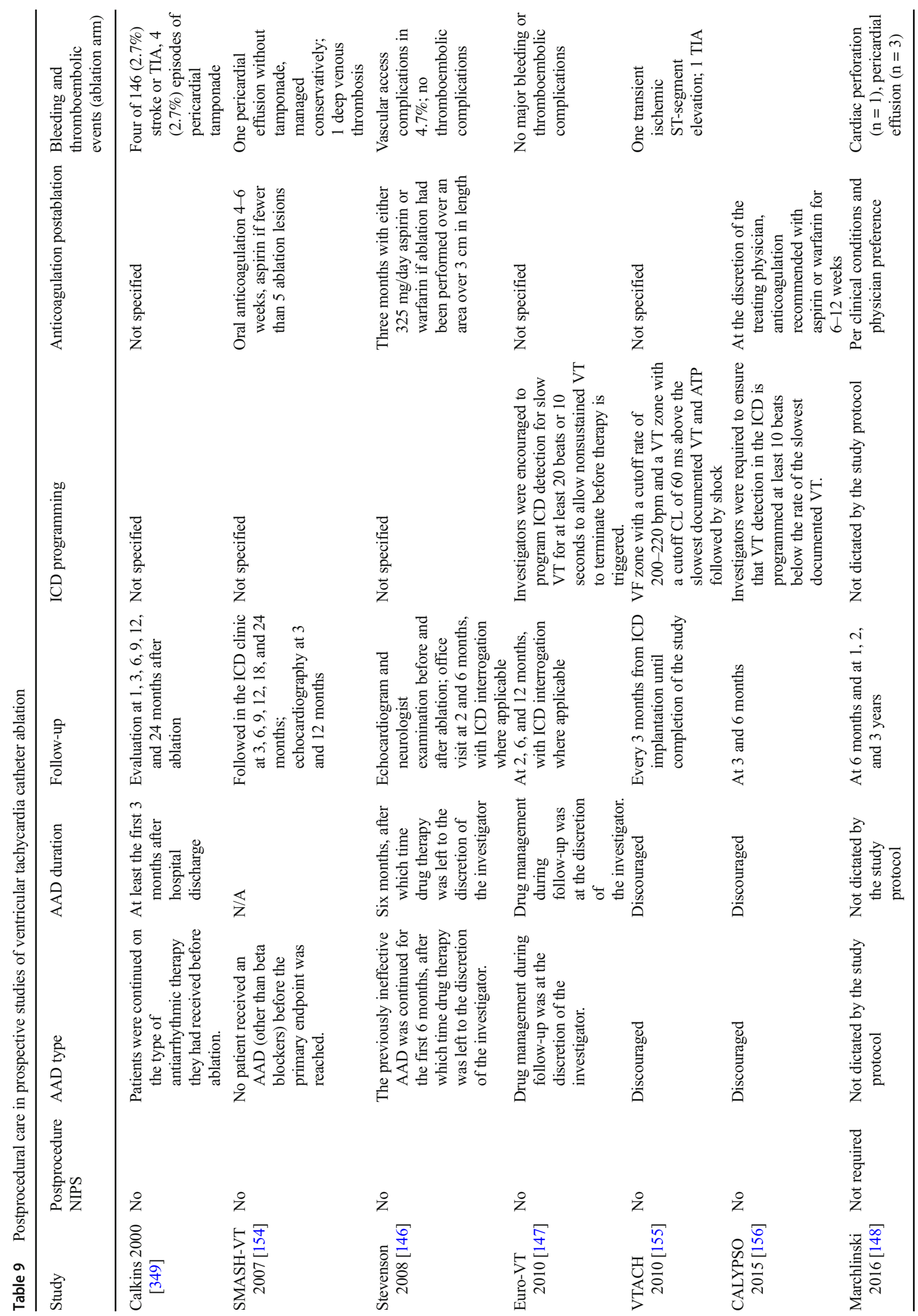




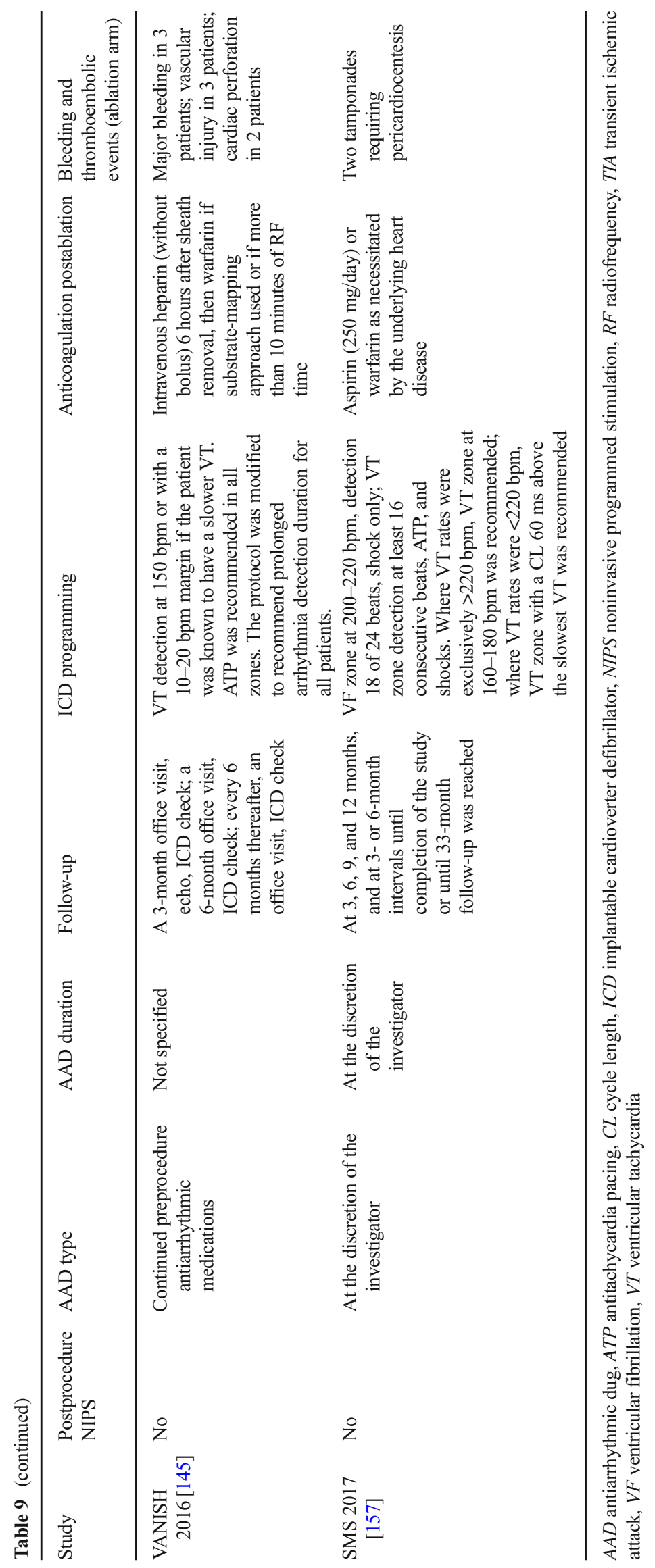




\subsection{Incidence and Management of Complications}

Table 10 Major complications of ventricular arrhythmia ablation in patients with structural heart disease

\begin{tabular}{|c|c|c|c|c|c|c|}
\hline Complication & Incidence & Mechanisms & Presentation & Prevention & Treatment & Ref. \\
\hline In-hospital mortality & $0 \%-3 \%$ & $\begin{array}{l}\text { VT recurrence, heart } \\
\text { failure, } \\
\text { complications of } \\
\text { catheter ablation }\end{array}$ & Not applicable & $\begin{array}{l}\text { Correct electrolyte } \\
\text { disturbances and } \\
\text { optimize } \\
\text { medical status } \\
\text { before } \\
\text { ablation }\end{array}$ & - & $\begin{array}{c}{[146,154,155} \\
300,350]\end{array}$ \\
\hline Long-term mortality & $\begin{array}{l}3 \%-35 \% \\
\quad(12-39 \\
\text { months of } \\
\text { follow-up) }\end{array}$ & $\begin{array}{l}\text { VT recurrence and } \\
\text { progression } \\
\text { of heart failure }\end{array}$ & $\begin{array}{l}\text { Cardiac } \\
\text { nonarrhythmic } \\
\text { death (heart } \\
\text { failure) } \\
\text { and VT } \\
\text { recurrence }\end{array}$ & $\begin{array}{l}\text { Identification of } \\
\text { patients } \\
\text { with indication for } \\
\text { heart } \\
\text { transplantation }\end{array}$ & - & $\begin{array}{l}{[146,154,155,} \\
300]\end{array}$ \\
\hline $\begin{array}{l}\text { Neurological } \\
\text { complication } \\
\text { (stroke, TIA, } \\
\text { cerebral } \\
\text { hemorrhage) }\end{array}$ & $0 \%-2.7 \%$ & $\begin{array}{l}\text { Emboli from left } \\
\text { ventricle, } \\
\text { aortic valve, or } \\
\text { aorta; } \\
\text { cerebral bleeding }\end{array}$ & $\begin{array}{l}\text { Focal or global } \\
\text { neurological } \\
\text { deficits }\end{array}$ & $\begin{array}{l}\text { Careful } \\
\text { anticoagulation } \\
\text { control; ICE can } \\
\text { help } \\
\text { detection of } \\
\text { thrombus } \\
\text { formation, and of } \\
\text { aortic } \\
\text { valve calcification; } \\
\text { TEE } \\
\text { to assess aortic arch }\end{array}$ & Thrombolytic therapy & $\begin{array}{c}{[146,154,155,} \\
300,350]\end{array}$ \\
\hline $\begin{array}{l}\text { Pericardial } \\
\text { complications: } \\
\text { cardiac } \\
\text { tamponade, } \\
\text { hemopericardium, } \\
\text { pericarditis }\end{array}$ & $0 \%-2.7 \%$ & $\begin{array}{l}\text { Catheter } \\
\text { manipulation, } \\
\text { RF delivery, } \\
\text { epicardial } \\
\text { perforation }\end{array}$ & $\begin{array}{l}\text { Abrupt or gradual } \\
\text { fall in } \\
\text { blood pressure; } \\
\text { arterial } \\
\text { line is } \\
\text { recommended } \\
\text { in } \\
\text { ablation of } \\
\text { complex VT }\end{array}$ & $\begin{array}{l}\text { Contact force can be } \\
\text { useful, careful in } \\
\text { RF } \\
\text { delivery in } \\
\text { perivenous } \\
\text { foci and RVOT }\end{array}$ & $\begin{array}{l}\text { Pericardiocentesis; if } \\
\text { necessary, } \\
\text { surgical drainage, } \\
\text { reversal } \\
\text { heparin; steroids } \\
\text { and } \\
\text { colchicine in } \\
\text { pericarditis }\end{array}$ & $\begin{array}{c}{[146,154,155} \\
300,350]\end{array}$ \\
\hline AV block & $0 \%-1.4 \%$ & $\begin{array}{l}\text { Energy delivery near } \\
\text { the } \\
\text { conduction } \\
\text { system }\end{array}$ & $\begin{array}{l}\text { Fall in blood } \\
\text { pressure and } \\
\text { ECG changes }\end{array}$ & $\begin{array}{l}\text { Careful monitoring } \\
\text { when } \\
\text { ablation is } \\
\text { performed } \\
\text { near the conduction } \\
\text { system; consider } \\
\text { cryoablation }\end{array}$ & $\begin{array}{l}\text { Pacemaker; upgrade } \\
\text { to a } \\
\text { biventricular pacing } \\
\text { device } \\
\text { might be necessary }\end{array}$ & $\begin{array}{l}{[146,154,300} \\
\quad 350]\end{array}$ \\
\hline $\begin{array}{c}\text { Coronary artery } \\
\text { damage/MI }\end{array}$ & $0.4 \%-1.9 \%$ & $\begin{array}{l}\text { Ablation near } \\
\text { coronary } \\
\text { artery, unintended } \\
\text { coronary damage } \\
\text { during } \\
\text { catheter } \\
\text { manipulation } \\
\text { in the aortic root } \\
\text { or } \\
\text { crossing the aortic } \\
\text { valve }\end{array}$ & $\begin{array}{l}\text { Acute coronary } \\
\text { syndrome; } \\
\text { confirmation } \\
\text { with } \\
\text { coronary } \\
\text { catheterization }\end{array}$ & $\begin{array}{l}\text { Limit power near } \\
\text { coronary } \\
\text { arteries and avoid } \\
\text { energy } \\
\text { delivery }<5 \mathrm{~mm} \\
\text { from } \\
\text { coronary vessel; } \\
\text { ICE is } \\
\text { useful to visualize } \\
\text { the } \\
\text { coronary ostium }\end{array}$ & $\begin{array}{l}\text { Percutaneous } \\
\text { coronary } \\
\text { intervention }\end{array}$ & $\begin{array}{c}{[146,154,155} \\
300,350]\end{array}$ \\
\hline $\begin{array}{l}\text { Heart } \\
\text { failure/pulmonary } \\
\text { edema }\end{array}$ & $0 \%-3 \%$ & $\begin{array}{l}\text { External irrigation, } \\
\text { sympathetic } \\
\text { response } \\
\text { due to ablation, } \\
\text { and } \\
\text { VT induction }\end{array}$ & $\begin{array}{r}\text { Heart failure } \\
\text { symptoms }\end{array}$ & $\begin{array}{l}\text { Urinary catheter and } \\
\text { careful } \\
\text { attention to fluid } \\
\text { balance } \\
\text { and diuresis, } \\
\text { optimize } \\
\text { clinical status } \\
\text { before } \\
\text { ablation, reduce }\end{array}$ & $\begin{array}{l}\text { New/increased } \\
\text { diuretics }\end{array}$ & $\begin{array}{l}{[146,154,155,} \\
300]\end{array}$ \\
\hline
\end{tabular}


Table 10 (continued)

\begin{tabular}{|c|c|c|c|c|c|c|}
\hline Complication & Incidence & Mechanisms & Presentation & Prevention & Treatment & Ref. \\
\hline & & & & $\begin{array}{l}\text { irrigation } \\
\text { volume if possible } \\
\text { (decrease } \\
\text { flow rates or use } \\
\text { closed } \\
\text { irrigation catheters) }\end{array}$ & & \\
\hline Valvular injury & $0 \%-0.7 \%$ & $\begin{array}{l}\text { Catheter } \\
\text { manipulation, } \\
\text { especially } \\
\text { retrograde } \\
\text { crossing the aortic } \\
\text { valve } \\
\text { and entrapment in } \\
\text { the } \\
\text { mitral valve; } \\
\text { energy } \\
\text { delivery to } \\
\text { subvalvular } \\
\text { structures, } \\
\text { including } \\
\text { papillary muscle }\end{array}$ & $\begin{array}{l}\text { Acute } \\
\text { cardiovascular } \\
\text { collapse, new } \\
\text { murmurs, } \\
\text { progressive } \\
\text { heart failure } \\
\text { symptoms }\end{array}$ & $\begin{array}{l}\text { Careful catheter } \\
\text { manipulation; } \\
\text { ICE can be useful } \\
\text { for } \\
\text { identification of } \\
\text { precise } \\
\text { location of energy } \\
\text { delivery }\end{array}$ & $\begin{array}{l}\text { Echocardiography is } \\
\text { essential in the } \\
\text { diagnosis; } \\
\text { medical therapy, } \\
\text { including } \\
\text { vasodilators and } \\
\text { dobutamine } \\
\text { before surgery; } \\
\text { IABP is useful } \\
\text { in acute mitral } \\
\text { regurgitation } \\
\text { and is } \\
\text { contraindicated in } \\
\text { aortic regurgitation }\end{array}$ & $\begin{array}{l}{[146,154,155,} \\
300]\end{array}$ \\
\hline $\begin{array}{l}\text { Acute periprocedural } \\
\text { hemodynamic } \\
\text { decompensation, } \\
\text { cardiogenic shock }\end{array}$ & $0 \%-11 \%$ & $\begin{array}{l}\text { Fluid overloading, } \\
\text { general } \\
\text { anesthesia, } \\
\text { sustained VT }\end{array}$ & $\begin{array}{l}\text { Sustained } \\
\text { hypotension } \\
\text { despite } \\
\text { optimized } \\
\text { therapy }\end{array}$ & $\begin{array}{l}\text { Close monitoring of } \\
\text { fluid } \\
\text { infusion and } \\
\text { hemodynamic } \\
\text { status } \\
\text {-Optimize medical } \\
\text { status } \\
\text { before ablation } \\
\text {-pLVAD } \\
\text {-Substrate mapping } \\
\text { preferred, avoid } \\
\text { VT } \\
\text { induction in } \\
\text { higher-risk } \\
\text { patients }\end{array}$ & Mechanical HS & $\begin{array}{c}{[146,154,155,} \\
300,351]\end{array}$ \\
\hline $\begin{array}{l}\text { Vascular injury: } \\
\text { hematomas, } \\
\text { pseudoaneurysm, } \\
\text { AV fistulae }\end{array}$ & $0 \%-6.9 \%$ & $\begin{array}{l}\text { Access to femoral } \\
\text { arterial } \\
\text { and catheter } \\
\text { manipulation }\end{array}$ & $\begin{array}{l}\text { Groin } \\
\text { hematomas, } \\
\text { groin pain, fall } \\
\text { in } \\
\text { hemoglobin }\end{array}$ & $\begin{array}{l}\text { Ultrasound-guided } \\
\text { access }\end{array}$ & $\begin{array}{l}\text { Ultrasound-guided } \\
\text { compression, } \\
\text { thrombin } \\
\text { injection, and } \\
\text { surgical closure }\end{array}$ & $\begin{array}{c}{[146,154,155,} \\
300,350]\end{array}$ \\
\hline $\begin{array}{l}\text { Overall major } \\
\text { complications with } \\
\text { SHD }\end{array}$ & $3.8 \%-11.24 \%$ & & & & & $\begin{array}{c}{[146,154,155,} \\
300,350]\end{array}$ \\
\hline $\begin{array}{l}\text { Overall all } \\
\text { complications }\end{array}$ & $7 \%-14.7 \%$ & & & & & {$[300,352,353]$} \\
\hline
\end{tabular}

$A V$ atrioventricular, $E C G$ electrocardiogram, $H S$ hemodynamic support, $I A B P$ intra-aortic balloon pump, $I C E$ intracardiac echocardiography, $M I$ myocardial infarction, $P L V A D$ percutaneous left ventricular assist device, $R F$ radiofrequency, $R V O T$ right ventricular outflow tract, $S H D$ structural heart disease, TEE transesophageal echocardiography, TIA transient ischemic attack, VT ventricular tachycardia

\subsection{Hemodynamic Deterioration and Proarrhythmia}

Recommendation for echocardiography after VA ablation

COR LOE Recommendation Reference

\begin{tabular}{cccc}
\hline I & C-LD & $\begin{array}{l}\text { 1. Echocardiography should be performed in case of hemodynamic deterioration post-VT } \\
\text { ablation to assess for pericardial effusion and cardiac tamponade. }\end{array}$ & [362] \\
\hline
\end{tabular}




\subsection{Follow-up of Patients Post Catheter Ablation of Ventricular Tachycardia}

Recommendation for noninvasive programmed stimulation after catheter ablation of VT

\begin{tabular}{cclll} 
COR & LOE & Recommendation & References \\
\hline IIa & B-NR & $\begin{array}{l}\text { 1. Noninvasive programmed stimulation can be useful in the several days following VT catheter } \\
\text { ablation to inform further management, including ICD programming, predicting the risk of VT } \\
\text { recurrence, and/or considering a repeat VT catheter ablation. }\end{array}$ \\
\hline
\end{tabular}

\section{Training and Institutional Requirements and Competencies}

This section contains the general training and institutional requirements with an emphasis on lifelong learning, professionalism, and acquisition and maintenance of knowledge and skills. In addition, institutional requirements for specific procedures are reviewed.

\subsection{Training Requirements and Competencies for Catheter Ablation of Ventricular Arrhythmias}

Recommendation for training requirements and competencies for catheter ablation of VA

\begin{tabular}{ccl}
\hline COR & LOE & Recommendation \\
\hline I & C-EO & $\begin{array}{c}\text { 1. For clinical cardiac electrophysiologists who perform catheter ablation for VAs, appropriate } \\
\text { advanced training and continued lifelong learning is recommended. }\end{array}$ \\
\hline
\end{tabular}

\subsection{Institutional Requirements for Catheter Ablation} of Ventricular Tachycardia

\section{Recommendations for institutional requirements for catheter ablation of VT}

\begin{tabular}{cc|c|c|c|c|c|c|}
\hline COR & LOE & Recommendations \\
\hline I & C-EO & $\begin{array}{l}\text { 1. Patients with certain underlying medical conditions and comorbidities undergoing complex } \\
\text { VA ablations who are deemed to have increased procedural risk should undergo procedures in } \\
\text { a hospital-based electrophysiology laboratory. }\end{array}$ \\
I & C-EO & $\begin{array}{l}\text { 2. Onsite interventional cardiology expertise is recommended for electrophysiology procedures } \\
\text { requiring coronary imaging to delineate coronary anatomy for epicardial ablation, } \\
\text { aortography to delineate coronary ostia for SV VT ablation, and need for placement of HS } \\
\text { devices. }\end{array}$ \\
I & C-EO & $\begin{array}{l}\text { 3. Onsite cardiothoracic surgical backup is recommended for electrophysiology procedures } \\
\text { requiring pericardial access due to the potential need for emergent sternotomy and } \\
\text { cardiopulmonary bypass. } \\
\text { Availability of anesthesia personnel is recommended for all patients undergoing catheter } \\
\text { ablation of VAs. }\end{array}$ \\
\hline
\end{tabular}

\section{Future Directions}

This section summarizes ongoing trials and the need for prospective evaluation of different clinical problems. It further reviews recent advances and limitations of various mapping techniques and addresses unanswered questions requiring future investigations. 


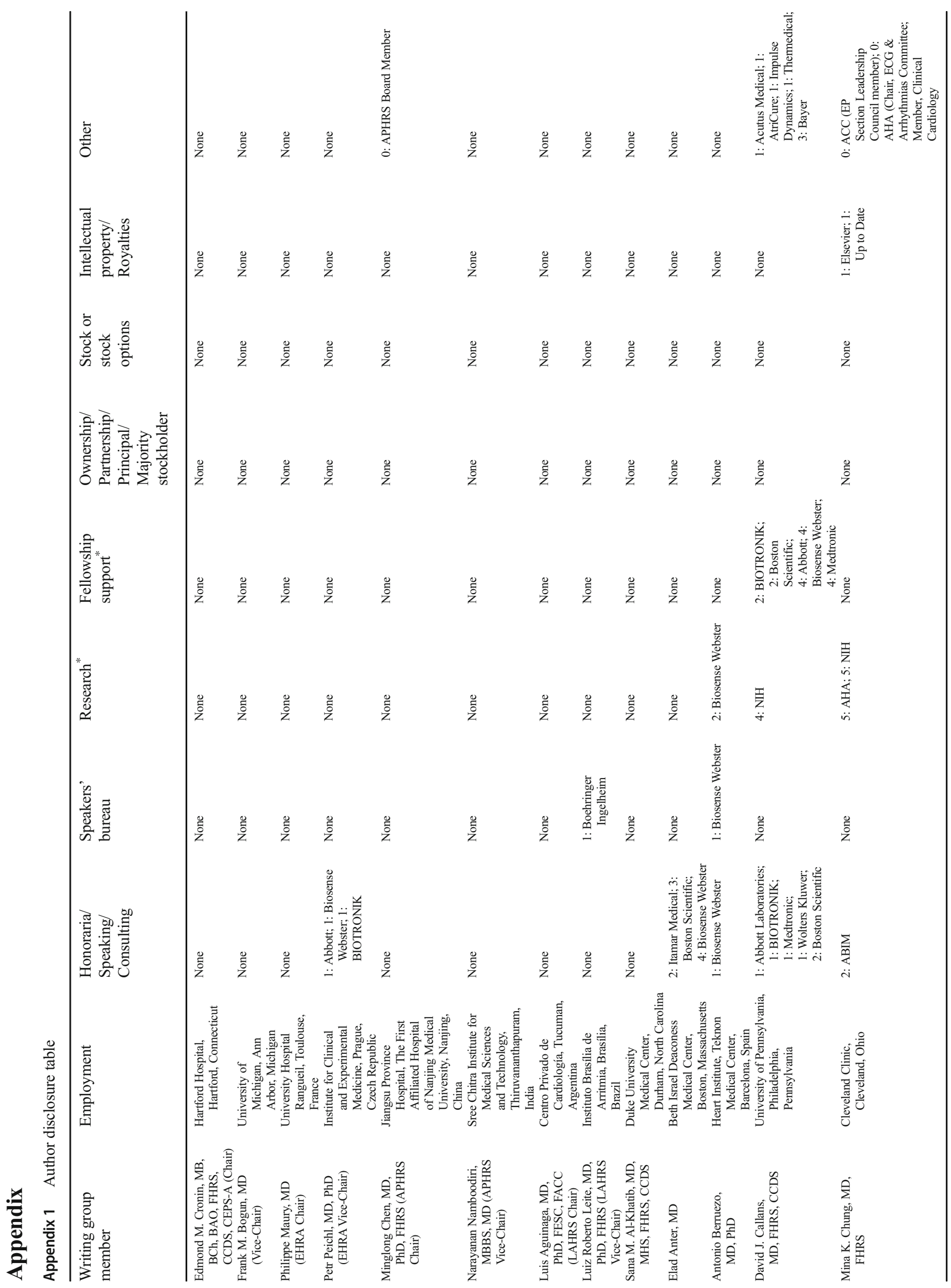




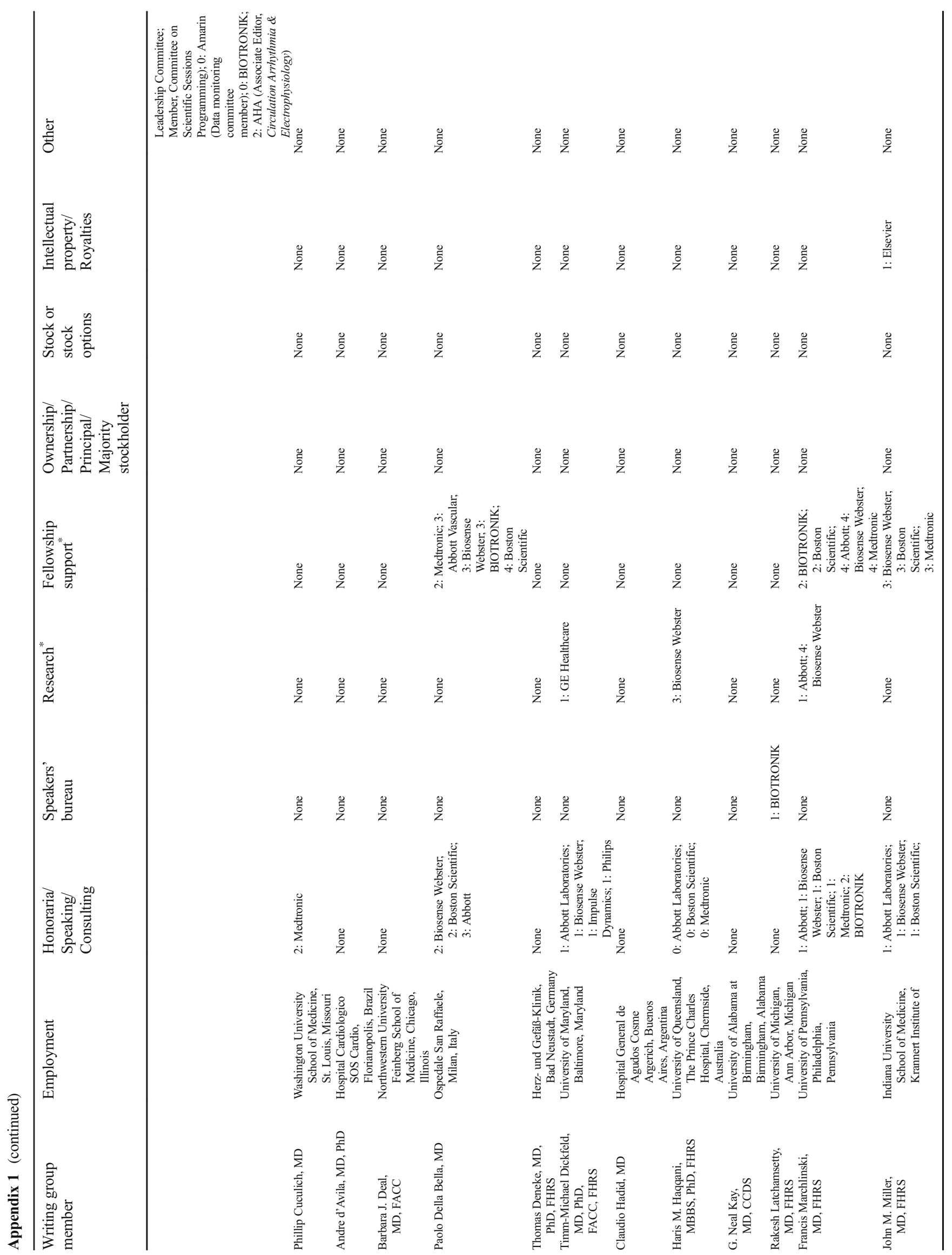




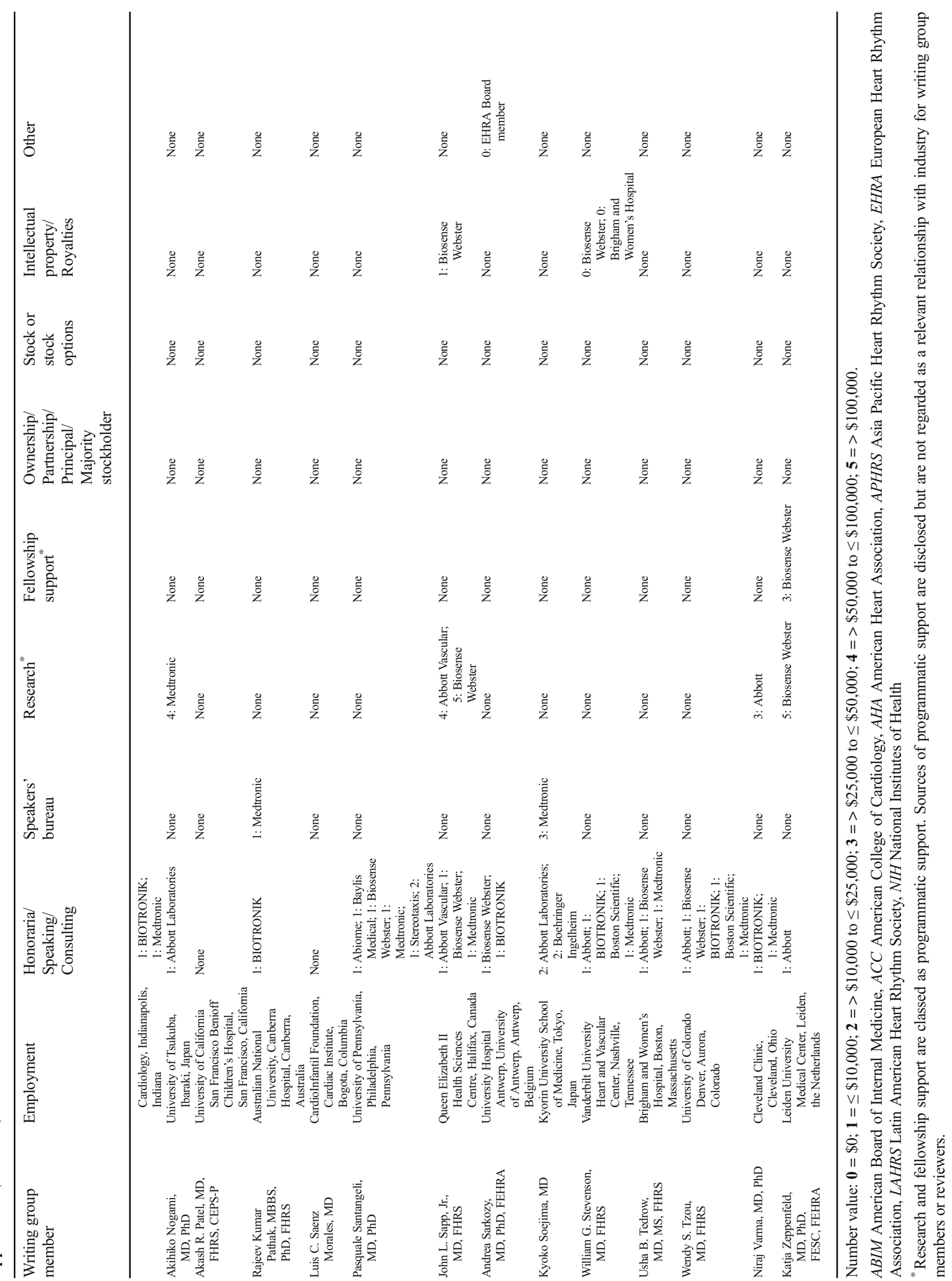




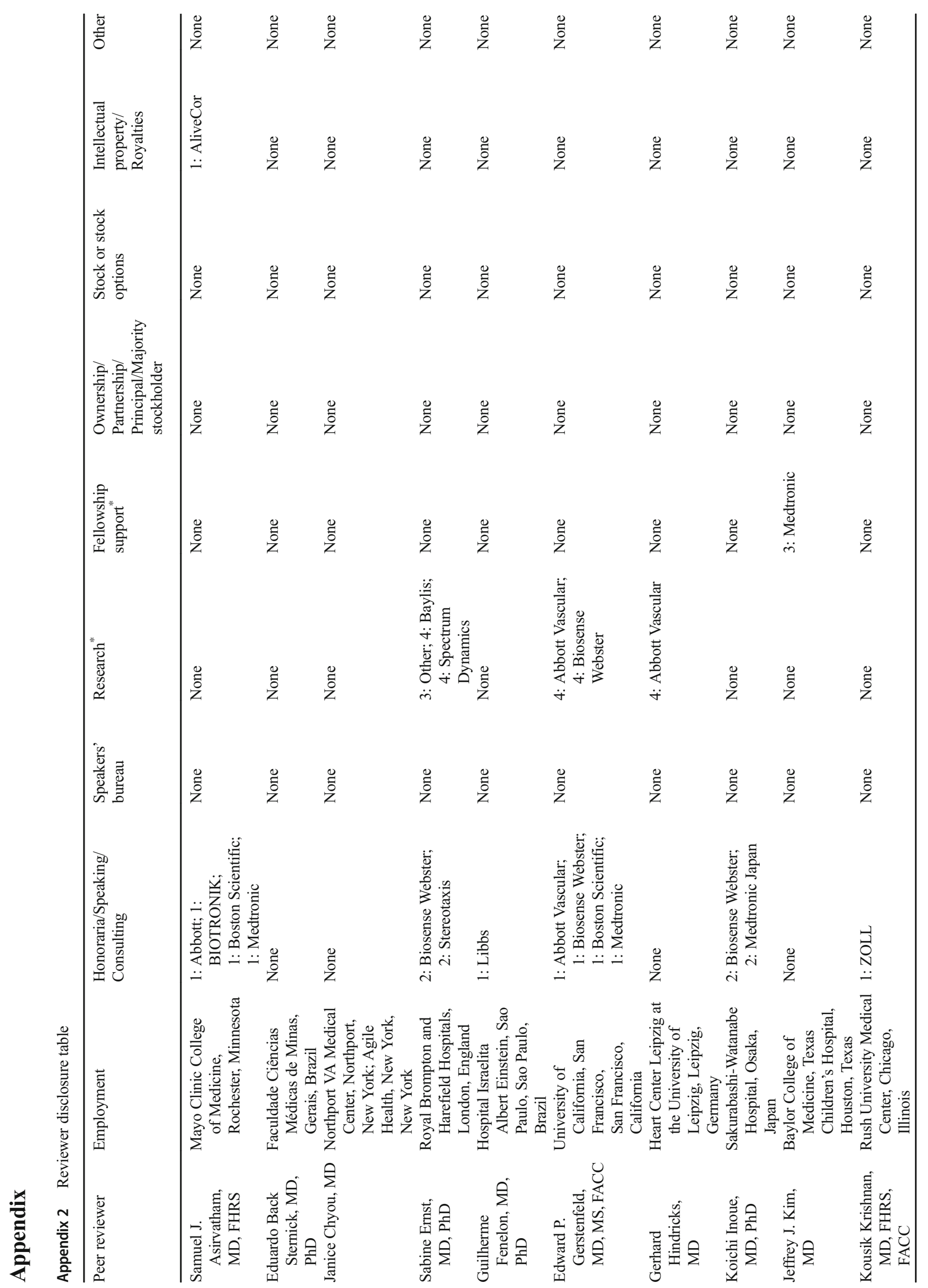




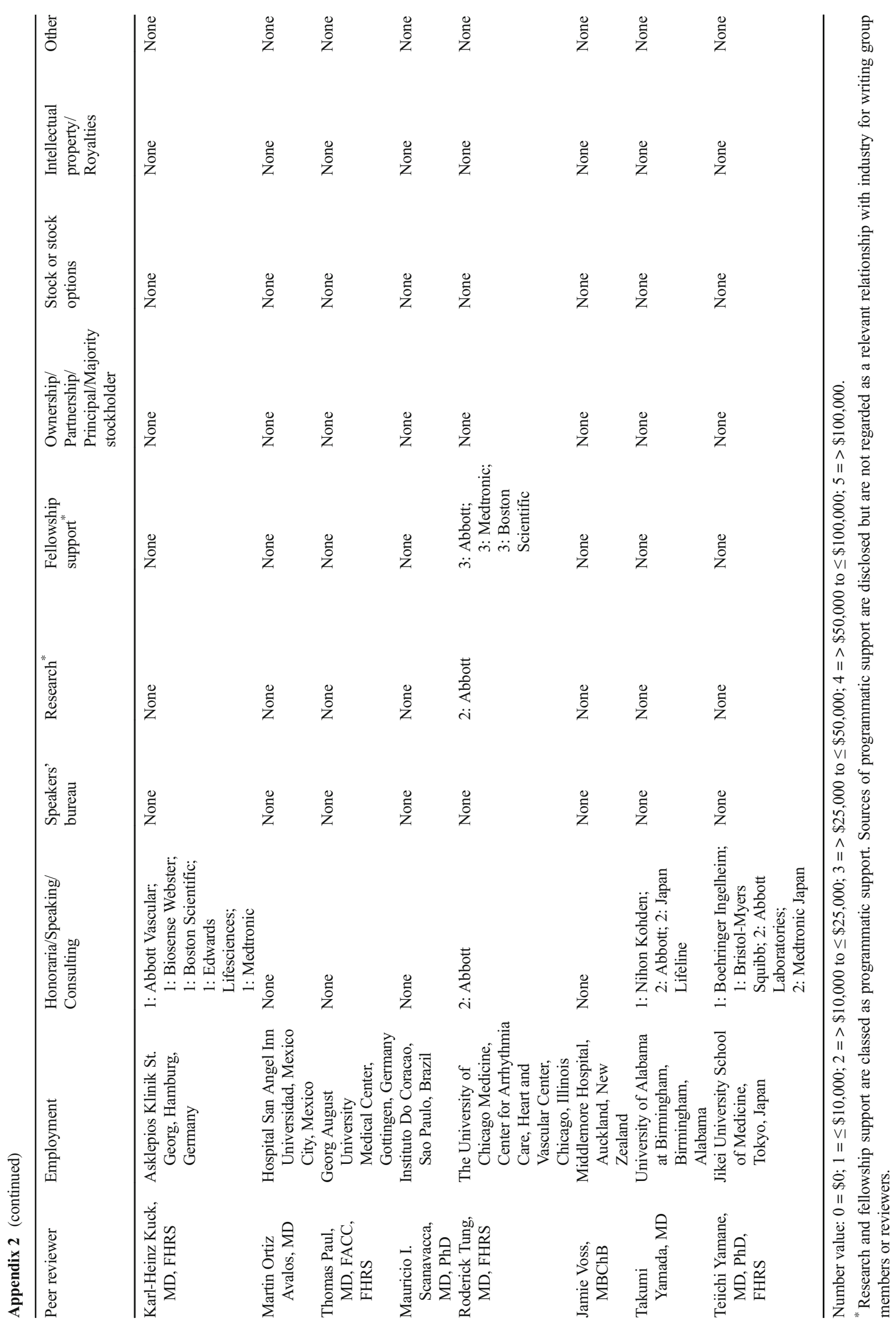


Open Access This article is licensed under a Creative Commons Attribution 4.0 International License, which permits use, sharing, adaptation, distribution and reproduction in any medium or format, as long as you give appropriate credit to the original author(s) and the source, provide a link to the Creative Commons licence, and indicate if changes were made. The images or other third party material in this article are included in the article's Creative Commons licence, unless indicated otherwise in a credit line to the material. If material is not included in the article's Creative Commons licence and your intended use is not permitted by statutory regulation or exceeds the permitted use, you will need to obtain permission directly from the copyright holder. To view a copy of this licence, visit http://creativecommons.org/licenses/by/4.0/.

\section{References}

1. Aliot EM, Stevenson WG, Almendral-Garrote JM, et al. EHRA/HRS expert consensus on catheter ablation of ventricular arrhythmias: developed in a partnership with the European Heart Rhythm Association (EHRA), a registered branch of the European Society of Cardiology (ESC), and the Heart Rhythm Society (HRS); in collaboration with the American College of Cardiology (ACC) and the American Heart Association (AHA). Heart Rhythm. 2009;6:886-933.

2. Hosseini SM, Rozen G, Saleh A, et al. Catheter ablation for cardiac arrhythmias: utilization and in-hospital complications, 2000 to 2013. JACC Clin Electrophysiol. 2017;3:1240-8.

3. Raatikainen MJP, Arnar DO, Merkely B, Nielsen JC, Hindricks G, Heidbuchel $\mathrm{H}$, et al. A decade of information on the use of cardiac implantable electronic devices and interventional electrophysiological procedures in the European Society of Cardiology Countries: 2017 report from the European Heart Rhythm Association. Europace. 2017;19(Suppl. 2):ii1-ii90.

4. Al-Khatib SM, Stevenson WG, Ackerman MJ, et al. 2017 AHA/ ACC/HRS guideline for management of patients with ventricular arrhythmias and the prevention of sudden cardiac death: a report of the American College of Cardiology/American Heart Association Task Force on Clinical Practice Guidelines and the Heart Rhythm Society. Heart Rhythm. 2018;15:e73-e189.

5. Priori SG, Blomström-Lundqvist C, Mazzanti A, et al. 2015 ESC guidelines for the management of patients with ventricular arrhythmias and the prevention of sudden cardiac death: the Task Force for the Management of Patients with Ventricular Arrhythmias and the Prevention of Sudden Cardiac Death of the European Society of Cardiology (ESC). Europace. 2015;17:160187.

6. Indik JH, Patton KK, Beardsall M, et al. HRS clinical document development methodology manual and policies: executive summary. Heart Rhythm. 2017;14:e495-500.

7. Halperin JL, Levine GN, Al-Khatib SM, et al. Further evolution of the ACC/AHA clinical practice guideline recommendation classification system: a report of the American College of Cardiology/American Heart Association Task Force on Clinical Practice Guidelines. J Am Coll Cardiol. 2016;67:1572-4.

8. Martinez BK, Baker WL, Konopka A, et al. Systematic review and meta-analysis of catheter ablation of ventricular tachycardia in ischemic heart disease. Heart Rhythm 2019.

9. Yamada T, Kay GN. Anatomical consideration in catheter ablation of idiopathic ventricular arrhythmias. Arrhythm Electrophysiol Rev. 2016;5:203-9.

10. Della Bella P, Maccabelli G, Carbucicchio C. Anatomical assessment for catheter ablation of ventricular tachycardia. In: Auricchio
A, editor. Cardiac Imaging in Electrophysiology. London: Springer-Verlag; 2012. p. 95-104.

11. Enriquez A, Malavassi F, Saenz LC, Supple G, Santangeli P, Marchlinski FE, et al. How to map and ablate left ventricular summit arrhythmias. Heart Rhythm. 2017;14:141-8.

12. Saremi F, Muresian H, Sanchez-Quintana D. Coronary veins: comprehensive CT-anatomic classification and review of variants and clinical implications. Radiographics. 2012;32:E1-E32.

13. Ho SY. Anatomic insights for catheter ablation of ventricular tachycardia. Heart Rhythm. 2009;6(Suppl. 8):S77-80.

14. Ho SY, Nihoyannopoulos P. Anatomy, echocardiography, and normal right ventricular dimensions. Heart. 2006;92(Suppl. 1):i2-i13.

15. Sánchez-Quintana D, Ho SY, Climent V, Murillo M, Cabrera JA. Anatomic evaluation of the left phrenic nerve relevant to epicardial and endocardial catheter ablation: implications for phrenic nerve injury. Heart Rhythm. 2009;6:764-8.

16. Yamada T, Litovsky SH, Kay GN. The left ventricular ostium: an anatomic concept relevant to idiopathic ventricular arrhythmias. Circ Arrhythm Electrophysiol. 2008;1:396-404.

17. McAlpine WA. Heart and Coronary Arteries: An Anatomical Atlas for Clinical Diagnosis, Radiological Investigation, and Surgical Treatment. New York: Springer-Verlag; 1975.

18. Brugada P, Brugada J, Mont L, Smeets J, Andries EW. A new approach to the differential diagnosis of a regular tachycardia with a wide QRS complex. Circulation. 1991;83:1649-59.

19. Wellens HJ, Bar FW, Lie KI. The value of the electrocardiogram in the differential diagnosis of a tachycardia with a widened QRS complex. Am J Med. 1978;64:27-33.

20. Vereckei A, Duray G, Szenasi G, Altemose GT, Miller JM. New algorithm using only lead aVR for differential diagnosis of wide QRS complex tachycardia. Heart Rhythm. 2008;5:89-98.

21. Ohe T, Shimomura K, Aihara N, et al. Idiopathic sustained left ventricular tachycardia: clinical and electrophysiologic characteristics. Circulation. 1988;77:560-8.

22. Dixit S, Gerstenfeld EP, Callans DJ, Marchlinski FE. Electrocardiographic patterns of superior right ventricular outflow tract tachycardias: distinguishing septal and free-wall sites of origin. J Cardiovasc Electrophysiol. 2003;14:1-7.

23. Callans DJ, Menz V, Schwartzman D, Gottlieb CD, Marchlinski FE. Repetitive monomorphic tachycardia from the left ventricular outflow tract: electrocardiographic patterns consistent with a left ventricular site of origin. J Am Coll Cardiol. 1997;29:1023-7.

24. Kanagaratnam L, Tomassoni G, Schweikert R, et al. Ventricular tachycardias arising from the aortic sinus of Valsalva: an underrecognized variant of left outflow tract ventricular tachycardia. J Am Coll Cardiol. 2001;37:1408-14.

25. Crawford T, Mueller G, Good E, et al. Ventricular arrhythmias originating from papillary muscles in the right ventricle. Heart Rhythm. 2010;7:725-30.

26. Yamada T, McElderry HT, Okada T, et al. Idiopathic focal ventricular arrhythmias originating from the anterior papillary muscle in the left ventricle. J Cardiovasc Electrophysiol. 2009;20:866-72.

27. Li S, Wang Z, Shan Z, et al. Surface electrocardiography characteristics and radiofrequency catheter ablation of idiopathic ventricular arrhythmias originating from the left infero-septal papillary muscles: differences from those originating from the left posterior fascicle. Europace. 2018;20:1028-34.

28. Berruezo A, Mont L, Nava S, Chueca E, Bartholomay E, Brugada $\mathrm{J}$. Electrocardiographic recognition of the epicardial origin of ventricular tachycardias. Circulation. 2004;109:1842-7.

29. Daniels DV, Lu YY, Morton JB, et al. Idiopathic epicardial left ventricular tachycardia originating remote from the sinus of Valsalva: electrophysiological characteristics, catheter ablation, and identification from the 12-lead electrocardiogram. Circulation. 2006;113:1659-66. 
30. Bazan V, Gerstenfeld EP, Garcia FC, et al. Site-specific twelvelead ECG features to identify an epicardial origin for left ventricular tachycardia in the absence of myocardial infarction. Heart Rhythm. 2007;4:1403-10.

31. Valles E, Bazan V, Marchlinski FE. ECG Criteria to identify epicardial ventricular tachycardia in nonischemic cardiomyopathy. Circ Arrhythm Electrophysiol. 2010;3:63-71.

32. Bazan V, Bala R, Garcia FC, et al. Twelve-lead ECG features to identify ventricular tachycardia arising from the epicardial right ventricle. Heart Rhythm. 2006;3:1132-9.

33. Perez-Rodon J, Martinez-Alday J, Baron-Esquivias G, et al. Prognostic value of the electrocardiogram in patients with syncope: data from the group for syncope study in the emergency room (GESINUR). Heart Rhythm. 2014;11:2035-44.

34. Solomon SD, Zelenkofske S, McMurray JJ, et al. Sudden death in patients with myocardial infarction and left ventricular dysfunction, heart failure, or both. N Engl J Med. 2005;352:2581-8.

35. Gula LJ, Klein GJ, Hellkamp AS, et al. Ejection fraction assessment and survival: an analysis of the Sudden Cardiac Death in Heart Failure Trial (SCD-HeFT). Am Heart J. 2008;156:1196200.

36. Yoon Y, Ktagawa K, Kato S, et al. Prognostic value of unrecognised myocardial infarction detected by late gadoliniumenhanced MRI in diabetic patients with normal global and regional left ventricular systolic function. Eur Radiol. 2013;23:2101-8.

37. Olivotto I, Maron M, Autore C, et al. Assessment and significance of left ventricular mass by cardiovascular magnetic resonance in hypertrophic cardiomyopathy. J Am Coll Cardiol. 2008;52:55966.

38. Desjardins B, Yokokawa M, Good E, et al. Characteristics of intramural scar in patients with nonischemic cardiomyopathy and relation to intramural ventricular arrhythmias. Circ Arrhythm Electrophysiol. 2013;6:891-7.

39. Dweck M, Abgral R, Trivieri M, et al. Hybrid magnetic resonance imaging and positron emission tomography with fluorodeoxyglucose to diagnose active cardiac sarcoidosis. JACC Cardiovasc Imaging. 2018;11:94-107.

40. Piers SR, Tao Q, van Huls van Taxis CF, Schalij MJ, van der Geest RJ, Zeppenfeld K. Contrast-enhanced MRI-derived scar patterns and associated ventricular tachycardias in nonischemic cardiomyopathy: implications for the ablation strategy. Circ Arrhythm Electrophysiol. 2013;6:875-83.

41. Brugada J, Aguinaga L, Mont L, Betriu A, Mulet J, Sanz G. Coronary artery revascularization in patients with sustained ventricular arrhythmias in the chronic phase of a myocardial infarction: effects on the electrophysiologic substrate and outcome. J Am Coll Cardiol. 2001;37:529-33.

42. Nageh M, Kim J, Chen L, Yao JF. Implantable defibrillators for secondary prevention of sudden cardiac death in cardiac surgery patients with perioperative ventricular arrhythmias. J Am Heart Assoc. 2014;3:e000686.

43. Elsokkari I, Parkash R, Gray C, et al. Effect of coronary revascularization on long-term clinical outcomes in patients with ischemic cardiomyopathy and recurrent ventricular arrhythmia. Pacing Clin Electrophysiol. 2018;41:775-9.

44. Aquaro GD, Pingitore A, Strata E, Di Bella G, Molinaro S, Lombardi M. Cardiac magnetic resonance predicts outcome in patients with premature ventricular complexes of left bundle branch block morphology. J Am Coll Cardiol. 2010;56:1235-43.

45. Yokokawa M, Siontis KC, Kim HM, et al. Value of cardiac magnetic resonance imaging and programmed ventricular stimulation in patients with frequent premature ventricular complexes undergoing radiofrequency ablation. Heart Rhythm. 2017;14:1695701.

46. Niwano SY, Wakisaka $\mathrm{H}$, Niwano $\mathrm{H}$, et al. Prognostic significance of frequent premature ventricular contractions originating from the ventricular outflow tract in patients with normal left ventricular function. Heart. 2009;95:1230-7.

47. Halperin JL, Levine GN, Al-Khatib SM, et al. Further evolution of the ACC/AHA clinical practice guideline recommendation classification system: a report of the American College of Cardiology Foundation/American Heart Association Task Force on Clinical Practice Guidelines. Circulation. 2006;133:1426-8.

48. Khairy P, Van Hare GF, Balaji S, et al. PACES/HRS expert consensus statement on the recognition and management of arrhythmias in adult congenital heart disease: developed in partnership between the Pediatric and Congenital Electrophysiology Society (PACES) and the Heart Rhythm Society (HRS). Endorsed by the governing bodies of PACES, HRS, the American College of Cardiology (ACC), the American Heart Association (AHA), the European Heart Rhythm Association (EHRA), the Canadian Heart Rhythm Society (CHRS), and the International Society for Adult Congenital Heart Disease (ISACHD). Heart Rhythm. 2014;11: e102-65.

49. Tracy CM, Epstein AE, Darbar D, et al. 2012 ACCF/AHA/HRS focused update of the 2008 guidelines for device-based therapy of cardiac rhythm abnormalities: a report of the American College of Cardiology Foundation/American Heart Association Task Force on Practice Guidelines. Heart Rhythm. 2012;9:1737-53.

50. Ling Z, Liu Z, Su L, et al. Radiofrequency ablation versus antiarrhythmic medication for treatment of ventricular premature beats from the right ventricular outflow tract: prospective randomized study. Circ Arrhythm Electrophysiol. 2014;7:237-43.

51. Zhang F, Yang B, Chen H, Ju W, Kojodjojo P, Cao K, et al. Magnetic versus manual catheter navigation for mapping and $a b-$ lation of right ventricular outflow tract ventricular arrhythmias: a randomized controlled study. Heart Rhythm. 2013;10:1178-83.

52. Krittayaphong R, Sriratanasathavorn C, Dumavibhat C, et al. Electrocardiographic predictors of long term outcomes after radiofrequency ablation in patients with right-ventricular outflow tract tachycardia. Europace. 2006;8:601-6.

53. Vestal M, Wen MS, Yeh SJ, Wang CC, Lin FC, Wu D. Electrocardiographic predictors of failure and recurrence in patients with idiopathic right ventricular outflow tract tachycardia and ectopy who underwent radiofrequency catheter ablation. J Electrocardiol. 2003;36:327-32.

54. Miyazawa K, Ueda M, Kondo Y, Hayashi T, Nakano M, Ishimura $\mathrm{M}$, et al. Rapid mapping and differentiation in ventricular outflow tract arrhythmia using non-contact mapping. J Interv Card Electrophysiol. 2017;49:41-9.

55. Akdeniz C, Gul EE, Celik N, Karacan M, Tuzcu V. Catheter ablation of idiopathic right ventricular arrhythmias in children with limited fluoroscopy. J Interv Card Electrophysiol. 2016;46:35560.

56. Morady F, Kadish AH, DiCarlo L, Kou WH, Winston S, deBuitlier M, et al. Long-term results of catheter ablation of idiopathic right ventricular tachycardia. Circulation. 1990;82:2093-9.

57. Liao Z, Zhan X, Wu S, et al. Idiopathic ventricular arrhythmias originating from the pulmonary sinus cusp: prevalence, electrocardiographic/electrophysiological characteristics, and catheter ablation. J Am Coll Cardiol. 2015;66:2633-44.

58. Bogun F, Crawford T, Reich S, Koelling TM, Armstrong W, Good $\mathrm{E}$, et al. Radiofrequency ablation of frequent, idiopathic premature ventricular complexes: comparison with a control group without intervention. Heart Rhythm. 2007;4:863-7.

59. Chen H, Shehata M, Swerdlow C, et al. Intramural outflow tract ventricular tachycardia: anatomy, mapping, and ablation. Circ Arrhythm Electrophysiol. 2014;7:978-81.

60. Teh AW, Reddy VY, Koruth JS, et al. Bipolar radiofrequency catheter ablation for refractory ventricular outflow tract arrhythmias. J Cardiovasc Electrophysiol. 2014;25:1093-9. 
61. Lamba J, Redfearn DP, Michael KA, Simpson CS, Abdollah H, Baranchuk A. Radiofrequency catheter ablation for the treatment of idiopathic premature ventricular contractions originating from the right ventricular outflow tract: a systematic review and metaanalysis. Pacing Clin Electrophysiol. 2014;37:73-8.

62. Calkins H, Kalbfleisch J, El-Atassi R, Langberg J, Morady F. Relation between efficacy of radiofrequency catheter ablation and site of origin of idiopathic ventricular tachycardia. Am J Cardiol. 1993;71:827-33.

63. Rodriguez LM, Smeets JL, Timmermans C, Wellens HJ. Predictors for successful ablation of right- and left-sided idiopathic ventricular tachycardia. Am J Cardiol. 1997;79:309-14.

64. Coggins DL, Lee RJ, Sweeney J, et al. Radiofrequency catheter ablation as a cure for idiopathic tachycardia of both left and right ventricular origin. J Am Coll Cardiol. 1994;23:1333-41.

65. Wen MS, Yeh SJ, Wang CC, Lin FC, Chen IC, Wu D. Radiofrequency ablation therapy in idiopathic left ventricular tachycardia with no obvious structural heart disease. Circulation. 1994;89:1690-6.

66. Movsowitz C, Schwartzman D, Callans DJ, et al. Idiopathic right ventricular outflow tract tachycardia: narrowing the anatomic location for successful ablation. Am Heart J. 1996;131:930-6.

67. Frey B, Kreiner G, Fritsch S, Veit F, Gossinger HD. Successful treatment of idiopathic left ventricular outflow tract tachycardia by catheter ablation or minimally invasive surgical cryoablation. Pacing Clin Electrophysiol. 2000;23:870-6.

68. Krebs ME, Krause PC, Engelstein ED, Zipes DP, Miles WM. Ventricular tachycardias mimicking those arising from the right ventricular outflow tract. J Cardiovasc Electrophysiol. 2000;11: $45-51$.

69. Kumagai K, Fukuda K, Wakayama Y, et al. Electrocardiographic characteristics of the variants of idiopathic left ventricular outflow tract ventricular tachyarrhythmias. J Cardiovasc Electrophysiol. 2008;19:495-501.

70. Latchamsetty R, Yokokawa M, Morady F, et al. Multicenter outcomes for catheter ablation of idiopathic premature ventricular complexes. JACC Clin Electrophysiol. 2015;1:116-23.

71. Kamakura S, Shimizu W, Matsuo K, et al. Localization of optimal ablation site of idiopathic ventricular tachycardia from right and left ventricular outflow tract by body surface ECG. Circulation. 1998;98:1525-33.

72. Yamada T, Yoshida N, Murakami Y, et al. Electrocardiographic characteristics of ventricular arrhythmias originating from the junction of the left and right coronary sinuses of Valsalva in the aorta: the activation pattern as a rationale for the electrocardiographic characteristics. Heart Rhythm. 2008;5:184-92.

73. Tada $\mathrm{H}$, Naito S, Ito $\mathrm{S}$, et al. Significance of two potentials for predicting successful catheter ablation from the left sinus of Valsalva for left ventricular epicardial tachycardia. Pacing Clin Electrophysiol. 2004;27:1053-9.

74. Ouyang F, Fotuhi P, Ho SY, et al. Repetitive monomorphic ventricular tachycardia originating from the aortic sinus cusp: electrocardiographic characterization for guiding catheter ablation. J Am Coll Cardiol. 2002;39:500-8.

75. Bala R, Garcia FC, Hutchinson MD, et al. Electrocardiographic and electrophysiologic features of ventricular arrhythmias originating from the right/left coronary cusp commissure. Heart Rhythm. 2010;7:312-22.

76. Tada H, Nogami A, Naito S, et al. Left ventricular epicardial outflow tract tachycardia: a new distinct subgroup of outflow tract tachycardia. Jpn Circ J. 2001;65:723-30.

77. Baman TS, Ilg KJ, Gupta SK, et al. Mapping and ablation of epicardial idiopathic ventricular arrhythmias from within the coronary venous system. Circ Arrhythm Electrophysiol. 2010;3:274 9.
78. Carrigan T, Patel S, Yokokawa M, Schmidlin E, Swanson S, Morady F, et al. Anatomic relationships between the coronary venous system, surrounding structures, and the site of origin of epicardial ventricular arrhythmias. J Cardiovasc Electrophysiol. 2014;25:1336-42.

79. Santangeli P, Marchlinski FE, Zado ES, et al. Percutaneous epicardial ablation of ventricular arrhythmias arising from the left ventricular summit: outcomes and electrocardiogram correlates of success. Circ Arrhythm Electrophysiol. 2015;8:337-43.

80. Nagashima K, Choi EK, Lin KY, et al. Ventricular arrhythmias near the distal great cardiac vein: challenging arrhythmia for ablation. Circ Arrhythm Electrophysiol. 2014;7:906-12.

81. Van Herendael H, Garcia F, Lin D, et al. Idiopathic right ventricular arrhythmias not arising from the outflow tract: prevalence, electrocardiographic characteristics, and outcome of catheter ablation. Heart Rhythm. 2011;8:511-8.

82. Sadek MM, Benhayon D, Sureddi R, et al. Idiopathic ventricular arrhythmias originating from the moderator band: electrocardiographic characteristics and treatment by catheter ablation. Heart Rhythm. 2015;12:67-75.

83. Tada H, Tadokoro K, Miyaji K, et al. Idiopathic ventricular arrhythmias arising from the pulmonary artery: prevalence, characteristics, and topography of the arrhythmia origin. Heart Rhythm. 2008;5:419-26.

84. Tada H, Tadokoro $\mathrm{K}$, Ito $\mathrm{S}$, et al. Idiopathic ventricular arrhythmias originating from the tricuspid annulus: prevalence, electrocardiographic characteristics, and results of radiofrequency catheter ablation. Heart Rhythm. 2007;4:7-16.

85. Santoro F, DiBiase L, Hranitzky P, et al. Ventricular tachycardia originating from the septal papillary muscle of the right ventricle: electrocardiographic and electrophysiological characteristics. J Cardiovasc Electrophysiol. 2015;26:145-50.

86. Sasaki K, Sasaki S, Kimura M, et al. Catheter ablation of ventricular arrhythmias arising from the basal septum of the right ventricle: characteristics and significance of junctional rhythm appearing during ablation. J Interv Card Electrophysiol. 2016;45:159-67.

87. Yue-Chun L, Wen-Wu Z, Na-Dan Z, et al. Idiopathic premature ventricular contractions and ventricular tachycardias originating from the vicinity of tricuspid annulus: results of radiofrequency catheter ablation in thirty-five patients. BMC Cardiovasc Disord. 2012;10:12-32.

88. Yamada T, Yoshida N, Itoh T, Litovsky SH, Doppalapudi H, McElderry HT, et al. Idiopathic ventricular arrhythmias originating from the parietal band: electrocardiographic and electrophysiological characteristics and outcome of catheter ablation. Circ Arrhythm Electrophysiol. 2017;10:e005099.

89. Ceresnak SR, Pass RH, Krumerman AK, Kim SG, Nappo L, Fisher JD. Characteristics of ventricular tachycardia arising from the inflow region of the right ventricle. J Electrocardiol. 2012;45: 385-90.

90. Yamada T, Yoshida N, Litovsky SH, Itoh T, Doppalapudi H, Kay $\mathrm{GN}$. Idiopathic ventricular arrhythmias originating from the infundibular muscles: prevalence, electrocardiographic and electrophysiological characteristics, and outcome of catheter ablation. Circ Arrhythm Electrophysiol. 2018;11:e005749.

91. Li T, Zhan XZ, Xue YM, et al. Combined approach improves the outcomes of catheter ablation of idiopathic ventricular arrhythmias originating from the vicinity of tricuspid annulus. Pacing Clin Electrophysiol. 2014;37:624-9.

92. Lian-Pin W, Yue-Chun L, Jing-Lin Z, et al. Catheter ablation of idiopathic premature ventricular contractions and ventricular tachycardias originating from right ventricular septum. PLoS One. 2013;8:e67038.

93. Enriquez A, Pathak RK, Santangeli P, et al. Inferior lead discordance in ventricular arrhythmias: a specific marker for certain 
arrhythmia locations. J Cardiovasc Electrophysiol. 2017;28:117986.

94. Doppalapudi H, Yamada T, McElderry HT, Plumb VJ, Epstein AE, Kay GN. Ventricular tachycardia originating from the posterior papillary muscle in the left ventricle: a distinct clinical syndrome. Circ Arrhythm Electrophysiol. 2008;1:23-9.

95. Yamada T, Doppalapudi H, McElderry HT, et al. Idiopathic ventricular arrhythmias originating from the papillary muscles in the left ventricle: prevalence, electrocardiographic and electrophysiological characteristics, and results of the radiofrequency catheter ablation. J Cardiovasc Electrophysiol. 2010;21:62-9.

96. Yamada T, Doppalapudi H, McElderry HT, et al. Electrocardiographic and electrophysiological characteristics in idiopathic ventricular arrhythmias originating from the papillary muscles in the left ventricle: relevance for catheter ablation. Circ Arrhythm Electrophysiol. 2010;3:324-31.

97. Bassil G, Liu CF, Markowitz SM, et al. Comparison of robotic magnetic navigation-guided and manual catheter ablation of ventricular arrhythmias arising from the papillary muscles. Europace. 2018;20(Suppl. 2):ii5-ii10.

98. Ban JE, Lee HS, Lee DI, et al. Electrophysiological characteristics related to outcome after catheter ablation of idiopathic ventricular arrhythmia originating from the papillary muscle in the left ventricle. Korean Circ J. 2013;43:811-8.

99. Yokokawa M, Good E, Desjardins B, et al. Predictors of successful catheter ablation of ventricular arrhythmias arising from the papillary muscles. Heart Rhythm. 2010;7:1654-9.

100. Rivera S, Ricapito Mde L, Tomas L, et al. Results of cryoenergy and radiofrequency-based catheter ablation for treating ventricular arrhythmias arising from the papillary muscles of the left ventricle, guided by intracardiac echocardiography and image integration. Circ Arrhythm Electrophysiol. 2016;9:e003874.

101. Al'Aref SJ, Ip JE, Markowitz SM, et al. Differentiation of papillary muscle from fascicular and mitral annular ventricular arrhythmias in patients with and without structural heart disease. Circ Arrhythm Electrophysiol. 2015;8:616-24.

102. Wasmer K, Köbe J, Dechering DG, et al. Ventricular arrhythmias from the mitral annulus: patient characteristics, electrophysiological findings, ablation, and prognosis. Heart Rhythm. 2013;10: 783-8.

103. Kumagai K, Yamauchi Y, Takahashi A, et al. Idiopathic left ventricular tachycardia originating from the mitral annulus. $\mathrm{J}$ Cardiovasc Electrophysiol. 2005;16:1029-36.

104. Tada H, Ito $\mathrm{S}$, Naito $\mathrm{S}$, et al. Idiopathic ventricular arrhythmia arising from the mitral annulus: a distinct subgroup of idiopathic ventricular arrhythmias. J Am Coll Cardiol. 2005;45:877-86.

105. Yue-Chun L, Cheng Z, Jun H, Jun-Hua C, Jing-Lin Z, JiaFeng L. Catheter ablation of idiopathic premature ventricular contractions and ventricular tachycardias originating from the vicinity of endocardial and epicardial mitral annulus. PLoS One. 2013;8:e80777.

106. Yamada T, Doppalapudi H, McElderry HT, Kay GN. Idiopathic mitral annular PVCs with multiple breakouts and preferential conduction unmasked by radiofrequency catheter ablation. Pacing Clin Electrophysiol. 2012;35:e112-5.

107. Chen J, Hoff PI, Rossvoll O, et al. Ventricular arrhythmias originating from the aortomitral continuity: an uncommon variant of left ventricular outflow tract tachycardia. Europace. 2012;14:388 95.

108. Hai JJ, Chahal AA, Friedman PA, et al. Electrophysiologic characteristics of ventricular arrhythmias arising from the aortic mitral continuity-potential role of the conduction system. J Cardiovasc Electrophysiol. 2015;26:158-63.

109. Yamada T, McElderry HT, Doppalapudi H, et al. Idiopathic ventricular arrhythmias originating from the left ventricular summit: anatomic concepts relevant to ablation. Circ Arrhythm Electrophysiol. 2010;3:616-23.

110. Mountantonakis SE, Frankel DS, Tschabrunn CM, et al. Ventricular arrhythmias from the coronary venous system: prevalence, mapping, and ablation. Heart Rhythm. 2015;12:1145-53.

111. Meininger GR, Berger RD. Idiopathic ventricular tachycardia originating in the great cardiac vein. Heart Rhythm. 2006;3:464 6.

112. Yamada T, Doppalapudi H, Litovsky SH, McElderry HT, Kay GN. Challenging radiofrequency catheter ablation of idiopathic ventricular arrhythmias originating from the left ventricular summit near the left main coronary artery. Circ Arrhythm Electrophysiol. 2016;9:e004202.

113. Yokokawa M, Latchamsetty R, Good E, et al. Ablation of epicardial ventricular arrhythmias from nonepicardial sites. Heart Rhythm. 2011;8:1525-9.

114. Jauregui Abularach ME, Campos B, Park KM, et al. Ablation of ventricular arrhythmias arising near the anterior epicardial veins from the left sinus of Valsalva region: ECG features, anatomic distance, and outcome. Heart Rhythm. 2012;9:865-73.

115. Yokokawa M, Good E, Chugh A, et al. Intramural idiopathic ventricular arrhythmias originating in the intraventricular septum: mapping and ablation. Circ Arrhythm Electrophysiol. 2012;5: 258-63.

116. Doppalapudi H, Yamada T, Ramaswamy K, Ahn J, Kay GN. Idiopathic focal epicardial ventricular tachycardia originating from the crux of the heart. Heart Rhythm. 2009;6:44-50.

117. Kawamura M, Gerstenfeld EP, Vedantham V, et al. Idiopathic ventricular arrhythmia originating from the cardiac crux or inferior septum. Circ Arrhythm Electrophysiol. 2014;7:1152-8.

118. Larroussi L, Badhwar N. Ventricular tachycardia arising from cardiac crux: electrocardiogram recognition and site of ablation. Card Electrophysiol Clin. 2016;8:109-13.

119. Yui Y, Sekiguchi Y, Nogami A, et al. Electrophysiological characteristics and radiofrequency catheter ablation treatment of idiopathic ventricular arrhythmias successfully ablated from the ostium of the coronary sinus. Circ J. 2017;81:1807-15.

120. Komatsu Y, Otomo K, Taniguchi H, et al. Catheter ablation of ventricular arrhythmias arising from the right ventricular septum close to the His bundle: features of the local electrogram at the optimal ablation site. J Cardiovasc Electrophysiol. 2011;22:87885.

121. Yamada T, Plumb VJ, McElderry HT, Doppalapudi H, Epstein AE, Kay GN. Focal ventricular arrhythmias originating from the left ventricle adjacent to the membranous septum. Europace. 2010;12:1467-74.

122. Wei HQ, Guo XG, Liu X, et al. Safety and efficacy of catheter ablation of ventricular arrhythmias with para-Hisian origin via a systematic direct approach from the aortic sinus cusp. Heart Rhythm. 2018;15:1626-33.

123. Yamauchi Y, Aonuma K, Takahashi A, et al. Electrocardiographic characteristics of repetitive monomorphic right ventricular tachycardia originating near the His-bundle. J Cardiovasc Electrophysiol. 2005;16:1041-8.

124. Komatsu Y, Taniguchi H, Miyazaki S, et al. Two distinct electrocardiographic forms of idiopathic ventricular arrhythmia originating in the vicinity of the His bundle. Europace. 2012;14:1778-85.

125. Enriquez A, Tapias C, Rodriguez D, et al. How to map and ablate parahisian ventricular arrhythmias. Heart Rhythm. 2018;15:126874.

126. Santangeli P, Hutchinson MD, Supple GE, Callans DJ, Marchlinski FE, Garcia FC. Right atrial approach for ablation of ventricular arrhythmias arising from the left posterior-superior process of the left ventricle. Circ Arrhythm Electrophysiol. 2016;9:e004048. 
127. Li A, Zuberi Z, Bradfield JS, et al. Endocardial ablation of ventricular ectopic beats arising from the basal inferoseptal process of the left ventricle. Heart Rhythm. 2018;15:1356-62.

128. Tavares L, Dave A, Valderrábano M. Successful ablation of premature ventricular contractions originating from the inferoseptal process of the left ventricle using a coronary sinus approach. HeartRhythm Case Rep. 2018;4:371-4.

129. Latchamsetty RY, Morady M, Kim F, et al. Multicenter outcomes for catheter ablation of idiopathic premature ventricular complexes. JACC Clinical Electrophysiol. 2015;1:116-23.

130. Singh SN, Fletcher RD, Fisher SG, et al. Amiodarone in patients with congestive heart failure and asymptomatic ventricular arrhythmia: survival trial of antiarrhythmic therapy in congestive heart failure. N Engl J Med. 1995;333:77-82.

131. Mountantonakis SE, Frankel DS, Gerstenfeld EP, et al. Reversal of outflow tract ventricular premature depolarization-induced cardiomyopathy with ablation: effect of residual arrhythmia burden and preexisting cardiomyopathy on outcome. Heart Rhythm. 2011;8: 1608-14.

132. Zang M, Zhang T, Mao J, Zhou S, He B. Beneficial effects of catheter ablation of frequent premature ventricular complexes on left ventricular function. Heart. 2014;100:787-93.

133. Lee A, Denman R, Haqqani HM. Ventricular ectopy in the context of left ventricular systolic dysfunction: risk factors and outcomes following catheter ablation. Heart Lung Circ. 2019;28:379-88.

134. Takemoto M, Yoshimura H, Ohba Y, et al. Radiofrequency catheter ablation of premature ventricular complexes from right ventricular outflow tract improves left ventricular dilation and clinical status in patients without structural heart disease. J Am Coll Cardiol. 2005;45:1259-65.

135. Baman TS, Lange DC, Ilg KJ, et al. Relationship between burden of premature ventricular complexes and left ventricular function. Heart Rhythm. 2010;7:865-9.

136. Yarlagadda RK, Iwai S, Stein KM, et al. Reversal of cardiomyopathy in patients with repetitive monomorphic ventricular ectopy originating from the right ventricular outflow tract. Circulation. 2005; 112:1092-7.

137. Wijnmaalen AP, Delgado V, Schalij MJ, et al. Beneficial effects of catheter ablation on left ventricular and right ventricular function in patients with frequent premature ventricular contractions and preserved ejection fraction. Heart. 2010;96:1275-80.

138. Sarrazin JF, Labounty T, Kuhne M, et al. Impact of radiofrequency ablation of frequent post-infarction premature ventricular complexes on left ventricular ejection fraction. Heart Rhythm. 2009;6:1543-9.

139. El Kadri M, Yokokawa M, Labounty T, et al. Effect of ablation of frequent premature ventricular complexes on left ventricular function in patients with nonischemic cardiomyopathy. Heart Rhythm. 2015;12:706-13.

140. Haïssaguerre M, Shoda M, Jaïs P, et al. Mapping and ablation of idiopathic ventricular fibrillation. Circulation. 2002;106:962-7.

141. Knecht S, Sacher F, Wright M, et al. Long-term follow-up of idiopathic ventricular fibrillation ablation: a multicenter study. J Am Coll Cardiol. 2009;54:522-8.

142. Peichl P, Cihák R, Kozeluhová M, Wichterle D, Vancura V, Kautzner J. Catheter ablation of arrhythmic storm triggered by monomorphic ectopic beats in patients with coronary artery disease. J Interv Card Electrophysiol. 2010;27:51-9.

143. Haïssaguerre M, Extramiana F, Hocini M, et al. Mapping and ablation of ventricular fibrillation associated with long-QT and Brugada syndromes. Circulation. 2003;108:925-8.

144. Lakkireddy D, Di Biase L, Ryschon K, et al. Radiofrequency ablation of premature ventricular ectopy improves the efficacy of cardiac resynchronization therapy in nonresponders. J Am Coll Cardiol. 2012;60:1531-9.
145. Sapp JL, Wells GA, Parkash R, et al. Ventricular tachycardia ablation versus escalation of antiarrhythmic drugs. N Engl J Med. 2016;375:111-21.

146. Stevenson WG, Wilber DJ, Natale A, et al. Irrigated radiofrequency catheter ablation guided by electroanatomic mapping for recurrent ventricular tachycardia after myocardial infarction: the multicenter thermocool ventricular tachycardia ablation trial. Circulation. 2008;118:2773-82.

147. Tanner H, Hindricks G, Volkmer M, et al. Catheter ablation of recurrent scar-related ventricular tachycardia using electroanatomical mapping and irrigated ablation technology: results of the prospective multicenter Euro-VT-study. J Cardiovasc Electrophysiol. 2010;21:47-53.

148. Marchlinski FE, Haffajee CI, Beshai JF, et al. Long-term success of irrigated radiofrequency catheter ablation of sustained ventricular tachycardia: post-approval THERMOCOOL VT trial. J Am Coll Cardiol. 2016;67:674-83.

149. Carbucicchio C, Santamaria M, Trevisi N, et al. Catheter ablation for the treatment of electrical storm in patients with implantable cardioverter-defibrillators: short- and long-term outcomes in a prospective single-center study. Circulation. 2008;117:462-9.

150. Deneke T, Shin D, Lawo T, et al. Catheter ablation of electrical storm in a collaborative hospital network. Am J Cardiol. 2011;108:233-9.

151. Muser D, Liang JJ, Pathak RK, et al. Long-term outcomes of catheter ablation of electrical storm in nonischemic dilated cardiomyopathy compared with ischemic cardiomyopathy. JACC Clin Electrophysiol. 2017;3:767-78.

152. Kumar S, Fujii A, Kapur S, et al. Beyond the storm: comparison of clinical factors, arrhythmogenic substrate, and catheter ablation outcomes in structural heart disease patients with versus those without a history of ventricular tachycardia storm. J Cardiovasc Electrophysiol. 2017;28:56-67.

153. Nayyar S, Ganesan AN, Brooks AG, Sullivan T, RobertsThomson KC, Sanders P. Venturing into ventricular arrhythmia storm: a systematic review and meta-analysis. Eur Heart J. 2013;34:560-9.

154. Reddy VY, Reynolds MR, Neuzil P, et al. Prophylactic catheter ablation for the prevention of defibrillator therapy. N Engl J Med. 2007;357:2657-65.

155. Kuck KH, Schaumann A, Eckhardt L, et al. Catheter ablation of stable ventricular tachycardia before defibrillator implantation in patients with coronary heart disease (VTACH): a multicentre randomised controlled trial. Lancet. 2010;375:31-40.

156. Al-Khatib SM, Daubert JP, Anstrom KJ, et al. Catheter ablation for ventricular tachycardia in patients with an implantable cardioverter defibrillator (CALYPSO) pilot trial. J Cardiovasc Electrophysiol. 2015;26:151-7.

157. Kuck KH, Tilz RR, Deneke T, et al. Impact of substrate modification by catheter ablation on implantable cardioverter-defibrillator interventions in patients with unstable ventricular arrhythmias and coronary artery disease: results from the multicenter randomized controlled SMS (Substrate Modification Study). Circ Arrhythm Electrophysiol. 2017;10:e004422.

158. Littmann L, Svenson RH, Gallagher JJ, et al. Functional role of the epicardium in postinfarction ventricular tachycardia: observations derived from computerized epicardial activation mapping, entrainment, and epicardial laser photoablation. Circulation. 1991;83: 1577-91.

159. Sosa E, Scanavacca M, d'Avila A, Oliveira F, Ramires JA. Nonsurgical transthoracic epicardial catheter ablation to treat recurrent ventricular tachycardia occurring late after myocardial infarction. J Am Coll Cardiol. 2000;35:1442-9.

160. Schmidt B, Chun KR, Baensch D, Antz M, Koektuerk B, Tilz RR, et al. Catheter ablation for ventricular tachycardia after failed 
endocardial ablation: epicardial substrate or inappropriate endocardial ablation? Heart Rhythm. 2010;7:1746-52.

161. Di Biase L, Santangeli P, Burkhardt DJ, et al. Endo-epicardial homogenization of the scar versus limited endocardial substrate ablation for the treatment of electrical storms in patients with ischemic cardiomyopathy. J Am Coll Cardiol. 2012;60:132-41.

162. Izquierdo M, Sánchez-Gómez JM, Ferrero de Loma-Osorio A, Martínez A, Bellver A, Peláez A, et al. Endo-epicardial versus only-endocardial ablation as a first line strategy for the treatment of ventricular tachycardia in patients with ischemic heart disease. Circ Arrhythm Electrophysiol. 2015;8:882-9.

163. Muser D, Santangeli P, Castro SA, et al. Long-term outcome after catheter ablation of ventricular tachycardia in patients with nonischemic dilated cardiomyopathy. Circ Arrhythm Electrophysiol. 2016;9:e004328.

164. Proietti R, Essebag V, Beardsall J, et al. Substrate-guided ablation of haemodynamically tolerated and untolerated ventricular tachycardia in patients with structural heart disease: effect of cardiomyopathy type and acute success on long-term outcome. Europace. 2015; 17:461-7.

165. Dinov B, Arya A, Bertagnolli L, et al. Early referral for ablation of scar-related ventricular tachycardia is associated with improved acute and long-term outcomes: results from the Heart Center of Leipzig ventricular tachycardia registry. Circ Arrhythm Electrophysiol. 2014;7:1144-51.

166. Dinov B, Fiedler L, Schönbauer R, et al. Outcomes in catheter ablation of ventricular tachycardia in dilated nonischemic cardiomyopathy compared with ischemic cardiomyopathy: results from the Prospective Heart Centre of Leipzig VT (HELP-VT) study. Circulation. 2014;129:728-36.

167. Tokuda M, Tedrow UB, Kojodjojo P, et al. Catheter ablation of ventricular tachycardia in nonischemic heart disease. Circ Arrhythm Electrophysiol. 2012;5:992-1000.

168. Tung R, Vaseghi M, Frankel DS, et al. Freedom from recurrent ventricular tachycardia after catheter ablation is associated with improved survival in patients with structural heart disease: an International VT Ablation Center Collaborative Group study. Heart Rhythm. 2015;12:1997-2007.

169. Arya A, Bode K, Piorkowski C, et al. Catheter ablation of electrical storm due to monomorphic ventricular tachycardia in patients with nonischemic cardiomyopathy: acute results and its effect on long-term survival. Pacing Clin Electrophysiol. 2010;33:1504-9.

170. Hu J, Zeng S, Zhou Q, et al. Can ventricular tachycardia noninducibility after ablation predict reduced ventricular tachycardia recurrence and mortality in patients with non-ischemic cardiomyopathy? A meta-analysis of twenty-four observational studies. Int J Cardiol. 2016;222:689-95.

171. Della Bella P, Brugada J, Zeppenfeld K, et al. Epicardial ablation for ventricular tachycardia: a European multicenter study. Circ Arrhythm Electrophysiol. 2011;4:653-9.

172. Sacher F, Roberts-Thomson K, Maury P, et al. Epicardial ventricular tachycardia ablation a multicenter safety study. J Am Coll Cardiol. 2010;55:2366-72.

173. Cano O, Hutchinson M, Lin D, et al. Electroanatomic substrate and ablation outcome for suspected epicardial ventricular tachycardia in left ventricular nonischemic cardiomyopathy. J Am Coll Cardiol. 2009;54:799-808.

174. Jefic D, Joel B, Good E, et al. Role of radiofrequency catheter ablation of ventricular tachycardia in cardiac sarcoidosis: report from a multicenter registry. Heart Rhythm. 2009;6:189-95.

175. Naruse Y, Sekiguchi Y, Nogami A, et al. Systematic treatment approach to ventricular tachycardia in cardiac sarcoidosis. Circ Arrhythm Electrophysiol. 2014;7:407-13.

176. Kumar S, Barbhaiya C, Nagashima K, et al. Ventricular tachycardia in cardiac sarcoidosis: characterization of ventricular substrate and outcomes of catheter ablation. Circ Arrhythm Electrophysiol. 2015;8:87-93.

177. Muser D, Santangeli P, Pathak RK, et al. Long-term outcomes of catheter ablation of ventricular tachycardia in patients with cardiac sarcoidosis. Circ Arrhythm Electrophysiol. 2016;9:e004333.

178. Papageorgiou N, Providência R, Bronis K, et al. Catheter ablation for ventricular tachycardia in patients with cardiac sarcoidosis: a systematic review. Europace. 2018;20:682-91.

179. Kumar S, Androulakis AF, Sellal JM, et al. Multicenter experience with catheter ablation for ventricular tachycardia in lamin A/C cardiomyopathy. Circ Arrhythm Electrophysiol. 2016;9:e04357.

180. Cohen TJ, Chien WW, Lurie KG, et al. Radiofrequency catheter ablation for treatment of bundle branch reentrant ventricular tachycardia: results and long-term follow-up. J Am Coll Cardiol. 1991;18:1767-73.

181. Blank Z, Dhala A, Deshpande S, Sra J, Jazayeri M, Akhtar M. Bundle branch reentrant ventricular tachycardia: Cumulative experience in 48 patients. J Cardiovasc Electrophysiol. 1993;4:25362.

182. Mehdirad AA, Keim S, Rist K, Tchou P. Long-term clinical outcome of right bundle branch radiofrequency catheter ablation for treatment of bundle branch reentrant ventricular tachycardia. Pacing Clin Electrophysiol. 1995;18(12 Pt 1):2135-43.

183. Pathak RK, Fahed J, Santangeli P, et al. Long-term outcome of catheter ablation for treatment of bundle branch re-entrant tachycardia. JACC Clin Electrophysiol. 2018;4:331-8.

184. Narasimhan C, Jazayeri MR, Sra J, et al. Ventricular tachycardia in valvular heart disease: facilitation of bundle-branch reentry by valve surgery. Circulation. 1997;96:4307-13.

185. Li YG, Grönefeld G, Israel C, Bogun F, Hohnloser SH. Bundle branch reentrant tachycardia in patients with apparent normal HisPurkinje conduction: the role of functional conduction impairment. J Cardiovasc Electrophysiol. 2002;13:1233-9.

186. Schmidt B, Tang M, Chun KR, et al. Left bundle branch-Purkinje system in patients with bundle branch reentrant tachycardia: lessons from catheter ablation and electroanatomic mapping. Heart Rhythm. 2009;6:51-8.

187. Blanck Z, Jazayeri M, Dhala A, Deshpande S, Sra J, Akhtar M. Bundle branch reentry: a mechanism of ventricular tachycardia in the absence of myocardial or valvular dysfunction. J Am Coll Cardiol. 1993;22:1718-22.

188. Chen H, Shi L, Yang B, et al. Electrophysiological characteristics of bundle branch reentry ventricular tachycardia in patients without structural heart disease. Circ Arrhythm Electrophysiol. 2018;11:e006049.

189. Nogami A, Naito S, Tada H, et al. Demonstration of diastolic and presystolic Purkinje potentials as critical potentials in a macroreentry circuit of verapamil-sensitive idiopathic left ventricular tachycardia. J Am Coll Cardiol. 2000;36:811-23.

190. Ouyang F, Cappato R, Ernst S, et al. Electroanatomic substrate of idiopathic left ventricular tachycardia: unidirectional block and macroreentry within the Purkinje network. Circulation. 2002;105:462-9.

191. Liu Y, Fang Z, Yang B, et al. Catheter ablation of fascicular ventricular tachycardia: long-term clinical outcomes and mechanisms of recurrence. Circ Arrhythm Electrophysiol. 2015;8:1443-51.

192. Nakagawa H, Beckman KJ, McClelland JH, et al. Radiofrequency catheter ablation of idiopathic left ventricular tachycardia guided by a Purkinje potential. Circulation. 1993;88:2607-17.

193. Chen M, Yang B, Zou J, et al. Non-contact mapping and linear ablation of the left posterior fascicle during sinus rhythm in the treatment of idiopathic left ventricular tachycardia. Europace. 2005;7:138-44.

194. Kottkamp H, Chen X, Hindricks G, et al. Idiopathic left ventricular tachycardia: new insights into electrophysiological characteristics 
and radiofrequency catheter ablation. Pacing Clin Electrophysiol. 1995;18:1285-97.

195. Lin D, Hsia HH, Gerstenfeld EP, et al. Idiopathic fascicular left ventricular tachycardia: linear ablation lesion strategy for noninducible or nonsustained tachycardia. Heart Rhythm. 2005;2:934-9.

196. Tada H, Nogami A, Naito S, et al. Retrograde Purkinje potential activation during sinus rhythm following catheter ablation of idiopathic left ventricular tachycardia. J Cardiovasc Electrophysiol. 1998;9:1218-24.

197. Tsuchiya T, Okumura K, Honda T, et al. Significance of late diastolic potential preceding Purkinje potential in verapamil-sensitive idiopathic left ventricular tachycardia. Circulation. 1999;99:240813.

198. Wen MS, Yeh SJ, Wang CC, Lin FC, Wu D. Successful radiofrequency ablation of idiopathic left ventricular tachycardia at a site away from the tachycardia exit. J Am Coll Cardiol. 1997;30: 1024-31.

199. Arya A, Haghjoo M, Emkanjoo Z, et al. Comparison of presystolic Purkinje and late diastolic potentials for selection of ablation site in idiopathic verapamil sensitive left ventricular tachycardia. J Interv Card Electrophysiol. 2004;11:135-41.

200. Liu Q, Shehata M, Jiang R, et al. Macroreentrant loop in ventricular tachycardia from the left posterior fascicle: new implications for mapping and ablation. Circ Arrhythm Electrophysiol. 2016;9: e004272.

201. Guo XG, Liu X, Zhou GB, et al. Clinical, electrocardiographic, and electrophysiological characteristics of left upper septal fascicular ventricular tachycardia. Europace. 2018;20:673-81.

202. Collins KK, Schaffer MS, Liberman L, et al. Fascicular and nonfascicular left ventricular tachycardias in the young: an international multicenter study. J Cardiovasc Electrophysiol. 2013;24: 640-8.

203. Suzuki T, Nakamura Y, Yoshida S, et al. Radiofrequency catheter ablation of idiopathic left anterior fascicular ventricular tachycardia in children. Heart Rhythm. 2014;11:1948-56.

204. Fishberger SB, Olen MM, Rollinson NL, Rossi AF. Creation of partial fascicular block: an approach to ablation of idiopathic left ventricular tachycardia in the pediatric population. Pacing Clin Electrophysiol. 2015;38:209-15.

205. Saul JP, Kanter RJ, Abrams D, et al. PACES/HRS expert consensus statement on the use of catheter ablation in children and patients with congenital heart disease: developed in partnership with the Pediatric and Congenital Electrophysiology Society (PACES) and the Heart Rhythm Society (HRS). Endorsed by the governing bodies of PACES, HRS, the American Academy of Pediatrics (AAP), the American Heart Association (AHA), and the Association for European Pediatric and Congenital Cardiology (AEPC). Heart Rhythm. 2016;13:e251-89.

206. Talib AK, Nogami A, Morishima I, et al. Non-reentrant fascicular tachycardia: clinical and electrophysiological characteristics of a distinct type of idiopathic ventricular tachycardia. Circ Arrhythm Electrophysiol. 2016;9:e004177.

207. Lopera G, Stevenson WG, Soejima K, et al. Identification and ablation of three types of ventricular tachycardia involving the His-Purkinje system in patients with heart disease. J Cardiovasc Electrophysiol. 2004;15:52-8.

208. Gonzalez RP, Scheinman MM, Lesh MD, Helmy I, Torres V, Van Hare GF. Clinical and electrophysiologic spectrum of fascicular tachycardias. Am Heart J. 1994;128:147-56.

209. Nogami A. Purkinje-related arrhythmias. Part I: monomorphic ventricular tachycardias. Pacing Clin Electrophysiol. 2011;34: 624-50.

210. Hayashi M, Kobayashi Y, Iwasaki YK, et al. Novel mechanism of postinfarction ventricular tachycardia originating in surviving left posterior Purkinje fibers. Heart Rhythm. 2006;3:908-18.
211. Bogun F, Good E, Reich S, et al. Role of Purkinje fibers in postinfarction ventricular tachycardia. J Am Coll Cardiol. 2006;48: 2500-7.

212. Gatzoulis MA, Till JA, Somerville J, Redington AN. Mechanoelectrical interaction in tetralogy of Fallot. QRS prolongation relates to right ventricular size and predicts malignant ventricular arrhythmias and sudden death. Circulation. 1995;92:2317.

213. Harrison DA, Harris L, Siu SC, et al. Sustained ventricular tachycardia in adult patients late after repair of tetralogy of Fallot. J Am Coll Cardiol. 1997;30:1368-73.

214. Knauth AL, Gauvreau K, Powell AJ, et al. Ventricular size and function assessed by cardiac MRI predict major adverse clinical outcomes late after tetralogy of Fallot repair. Heart. 2008;94:2116.

215. Diller GP, Kempny A, Liodakis E, et al. Left ventricular longitudinal function predicts life-threatening ventricular arrhythmia and death in adults with repaired tetralogy of Fallot. Circulation. 2012;125:2440-6.

216. Koyak Z, Harris L, de Groot JR, et al. Sudden cardiac death in adult congenital heart disease. Circulation. 2012;126:1944-54.

217. Koyak Z, de Groot JR, Bouma BJ, et al. Sudden cardiac death in adult congenital heart disease: can the unpredictable be foreseen? Europace. 2017;19:401-6.

218. Deal BJ, Scagliotti D, Miller SM, Gallastegui JL, Hariman RJ, Levitsky S. Electrophysiologic drug testing in symptomatic ventricular arrhythmias after repair of tetralogy of Fallot. Am J Cardiol. 1987;59:1380-5.

219. Oechslin EN, Harrison DA, Harris L, et al. Reoperation in adults with repair of tetralogy of Fallot: indications and outcomes. J Thorac Cardiovasc Surg. 1999;118:245-51.

220. Therrien J, Siu SC, Harris L, et al. Impact of pulmonary valve replacement on arrhythmia propensity late after repair of tetralogy of Fallot. Circulation. 2001;103:2489-94.

221. Therrien J, Provost Y, Merchant N, Williams W, Colman J, Webb G. Optimal timing for pulmonary valve replacement in adults after tetralogy of Fallot repair. Am J Cardiol. 2005;95:779-82.

222. Mavroudis C, Deal BJ, Backer CL, Tsao S. Arrhythmia surgery in patients with and without congenital heart disease. Ann Thorac Surg. 2008;86:857-68.

223. Adamson L, Vohra HA, Haw MP. Does pulmonary valve replacement post repair of tetralogy of Fallot improve right ventricular function? Interact Cardiovasc Thorac Surg. 2009;9:520-7.

224. Miyazaki A, Sakaguchi H, Ohuchi H, et al. Efficacy of hemodynamic-based management of tachyarrhythmia after repair of tetralogy of Fallot. Circ J. 2012;76:2855-62.

225. Lin YS, Liu PH, Wu LS, Chen YM, Chang CJ, Chu PH. Major adverse cardiovascular events in adult congenital heart disease: a population-based follow-up study from Taiwan. BMC Cardiovasc Disord. 2014;14:38.

226. Sabate Rotes A, Connolly HM, Warnes CA, et al. Ventricular arrhythmia risk stratification in patients with tetralogy of Fallot at the time of pulmonary valve replacement. Circ Arrhythm Electrophysiol. 2015;8:110-6.

227. Gonska BD, Cao K, Raab J, Eigster G, Kreuzer H. Radiofrequency catheter ablation of right ventricular tachycardia late after repair of congenital heart defects. Circulation. 1996;94:1902-8.

228. Morwood JG, Triedman JK, Berul CI, et al. Radiofrequency catheter ablation of ventricular tachycardia in children and young adults with congenital heart disease. Heart Rhythm. 2004;1:3018.

229. Zeppenfeld K, Schalij MJ, Bartelings MM, et al. Catheter ablation of ventricular tachycardia after repair of congenital heart disease: electroanatomic identification of the critical right ventricular isthmus. Circulation. 2007;116:2241-52. 
230. Kriebel T, Saul JP, Schneider H, Sigler M, Paul T. Noncontact mapping and radiofrequency catheter ablation of fast and hemodynamically unstable ventricular tachycardia after surgical repair of tetralogy of Fallot. J Am Coll Cardiol. 2007;50:2162-8.

231. Kapel GF, Reichlin T, Wijnmaalen AP, et al. Left-sided ablation of ventricular tachycardia in adults with repaired tetralogy of Fallot: a case series. Circ Arrhythm Electrophysiol. 2014;7:889-97.

232. Kapel GF, Reichlin T, Wijnmaalen AP, et al. Re-entry using anatomically determined isthmuses: a curable ventricular tachycardia in repaired congenital heart disease. Circ Arrhythm Electrophysiol. 2015;8:102-9.

233. van Zyl M, Kapa S, Padmanabhan D, et al. Mechanism and outcomes of catheter ablation for ventricular tachycardia in adults with repaired congenital heart disease. Heart Rhythm. 2016;13: 1449-54.

234. Kapel GF, Sacher F, Dekkers OM, et al. Arrhythmogenic anatomical isthmuses identified by electroanatomical mapping are the substrate for ventricular tachycardia in repaired tetralogy of Fallot. Eur Heart J. 2017;38:268-76.

235. Sandhu A, Ruckdeschel E, Sauer WH, et al. Perioperative electrophysiology study in patients with tetralogy of Fallot undergoing pulmonary valve replacement will identify those at high risk of subsequent ventricular tachycardia. Heart Rhythm. 2018;15:67985.

236. Berruezo A, Acosta J, Fernández-Armenta J, et al. Safety, longterm outcomes and predictors of recurrence after first-line combined endoepicardial ventricular tachycardia substrate ablation in arrhythmogenic cardiomyopathy. Impact of arrhythmic substrate distribution pattern. A prospective multicentre study. Europace. 2017;19:607-16

237. Jiang H, Zhang X, Yang Q, et al. Catheter ablation for ventricular tachycardia in patients with arrhythmogenic right ventricular dysplasia/cardiomyopathy: a systematic review and meta-analysis. Acta Cardiol. 2016;71:639-49.

238. Philips B, te Riele AS, Sawant A, et al. Outcomes and ventricular tachycardia recurrence characteristics after epicardial ablation of ventricular tachycardia in arrhythmogenic right ventricular dysplasia/cardiomyopathy. Heart Rhythm. 2015;12:716-25.

239. Santangeli P, Zado ES, Supple GE, et al. Long-term outcome with catheter ablation of ventricular tachycardia in patients with arrhythmogenic right ventricular cardiomyopathy. Circ Arrhythm Electrophysiol. 2015;8:1413-21.

240. Philips B, Madhavan S, James C, et al. Outcomes of catheter ablation of ventricular tachycardia in arrhythmogenic right ventricular dysplasia/cardiomyopathy. Circ Arrhythm Electrophysiol. 2012;5:499-505.

241. Bai R, Di Biase L, Shivkumar K, et al. Ablation of ventricular arrhythmias in arrhythmogenic right ventricular dysplasia/cardiomyopathy: arrhythmia-free survival after endo-epicardial substrate based mapping and ablation. Circ Arrhythm Electrophysiol. 2011;4:478-85.

242. Garcia FC, Bazan V, Zado ES, Ren JF, Marchlinski FE. Epicardial substrate and outcome with epicardial ablation of ventricular tachycardia in arrhythmogenic right ventricular cardiomyopathy/ dysplasia. Circulation. 2009;120:366-75.

243. Dalal D, Jain R, Tandri H, et al. Long-term efficacy of catheter ablation of ventricular tachycardia in patients with arrhythmogenic right ventricular dysplasia/cardiomyopathy. J Am Coll Cardiol. 2007;50:432-40.

244. Verma A, Kilicaslan F, Schweikert RA, et al. Short- and long-term success of substrate-based mapping and ablation of ventricular tachycardia in arrhythmogenic right ventricular dysplasia. Circulation. 2005;111:3209-16.

245. Marchlinski FE, Zado E, Dixit S, et al. Electroanatomic substrate and outcome of catheter ablative therapy for ventricular tachycardia in setting of right ventricular cardiomyopathy. Circulation. 2004;110:2293-8.

246. Nogami A, Sugiyasu A, Tada $\mathrm{H}$, et al. Changes in the isolated delayed component as an endpoint of catheter ablation in arrhythmogenic right ventricular cardiomyopathy: predictor for long-term success. J Cardiovasc Electrophysiol. 2008;19:681-8.

247. Müssigbrodt A, Efimova E, Knopp H, et al. Should all patients with arrhythmogenic right ventricular dysplasia/cardiomyopathy undergo epicardial catheter ablation? J Interv Card Electrophysiol. 2017:48:193-9.

248. Pokushalov E, Romanov A, Turov A, Artyomenko S, Shirokova N, Karaskov A. Percutaneous epicardial ablation of ventricular tachycardia after failure of endocardial approach in the pediatric population with arrhythmogenic right ventricular dysplasia. Heart Rhythm. 2010;7:1406-10.

249. Pappone C, Brugada J, Vicedomini G, et al. Electrical substrate elimination in 135 consecutive patients with Brugada syndrome. Circ Arrhythm Electrophysiol. 2017;10:e005053.

250. Brugada J, Pappone C, Berruezo A, et al. Brugada syndrome phenotype elimination by epicardial substrate ablation. Circ Arrhythm Electrophysiol. 2015;8:1373-81.

251. Zhang P, Tung R, Zhang Z, et al. Characterization of the epicardial substrate for catheter ablation of Brugada syndrome. Heart Rhythm. 2016;13:2151-8.

252. Nademanee K, Veerakul G, Chandanamattha P, et al. Prevention of ventricular fibrillation episodes in Brugada syndrome by catheter ablation over the anterior right ventricular outflow tract epicardium. Circulation. 2011;123:1270-9.

253. Berruezo A, Fernández-Armenta J, Mont L, et al. Combined endocardial and epicardial catheter ablation in arrhythmogenic right ventricular dysplasia incorporating scar dechanneling technique. Circ Arrhythm Electrophysiol. 2012;5:111-21.

254. Dukkipati SR, d'Avila A, Soejima K, et al. Long-term outcomes of combined epicardial and endocardial ablation of monomorphic ventricular tachycardia related to hypertrophic cardiomyopathy. Circ Arrhythm Electrophysiol. 2011;4:185-94.

255. Santangeli P, Di Biase L, Lakkireddy D, et al. Radiofrequency catheter ablation of ventricular arrhythmias in patients with hypertrophic cardiomyopathy: safety and feasibility. Heart Rhythm. 2010;7:1036-42.

256. Ueda A, Fukamizu S, Soejima K, et al. Clinical and electrophysiological characteristics in patients with sustained monomorphic reentrant ventricular tachycardia associated with dilated-phase hypertrophic cardiomyopathy. Europace. 2012;14:734 40.

257. Inada K, Seiler J, Roberts-Thomson KC, et al. Substrate characterization and catheter ablation for monomorphic ventricular tachycardia in patients with apical hypertrophic cardiomyopathy. J Cardiovasc Electrophysiol. 2011;22:41-8.

258. Igarashi M, Nogami A, Kurosaki K, et al. Radiofrequency catheter ablation of ventricular tachycardia in patients with hypertrophic cardiomyopathy and apical aneurysm. JACC Clin Electrophysiol. 2018;4:339-50.

259. Visser CA, Kan G, David GK, Lie KI, Durrer D. Two dimensional echocardiography in the diagnosis of left ventricular thrombus: a prospective study of 67 patients with anatomic validation. Chest. 1983;83:228-32.

260. Ezekowitz MD, Wilson DA, Smith EO, et al. Comparison of Indium-111 platelet scintigraphy and two-dimensional echocardiography in the diagnosis of left ventricular thrombi. N Engl J Med. 1982;306:1509-13.

261. Stratton JR, Lighty GW Jr, Pearlman AS, Ritchie JL. Detection of left ventricular thrombus by two-dimensional echocardiography: sensitivity, specificity, and causes of uncertainty. Circulation. 1982;66:156-66.

262. Thanigaraj S, Schechtman KB, Perez JE. Improved echocardiographic delineation of left ventricular thrombus with the use of 
intravenous second-generation contrast image enhancement. J Am Soc Echocardiogr. 1999;12:1022-6.

263. Weinsaft JW, Kim HW, Shah DJ, et al. Detection of left ventricular thrombus by delayed-enhancement cardiovascular magnetic resonance prevalence and markers in patients with systolic dysfunction. J Am Coll Cardiol. 2008;52:148-57.

264. Weinsaft JW, Kim RJ, Ross M, et al. Contrast-enhanced anatomic imaging as compared to contrast-enhanced tissue characterization for detection of left ventricular thrombus. JACC Cardiovasc Imaging. 2009;2:969-79.

265. Siontis KC, Kim HM, Sharaf Dabbagh G, et al. Association of preprocedural cardiac magnetic resonance imaging with outcomes of ventricular tachycardia ablation in patients with idiopathic dilated cardiomyopathy. Heart Rhythm. 2017;14:1487-93.

266. Zghaib T, Ipek EG, Hansford R, et al. Standard ablation versus magnetic resonance imaging-guided ablation in the treatment of ventricular tachycardia. Circ Arrhythm Electrophysiol. 2018;11: e005973.

267. Andreu D, Penela D, Acosta J, et al. Cardiac magnetic resonanceaided scar dechanneling: Influence on acute and long-term outcomes. Heart Rhythm. 2017;14:1121-8.

268. Codreanu A, Odille F, Aliot E, et al. Electroanatomic characterization of post-infarct scars comparison with 3-dimensional myocardial scar reconstruction based on magnetic resonance imaging. J Am Coll Cardiol. 2008;52:839-42.

269. Desjardins B, Crawford T, Good E, et al. Infarct architecture and characteristics on delayed enhanced magnetic resonance imaging and electroanatomic mapping in patients with postinfarction ventricular arrhythmia. Heart Rhythm. 2009;6:644-51.

270. Bogun FM, Desjardins B, Good E, et al. Delayed-enhanced magnetic resonance imaging in nonischemic cardiomyopathy: utility for identifying the ventricular arrhythmia substrate. J Am Coll Cardiol. 2009;53:1138-45.

271. Dickfeld T, Tian J, Ahmad G, et al. MRI-guided ventricular tachycardia ablation: integration of late gadolinium-enhanced 3D scar in patients with implantable cardioverter-defibrillators. Circ Arrhythm Electrophysiol. 2011;4:172-84.

272. Fernandez-Armenta J, Berruezo A, Andreu D, et al. Threedimensional architecture of scar and conducting channels based on high resolution ce-CMR: insights for ventricular tachycardia ablation. Circ Arrhythm Electrophysiol. 2013;6:528-37.

273. Gupta S, Desjardins B, Baman T, et al. Delayed-enhanced MR scar imaging and intraprocedural registration into an electroanatomical mapping system in post-infarction patients. JACC Cardiovasc Imaging. 2012;5:207-10.

274. Marra MP, Leoni L, Bauce B, et al. Imaging study of ventricular scar in arrhythmogenic right ventricular cardiomyopathy: comparison of 3D standard electroanatomical voltage mapping and contrast-enhanced cardiac magnetic resonance. Circ Arrhythm Electrophysiol. 2012;5:91-100.

275. Nakahara S, Vaseghi M, Ramirez RJ, et al. Characterization of myocardial scars: electrophysiological imaging correlates in a porcine infarct model. Heart Rhythm. 2011;8:1060-7.

276. Ghannam M, Cochet H, Jais P, et al. Correlation between computer tomography-derived scar topography and critical ablation sites in postinfarction ventricular tachycardia. J Cardiovasc Electrophysiol. 2018;29:438-45.

277. Esposito A, Palmisano A, Antunes S, et al. Cardiac CT with delayed enhancement in the characterization of ventricular tachycardia structural substrate: relationship between CT-segmented scar and electro-anatomic mapping. JACC Cardiovasc Imaging. 2016;9:822-32.

278. Tian J, Jeudy J, Smith MF, et al. Three-dimensional contrast-enhanced multidetector CT for anatomic, dynamic, and perfusion characterization of abnormal myocardium to guide ventricular tachycardia ablations. Circ Arrhythm Electrophysiol. 2010;3: 496-504.

279. Yamashita S, Sacher F, Mahida S, et al. Image integration to guide catheter ablation in scar-related ventricular tachycardia. J Cardiovasc Electrophysiol. 2016;27:699-708.

280. Komatsu Y, Cochet H, Jadidi A, et al. Regional myocardial wall thinning at multidetector computed tomography correlates to arrhythmogenic substrate in postinfarction ventricular tachycardia: assessment of structural and electrical substrate. Circ Arrhythm Electrophysiol. 2013;6:342-50.

281. Dickfeld T, Lei P, Dilsizian V, et al. Integration of threedimensional scar maps for ventricular tachycardia ablation with positron emission tomography-computed tomography. JACC Cardiovasc Imaging. 2008;1:73-82.

282. Tian J, Smith MF, Chinnadurai P, et al. Clinical application of $\mathrm{PET} / \mathrm{CT}$ fusion imaging for three-dimensional myocardial scar and left ventricular anatomy during ventricular tachycardia ablation. J Cardiovasc Electrophysiol. 2009;20:567-604.

283. Andreu D, Ortiz-Perez JT, Boussy T, et al. Usefulness of contrastenhanced cardiac magnetic resonance in identifying the ventricular arrhythmia substrate and the approach needed for ablation. Eur Heart J. 2014;35:1316-26.

284. Soto-Iglesias D, Acosta J, Penela D, et al. Image-based criteria to identify the presence of epicardial arrhythmogenic substrate in patients with transmural myocardial infarction. Heart Rhythm. 2018;15:814-21.

285. Wutzler A, Mueller A, Loehr L, et al. Minimal and deep sedation during ablation of ventricular tachycardia. Int J Cardiol. 2014;172: $161-4$.

286. Servatius H, Höfeler T, Hoffmann BA, et al. Propofol sedation administered by cardiologists for patients undergoing catheter ablation for ventricular tachycardia. Europace. 2016;18:1245-51.

287. Nazer B, Woods C, Dewland T, Moyers B, Badhwar N, Gerstenfeld EP. Importance of ventricular tachycardia induction and mapping for patients referred for epicardial ablation. Pacing Clin Electrophysiol. 2015;38:1333-42.

288. Sharma PS, Padala SK, Gunda S, Koneru JN, Ellenbogen KA. Vascular complications during catheter ablation of cardiac arrhythmias: a comparison between vascular ultrasound guided access and conventional vascular access. J Cardiovasc Electrophysiol. 2016;27:1160-6.

289. Tanaka-Esposito CC, Chung MK, Abraham JM, Cantillon DJ, Abi-Saleh B, Tchou PJ. Real-time ultrasound guidance reduces total and major vascular complications in patients undergoing pulmonary vein antral isolation on therapeutic warfarin. J Interv Card Electrophysiol. 2013;37:163-8.

290. Yamagata K, Wichterle D, Roubíček T, et al. Ultrasound-guided versus conventional femoral venipuncture for catheter ablation of atrial fibrillation: a multicentre randomized efficacy and safety trial (ULTRA-FAST trial). Europace. 2018;20:1107-14.

291. Sobolev M, Shiloh AL, Di Biase L, Slovut DP. Ultrasound-guided cannulation of the femoral vein in electrophysiological procedures: a systematic review and meta-analysis. Europace. 2017;19:850-5.

292. Seto AH, Abu-Fadel MS, Sparling JM, et al. Real-time ultrasound guidance facilitates femoral arterial access and reduces vascular complications: FAUST (Femoral Arterial Access With Ultrasound Trial). JACC Cardiovasc Interv. 2010;3:751-8.

293. Miller MA, Dukkipati SR, Mittnacht AJ, et al. Activation and entrainment mapping of hemodynamically unstable ventricular tachycardia using a percutaneous left ventricular assist device. J Am Coll Cardiol. 2011;58:1363-71.

294. Reddy YM, Chinitz L, Mansour M, et al. Percutaneous left ventricular assist devices in ventricular tachycardia ablation: multicenter experience. Circ Arrhythm Electrophysiol. 2014;7:244-50. 
295. Baratto F, Pappalardo F, Oloriz T, et al. Extracorporeal membrane oxygenation for hemodynamic support of ventricular tachycardia ablation. Circ Arrhythm Electrophysiol. 2016;9: e004492.

296. Kusa S, Miller MA, Whang W, et al. Outcomes of ventricular tachycardia ablation using percutaneous left ventricular assist devices. Circ Arrhythm Electrophysiol. 2017;10:e004717.

297. Mathuria N, Wu G, Rojas-Delgado F, et al. Outcomes of preemptive and rescue use of percutaneous left ventricular assist device in patients with structural heart disease undergoing catheter ablation of ventricular tachycardia. J Interv Card Electrophysiol. 2017;48:27-34

298. Turagam MK, Vuddanda V, Atkins D, et al. Hemodynamic support in ventricular tachycardia ablation: an International VT Ablation Center Collaborative Group Study. JACC Clin Electrophysiol. 2017;3:1534-43

299. Enriquez A, Liang J, Gentile J, et al. Outcomes of rescue cardiopulmonary support for periprocedural acute hemodynamic decompensation in patients undergoing catheter ablation of electrical storm. Heart Rhythm. 2018;15:75-80.

300. Calkins H, Epstein A, Packer D, et al. Catheter ablation of ventricular tachycardia in patients with structural heart disease using cooled radiofrequency energy: results of a prospective multicenter study. Cooled RF Multi Center Investigators Group. J Am Coll Cardiol. 2000;35:1905-14.

301. Siontis KC, Jamé S, Sharaf Dabbagh G, et al. Thromboembolic prophylaxis protocol with warfarin after radiofrequency catheter ablation of infarct-related ventricular tachycardia. J Cardiovasc Electrophysiol. 2018;29:584-90.

302. Di Biase L, Burkhardt JD, Lakkireddy D, et al. Ablation of stable VTs versus substrate ablation in ischemic cardiomyopathy: the VISTA randomized multicenter trial. J Am Coll Cardiol. 2015;66:2872-82.

303. Volkmer M, Ouyang F, Deger F, et al. Substrate mapping vs. tachycardia mapping using CARTO in patients with coronary artery disease and ventricular tachycardia: impact on outcome of catheter ablation. Europace. 2006;8:968-76.

304. Makimoto H, Nakajima I, Miyamoto K, et al. Clinical impact of mapping strategies for treatment of ventricular tachycardias in patients with structural heart disease. Pacing Clin Electrophysiol. 2015;38:630-40.

305. Carbucicchio C, Ahmad Raja N, Di Biase L, et al. High-density substrate-guided ventricular tachycardia ablation: role of activation mapping in an attempt to improve procedural effectiveness. Heart Rhythm. 2013;10:1850-8.

306. Briceño DF, Romero J, Villablanca PA, et al. Long-term outcomes of different ablation strategies for ventricular tachycardia in patients with structural heart disease: systematic review and metaanalysis. Europace. 2018;20:104-15.

307. Kumar S, Baldinger SH, Romero J, et al. Substrate-based ablation versus ablation guided by activation and entrainment mapping for ventricular tachycardia: a systematic review and meta-analysis. J Cardiovasc Electrophysiol. 2016;27:1437-47.

308. Acosta J, Penela D. Andreu D, et al. Multielectrode vs. point-bypoint mapping for ventricular tachycardia substrate ablation: a randomized study. Europace. 2018;20:512-9.

309. Berte B, Relan J, Sacher F, et al. Impact of electrode type on mapping of scar-related VT. J Cardiovasc Electrophysiol. 2015;26:1213-23.

310. Yamashita S, Cochet H, Sacher F, et al. Impact of new technologies and approaches for post-myocardial infarction ventricular tachycardia ablation during long-term follow-up. Circ Arrhythm Electrophysiol. 2016;9:e003901.

311. Hutchinson MD, Gerstenfeld EP, Desjardins B, et al. Endocardial unipolar voltage mapping to detect epicardial ventricular tachycardia substrate in patients with nonischemic left ventricular cardiomyopathy. Circ Arrhythmia Electrophysiol. 2011;4:49-55.

312. Polin GM, Haqqani H, Tzou W, et al. Endocardial unipolar voltage mapping to identify epicardial substrate in arrhythmogenic right ventricular cardiomyopathy/dysplasia. Heart Rhythm. 2011;8:7683.

313. Chopra N, Tokuda M, Ng J, et al. Relation of the unipolar lowvoltage penumbra surrounding the endocardial low-voltage scar to ventricular tachycardia circuit sites and ablation outcomes in ischemic cardiomyopathy. J Cardiovasc Electrophysiol. 2014;25: $602-8$.

314. Soto-Becerra R, Bazan V, Bautista W, et al. Ventricular tachycardia in the setting of Chagasic cardiomyopathy. Circ Arrhythm Electrophysiol. 2017;10:e004950.

315. Hoffmayer KS, Dewland TA, Hsia HH, et al. Safety of radiofrequency catheter ablation without coronary angiography in aortic cusp ventricular arrhythmias. Heart Rhythm. 2014;11:1117-21.

316. Hachiya H, Aonuma K, Yamauchi Y, Igawa M, Nogami A, Iesaka Y. How to diagnose, locate, and ablate coronary cusp ventricular tachycardia. J Cardiovasc Electrophysiol. 2002;13:551-6.

317. Yamada T, McElderry HT, Doppalapudi H, et al. Idiopathic ventricular arrhythmias originating from the aortic root prevalence, electrocardiographic and electrophysiologic characteristics, and results of radiofrequency catheter ablation. J Am Coll Cardiol. 2008;52:139-47.

318. D'Avila A, Gutierrez P, Scanavacca M, et al. Effects of radiofrequency pulses delivered in the vicinity of the coronary arteries: implications for nonsurgical transthoracic epicardial catheter ablation to treat ventricular tachycardia. Pacing Clin Electrophysiol. 2002;25:1488-95.

319. Good E, Desjardins B, Jongnarangsin K, et al. Ventricular arrhythmias originating from a papillary muscle in patients without prior infarction: a comparison with fascicular arrhythmias. Heart Rhythm. 2008;5:1530-7.

320. Proietti R, Rivera S, Dussault C, et al. Intracardiac echo-facilitated 3D electroanatomical mapping of ventricular arrhythmias from the papillary muscles: assessing the 'fourth dimension' during ablation. Europace. 2017;19:21-8.

321. Peichl P, Baran J, Wichterle D, et al. The tip of the muscle is a dominant location of ventricular ectopy originating from papillary muscles in the left ventricle. J Cardiovasc Electrophysiol. 2018;29:64-70.

322. Lee A, Hamilton-Craig C, Denman R, Haqqani HM. Catheter ablation of papillary muscle arrhythmias: implications of mitral valve prolapse and systolic dysfunction. Pacing Clin Electrophysiol. 2018;41:750-8.

323. Ren JF, Marchlinski FE. Early detection of iatrogenic pericardial effusion: importance of intracardiac echocardiography. JACC Cardiovasc Interv. 2010;3:127.

324. Filgueiras-Rama D, de Torres-Alba F, Castrejón-Castrejón S, et al. Utility of intracardiac echocardiography for catheter ablation of complex cardiac arrhythmias in a medium-volume training center. Echocardiography. 2015;32:660-70.

325. Weintraub AR, Schwartz SL, Smith J, Hsu TL, Pandian NG. Intracardiac two-dimensional echocardiography in patients with pericardial effusion and cardiac tamponade. J Am Soc Echocardiogr. 1991;4:571-6.

326. Bala R, Ren JF, Hutchinson MD, et al. Assessing epicardial substrate using intracardiac echocardiography during VT ablation. Circ Arrhythm Electrophysiol. 2011;4:667-73.

327. Peichl P, Wichterle D, Cihak R, Aldhoon B, Kautzner J. Catheter ablation of ventricular tachycardia in the presence of an old endocavitary thrombus guided by intracardiac echocardiography. Pacing Clin Electrophysiol. 2016;39:581-7. 
328. Khaykin Y, Skanes A, Whaley B, et al. Real-time integration of 2D intracardiac echocardiography and 3D electroanatomical mapping to guide ventricular tachycardia ablation. Heart Rhythm. 2008;5:1396-402.

329. Sporton SC, Earley MJ, Nathan AW, Schilling RJ. Electroanatomic versus fluoroscopic mapping for catheter ablation procedures: a prospective randomized study. J Cardiovasc Electrophysiol. 2004;15:310-5.

330. Earley MJ, Showkathali R, Alzetani M, et al. Radiofrequency ablation of arrhythmias guided by non-fluoroscopic catheter location: a prospective randomized trial. Eur Heart J. 2006;27:1223-9.

331. Marchlinski FE, Callans DJ, Gottlieb CD, Zado E. Linear ablation lesions for control of unmappable ventricular tachycardia in patients with ischemic and nonischemic cardiomyopathy. Circulation. 2000;101:1288-96.

332. Khongphatthanayothin A, Kosar E, Nademanee K. Nonfluoroscopic three-dimensional mapping for arrhythmia ablation: tool or toy? J Cardiovasc Electrophysiol. 2000;11:239-43.

333. Reithmann C, Hahnefeld A, Remp T, et al. Electroanatomic mapping of endocardial right ventricular activation as a guide for catheter ablation in patients with arrhythmogenic right ventricular dysplasia. Pacing Clin Electrophysiol. 2003;26:1308-16.

334. Zeppenfeld K, Schalij MJ, Bartelings MM, et al. Catheter ablation of ventricular tachycardia after repair of congenital heart disease. Circulation. 2007;116:2241-52.

335. Dinov B, Schoenbauer R, Wojdyla-Horodynska A, et al. Longterm efficacy of single procedure remote magnetic catheter navigation for ablation of ischemic ventricular tachycardia: a retrospective study. J Cardiovasc Electrophysiol. 2012;23:499-505.

336. Szili-Torok T, Schwagten B, Akca F, et al. Catheter ablation of ventricular tachycardias using remote magnetic navigation: a consecutive case-control study. J Cardiovasc Electrophysiol. 2012;23: 948-54.

337. Akca F, Theuns DA, Abkenari LD, de Groot NM, Jordaens L, Szili-Torok T. Outcomes of repeat catheter ablation using magnetic navigation or conventional ablation. Europace. 2013;15:142631.

338. Bauernfeind T, Akca F, Schwagten B, et al. The magnetic navigation system allows safety and high efficacy for ablation of arrhythmias. Europace. 2011;13:1015-21.

339. Jais P, Maury P, Khairy P, et al. Elimination of local abnormal ventricular activities: a new end point for substrate modification in patients with scar-related ventricular tachycardia. Circulation. 2012;125:2184-96.

340. Tilz RR, Makimoto H, Lin T, et al. Electrical isolation of a substrate after myocardial infarction: a novel ablation strategy for unmappable ventricular tachycardias-feasibility and clinical outcome. Europace. 2014;16:1040-52.

341. Tzou WS, Frankel DS, Hegeman T, et al. Core isolation of critical arrhythmia elements for treatment of multiple scarbased ventricular tachycardias. Circ Arrhythm Electrophysiol. 2015;8:353-61.

342. Silberbauer J, Oloriz T, Maccabelli G, et al. Noninducibility and late potential abolition: a novel combined prognostic procedural end point for catheter ablation of postinfarction ventricular tachycardia. Circ Arrhythm Electrophysiol. 2014;7:424-35.

343. Wolf M, Sacher F, Cochet H, et al. Long-term outcome of substrate modification in ablation of post-myocardial infarction ventricular tachycardia. Circ Arrhythm Electrophysiol. 2018;11:e005635.

344. Berruezo A, Fernandez-Armenta J, Andreu D, et al. Scar dechanneling: new method for scar-related left ventricular tachycardia substrate ablation. Circ Arrhythm Electrophysiol. 2015;8: 326-36.
345. Porta-Sanchez A, Jackson N, Lukac P, et al. Multicenter study of ischemic ventricular tachycardia ablation with decrement-evoked potential (DEEP) mapping with extra stimulus. JACC Clin Electrophysiol. 2018;4:307-15.

346. de Riva M, Naruse Y, Ebert M, et al. Targeting the hidden substrate unmasked by right ventricular extrastimulation improves ventricular tachycardia ablation outcome after myocardial infarction. JACC Clin Electrophysiol. 2018;4:316-27.

347. Koplan BA, Soejima K, Baughman KL, Epstein LM, Stevenson WG. Refractory ventricular tachycardia secondary to cardiac sarcoid: electrophysiologic characteristics, mapping, and ablation. Heart Rhythm. 2006;3:924-9.

348. Dechering DG, Kochhaüser S, Wasmer K, et al. Electrophysiological characteristics of ventricular tachyarrhythmias in cardiac sarcoidosis versus arrhythmogenic right ventricular cardiomyopathy. Heart Rhythm. 2013;10:158-64.

349. Calkins H, Epstein A, Packer D, et al. Catheter ablation of ventricular tachycardia in patients with structural heart disease using cooled radiofrequency energy: results of a prospective multicenter study. J Am Coll Cardiol. 2000;35:1905-14.

350. Palaniswamy C, Kolte D, Harikrishnan P, et al. Catheter ablation of postinfarction ventricular tachycardia: ten-year trends in utilization, in-hospital complications, and inhospital mortality in the United States. Heart Rhythm. 2014;11:2056-63.

351. Santangeli P, Muser D, Zado ES, et al. Acute hemodynamic decompensation during catheter ablation of scar-related ventricular tachycardia: incidence, predictors, and impact on mortality. Circ Arrhythm Electrophysiol. 2015;8:68-75.

352. Katz DF, Turakhia MP, Sauer WH, et al. Safety of ventricular tachycardia ablation in clinical practice: findings from 9699 hospital discharge records. Circ Arrhythmia Electrophysiol. 2015;8: 362-70.

353. Santangeli P, Frankel DS, Tung R, et al. Early mortality after catheter ablation of ventricular tachycardia in patients with structural heart disease. J Am Coll Cardiol. 2017;69:2105-15.

354. Jackson N, McGee M, Ahmed W, et al. Groin haemostasis with a purse string suture for patients following catheter ablation procedures (GITAR study). Heart Lung Circ. 2018. https://doi.org/10. 1016/j.hlc.2018.03.011.

355. Pracon R, Bangalore S, Henzel J, et al. A randomized comparison of modified subcutaneous "Z"-stitch versus manual compression to achieve hemostasis after large caliber femoral venous sheath removal. Catheter Cardiovasc Interv. 2018;91:105-12.

356. Ben-Dor I, Craig P, Torguson R, et al. MynxGrip vascular closure device versus manual compression for hemostasis of percutaneous transfemoral venous access closure: results from a prospective multicenter randomized study. Cardiovasc Revasc Med. 2018;19:418-22.

357. Robertson L, Andras A, Colgan F, Jackson R. Vascular closure devices for femoral arterial puncture site haemostasis. Cochrane Database Syst Rev. 2016;3:CD009541.

358. Jiang J, Zou J, Ma H, et al. Network meta-analysis of randomized trials on the safety of vascular closure devices for femoral arterial puncture site haemostasis. Sci Rep. 2015;5:13761.

359. Dyrda K, Piers SR, van Huls van Taxis CF, Schalij MJ, Zeppenfeld $\mathrm{K}$. Influence of steroid therapy on the incidence of pericarditis and atrial fibrillation after percutaneous epicardial mapping and ablation for ventricular tachycardia. Circ Arrhythm Electrophysiol. 2014;7:671-6.

360. Patel AA, Clyne CA, Henyan NN, et al. The use of protamine after radiofrequency catheter ablation: a pilot study. J Interv Card Electrophysiol. 2007;18:155-8. 
361. Ghannam M, Chugh A, Dillon P, et al. Protamine to expedite vascular hemostasis after catheter ablation of atrial fibrillation: a randomized controlled trial. Heart Rhythm. 2018;15:1642-7.

362. Cheitlin MD, Alpert JS, Armstrong WF, et al. ACC/AHA guidelines for the clinical application of echocardiography: a report of the American College of Cardiology/American Heart Association Task Force on Practice Guidelines (Committee on Clinical Application of Echocardiography). Circulation. 1997;95:1686744.

363. Frankel DS, Mountantonakis SE, Zado ES, et al. Noninvasive programmed ventricular stimulation early after ventricular tachycardia ablation to predict risk of late recurrence. J Am Coll Cardiol. 2012;59:1529-35.

364. Oloriz T, Baratto F, Trevisi N, et al. Defining the outcome of ventricular tachycardia ablation: timing and value of programmed ventricular stimulation. Circ Arrhythm Electrophysiol. 2018;11: $\mathrm{e} 005602$.

Publisher's note Springer Nature remains neutral with regard to jurisdictional claims in published maps and institutional affiliations.

\section{Affiliations}

Edmond M. Cronin ${ }^{1} \cdot$ Frank M. Bogun ${ }^{2} \cdot$ Philippe Maury $^{3} \cdot$ Petr Peichl $^{4} \cdot$ Minglong Chen $^{5} \cdot$ Narayanan Namboodiri $^{6}$. Luis Aguinaga ${ }^{7}$. Luiz Roberto Leite ${ }^{8}$. Sana M. Al-Khatib ${ }^{9}$. Elad Anter ${ }^{10}$. Antonio Berruezo ${ }^{11}$. David J. Callans ${ }^{12}$. Mina K. Chung ${ }^{13} \cdot$ Phillip Cuculich $^{14} \cdot$ Andre d'Avila $^{15} \cdot$ Barbara J. Deal $^{16} \cdot$ Paolo Della Bella $^{17} \cdot$ Thomas Deneke $^{18}$. Timm-Michael Dickfeld ${ }^{19}$. Claudio Hadid ${ }^{20}$ • Haris M. Haqqani ${ }^{21}$ • G. Neal Kay ${ }^{22}$ - Rakesh Latchamsetty ${ }^{2}$. Francis Marchlinski ${ }^{12}$ • John M. Miller ${ }^{23}$. Akihiko Nogami ${ }^{24}$. Akash R. Patel ${ }^{25}$ - Rajeev Kumar Pathak ${ }^{26}$. Luis C. Saenz Morales ${ }^{27}$. Pasquale Santangeli ${ }^{12} \cdot$ John L. Sapp Jr ${ }^{28}$ • Andrea Sarkozy ${ }^{29} \cdot$ Kyoko Soejima $^{30}$. William G. Stevenson ${ }^{31}$ • Usha B. Tedrow ${ }^{32}$ • Wendy S. Tzou ${ }^{33} \cdot$ Niraj Varma $^{13} \cdot$ Katja Zeppenfeld $^{34}$

1 Hartford Hospital, Hartford, CT, USA

2 University of Michigan, Ann Arbor, MI, USA

3 University Hospital Rangueil, Toulouse, France

4 Institute for Clinical and Experimental Medicine, Prague, Czech Republic

5 Jiangsu Province Hospital, The First Affiliated Hospital of Nanjing Medical University, Nanjing, China

6 Sree Chitra Institute for Medical Sciences and Technology, Thiruvananthapuram, India

7 Centro Privado de Cardiología, Tucuman, Argentina

8 Instituto Brasília de Arritmia, Brasília, Brazil

9 Duke University Medical Center, Durham, NC, USA

10 Beth Israel Deaconess Medical Center, Boston, MA, USA

11 Heart Institute, Teknon Medical Center, Barcelona, Spain

12 University of Pennsylvania, Philadelphia, PA, USA

13 Cleveland Clinic, Cleveland, OH, USA

14 Washington University School of Medicine, St. Louis, MO, USA

15 Hospital Cardiologico SOS Cardio, Florianopolis, Brazil

16 Northwestern University Feinberg School of Medicine, Chicago, IL, USA

17 Ospedale San Raffaele, Milan, Italy

18 Herz- und Gefäß-Klinik, Bad Neustadt, Germany

19 University of Maryland, Baltimore, MD, USA
20 Hospital General de Agudos Cosme Argerich, Buenos Aires, Argentina

21 University of Queensland, The Prince Charles Hospital, Chermside, Australia

22 University of Alabama at Birmingham, Birmingham, AL, USA

23 Indiana University School of Medicine, Krannert Institute of Cardiology, Indianapolis, IN, USA

24 University of Tsukuba, Ibaraki, Japan

25 University of California San Francisco Benioff Children's Hospital, San Francisco, CA, USA

26 Australian National University, Canberra Hospital, Canberra, Australia

27 CardioInfantil Foundation, Cardiac Institute, Bogota, Colombia

28 Queen Elizabeth II Health Sciences Centre, Halifax, Canada

29 University Hospital Antwerp, University of Antwerp, Antwerp, Belgium

30 Kyorin University School of Medicine, Tokyo, Japan

31 Vanderbilt University Heart and Vascular Center, Nashville, TN, USA

32 Brigham and Women's Hospital, Boston, MA, USA

33 University of Colorado Denver, Aurora, CO, USA

34 Leiden University Medical Center, Leiden, the Netherlands 